Portland State University

PDXScholar

Fall 1-7-2013

\title{
Patterns in Nature Forming Patterns in Minds : An Evaluation of an Introductory Physics Unit
}

Christopher Ryan Sheaffer

Portland State University

Follow this and additional works at: https://pdxscholar.library.pdx.edu/open_access_etds

Part of the Educational Methods Commons, Science and Mathematics Education Commons, and the Secondary Education and Teaching Commons

Let us know how access to this document benefits you.

\section{Recommended Citation}

Sheaffer, Christopher Ryan, "Patterns in Nature Forming Patterns in Minds : An Evaluation of an Introductory Physics Unit" (2013). Dissertations and Theses. Paper 925.

https://doi.org/10.15760/etd.925

This Thesis is brought to you for free and open access. It has been accepted for inclusion in Dissertations and Theses by an authorized administrator of PDXScholar. Please contact us if we can make this document more accessible: pdxscholar@pdx.edu. 
Patterns in Nature Forming Patterns in Minds:

An Evaluation of an Introductory Physics Unit

by

Christopher Ryan Sheaffer

A thesis submitted in partial fulfillment of the requirements for the degree of

Master of Science in Teaching

in

General Science

Thesis Committee:

Michael Flower, Chair

Stephanie Wagner

Sybil Kelley

Ralf Widenhorn

Portland State University

2012 


\begin{abstract}
:
Educators are increasingly focused on process over content. In science especially, teachers want students to understand the nature of science and investigation. The emergence of scientific inquiry and engineering design teaching methods have led to the development of new teaching and evaluation methods that concentrate on steps in a process rather than facts in a topic. Research supports the notion that an explicit focus on the scientific process can lead to student science knowledge gains. In response to new research and standards many teachers have been developing teaching methods that seem to work well in their classrooms, but lack the time and resources to test them in other classroom environments.
\end{abstract}

A high school Physics teacher (Bradford Hill) has developed a unit called Patterns in Nature (PIN) with objectives relating mathematical modeling to the scientific process. Designed for use in his large public school classroom, the unit was taken and used in a charter school with small classes. This study looks at specifically whether or not the PIN unit effectively teaches students how to graph the data they gather and fit an appropriate mathematical pattern, using that model to predict future measurements. Additionally, the study looks at the students' knowledge and views about the nature of science and the process of scientific investigation as it is affected by the PIN unit. Findings show that students are able to identify and apply patterns to data, but have 
difficulties explaining the meaning of the math. Students' show increases in their knowledge of the process of science, and the majority develop positive views about science in general.

A major goal of this study is to place this unit in the cyclical process of Design-Based Research and allow for Pattern in Nature's continuous improvement, development and evaluation. Design-Based Research (DBR) is an approach that can be applied to the implementation and evaluation of classroom materials. This method incorporates the complexities of different contexts and changing treatments into the research methods and analysis. From the use of DBR teachers can understand more about how the designed materials affect the students. Others may be able to use the development and analysis of PIN study as a guide to look at similar aspects of science units developed elsewhere. 
Table of Contents:

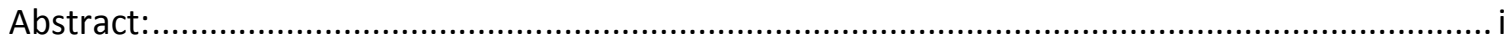

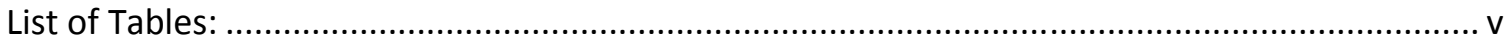

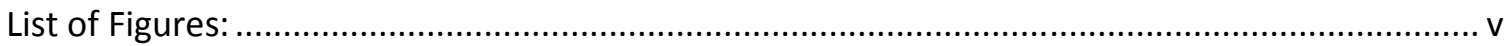

Introduction:

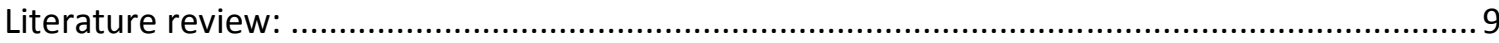

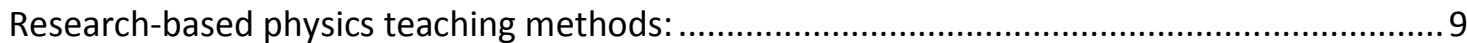

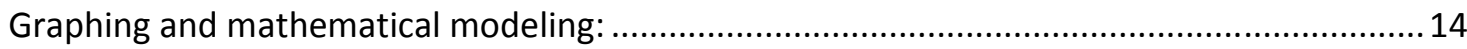

Graphing and mathematical modeling instructional strategies: ........................................... 16

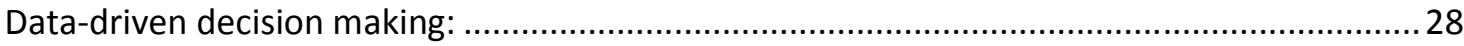

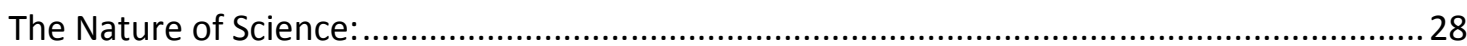

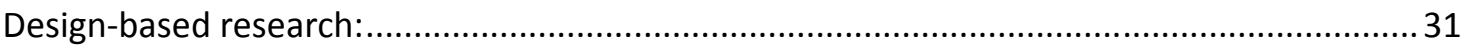

Summary:

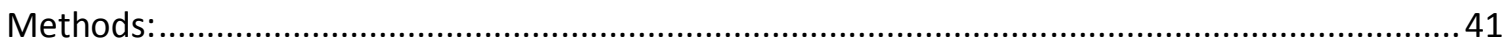

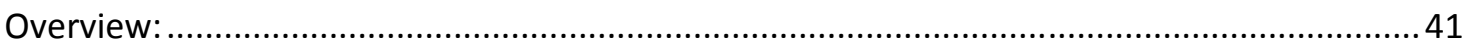

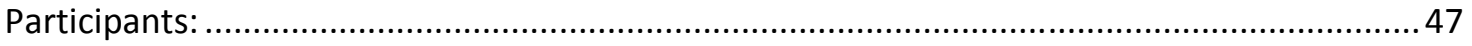

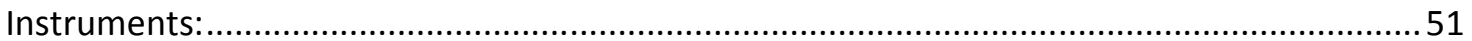

A. Survey: Epistemological Beliefs Assessment for Physical Science (EBAPS) .......................51

Preliminary study survey: "Student views about science" ..................................................5

B. Patterns in Nature unit summative content knowledge and skills test: ..........................56

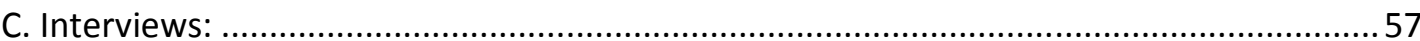

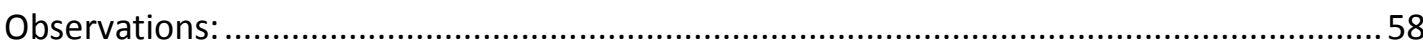

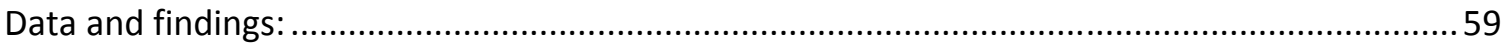

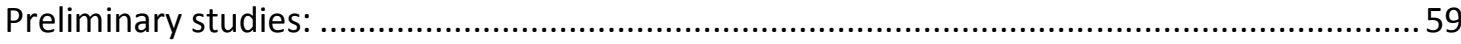

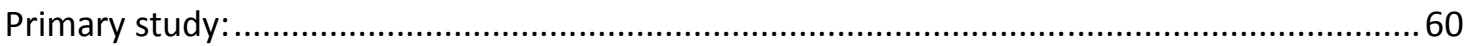

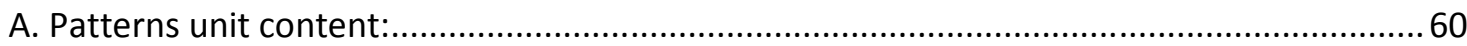

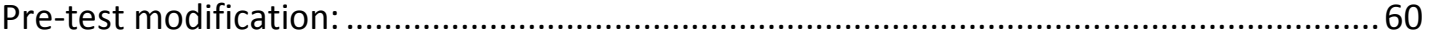

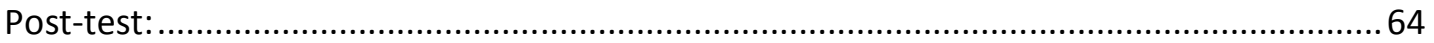


Interview questions on Patterns in Nature unit content:................................................... 73

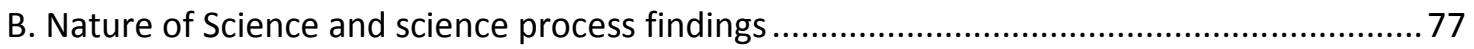

Epistemological Beliefs Assessment for Physical Science survey (EBAPS):............................ 77

Interview questions on Nature of Science and science process:............................................90

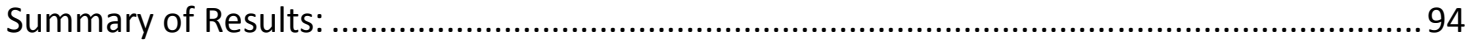

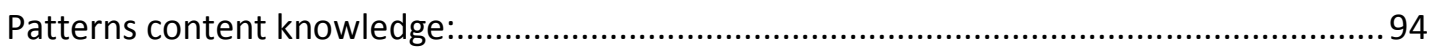

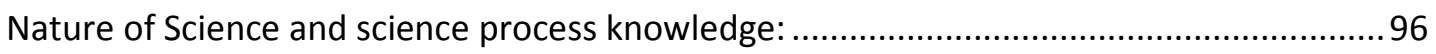

Implications of results and recommendations for changes to Patterns in Nature: ......................98

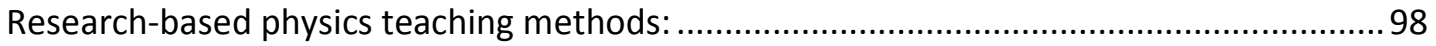

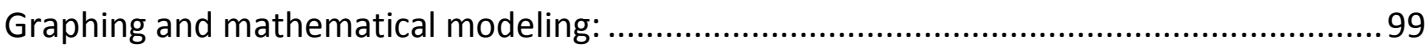

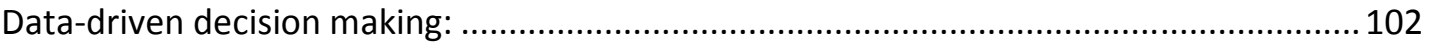

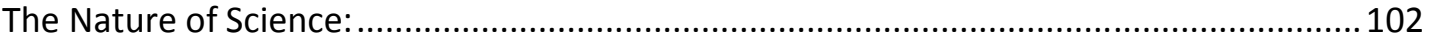

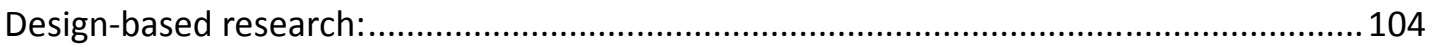

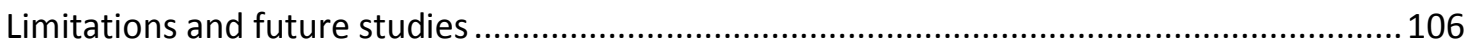

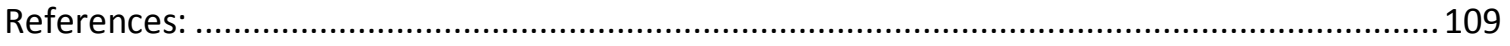

Appendix A: Patterns unit description by Bradford Hill............................................................ 112

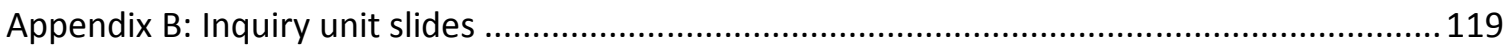

Appendix C: EBAPS survey with key and Views about science survey ..................................... 131

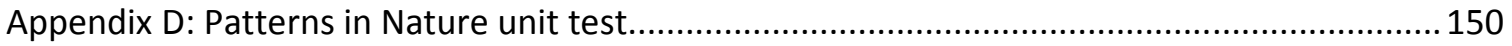

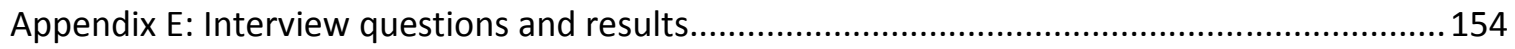




\section{List of Tables:}

Table 1: A time table comparing the instruments given to the students in the two classes studied.

Table 2: The five dimensions investigated by the EBAPS survey 52

Table 3: Diagnostic Test Experiments 62

Table 4: Pre and Post content test scores for each student. 66

Table 5: Content test questions categorized by type of knowledge, accompanied by a summary

of potential changes.

Table 6: A comparison of answers from different students to the last 4 questions of the content test. 72

Table 7: Students' answers to two of the mathematical patterns questions in the interview.....74

Table 8: Averaged results from all of the students on the EBAPS survey before and after the unit.

Table 9: Categories for EBAPS questions. 78

Table 10: Answers of two students to the Nature of Science questions in the interview.

\section{List of Figures:}

Figure 1: Pre and Post-test scores of students on the Unit Test from Mr. Hill's class. .65

Figure 2: Content test results, the number of correct answers by question. 68

Figure 3: Average scores of the class in each category of the survey on a scale of zero to four. .79 


\section{Introduction:}

Schools are constantly striving to improve students' knowledge and skills. In the scientific realm, two areas in need of improvement are data analysis skills and nature of science knowledge (Lederman, 2002; McClain, 2001). Subject content knowledge is the main focus of most classrooms and science process skills and background knowledge are often overlooked. Some schools are trying to address this disparity by creating an explicit focus on inquiry based experimental skills and developing a background in scientific process knowledge in earlier grades.

Patterns in Nature (PIN) was designed to meet the needs of a school that identified the need to teach inquiry skills in $9^{\text {th }}$ grade. The school created a required $9^{\text {th }}$ grade science class called Science Inquiry and split it into two trimester-long sessions, the first trimester was Physics content and the second trimester was Biology content. There was an explicit focus on inquiry in the course descriptions, but no set curriculum, so the teachers were given the freedom to cover scientific inquiry in whatever way they felt was best while also teaching the basic content. In the physics portion of the course, teacher concerns arose about keeping the content rigorous. Typically physics is taught at the end of a student's high school career, after students have developed an adequate mathematical background. The $9^{\text {th }}$ grade students at this school did not yet have that knowledge. At that point in their mathematical development the students had been 
taught algebra and modeling skills up to linear equations; however, a traditional physics class can involve the use of different types of equations of functions that many students have never seen before. The challenge is to find a way to teach inquiry-based physics that can still be rigorous, despite the lack of mathematical ability.

Students must be given the opportunity to take a wider look at how they are conducting inquiry investigations before they worry about the underlying physical concepts. Even a majority of college level physics students fail to understand where the equations that they are working with have been derived, not because they lack the mathematical background, but because they don't understand the process of scientific investigation which led to the development of a pattern.

In order to address students' needs to improve their data analysis skills at the beginning of their high school experience, Bradford Hill, a physics teacher at the Beaverton High School, devised a very promising unit for students just entering high school. He developed Patterns in Nature (PIN) to teach these inquiry skills and the mathematical skills that $9^{\text {th }}$ grade students might be lacking. ${ }^{1}$ Patterns In Nature is mathematical modeling of data gathered from investigations of natural phenomena. This curriculum involves the construction of a scientific framework for students, one that aids them in

\footnotetext{
${ }^{1}$ A more detailed description of the Patterns in Nature Unit written by the developer of the Unit, Bradford Hill of Southridge High School in Beaverton, Oregon is included in Appendix A.
} 
understanding the many different types of relationships that they will discover in future investigations.

The class conducts four simple experiments each with the goal of discovering a specific mathematical pattern from the results. Since it is designed to act as a framework for students to reference in the future, PIN concentrates on science as a process, rather than the underlying physics content. For example, the students perform an experiment about a swinging pendulum with no prior knowledge on the conservation of energy or gravity. They only think about finding the relationship between the variables.

Throughout the course of unit the students are authentically engaging in the scientific process and getting direct experience taking data, estimating uncertainty, learning how to use a computer graphing program, and modeling their raw data using error bars.

These new tasks are situated within the context of the traditional scientific method that the students already know and are followed by a data-based prediction for a new data point.

While the additional data provides the verification of the mathematical models that the students have developed, they also afford students the opportunity to participate in an important part of the scientific process. Through predicting the future, students can see the value of the investigation they just performed and with this process they can make the connection between quality data and quality predictions. This is an important point 
that many students miss when they are learning about science. They recognize that scientists develop and conduct experiments, but they do not recognize that scientists use their data to make evidence-based decisions. PIN can help paint a clearer picture of the practice of science in students' minds.

Initial reactions to the Patterns In Nature unit have been positive, as it has been adopted by all of the teachers of the Science Inquiry class at the school and other schools have started to notice its value (Hill, 2012). Although no formal study has previously been performed, students seem to have responded positively. Many have expressed an enjoyment of the class, and learned a great deal about physics and the nature of science, as shown by summative and formative test results. Now, a formal study is being done to test the unit's ability to teach specific skills and the scientific process. Additionally, this study seeks to examine the effect of the PIN unit in a new type of school atmosphere with smaller, longer classes and different types of students.

Time was spent observing and consulting with Mr. Hill and all of the materials were shared. This chapter of the study follows the PIN unit as it travels to a new environment. PIN is taught to a class of seven students in a small charter school in Oregon City School District over the course of five weeks with one three hour class each week. This drastically different classroom environment, the primary subject of the study, was then compared to Mr. Hill's class of 36 students from the same year. Both 
classes teach the same curriculum and focus on the same skills, but a small class provides a detailed look at each student.

Specifically, the skill being examined by this study was the ability to fit algebraic equations to scatterplots of real data. The students were asked to do this with and without the use of technology as an aide. The majority of students in $9^{\text {th }}$ grade can learn the skills addressed in this unit, and may learn them in their math classes as well. According to the National Council of Teachers of Mathematics (NCTM) these graphing skills are introduced as early as $3^{\text {rd }}-5^{\text {th }}$ grade and in $9^{\text {th }}-12^{\text {th }}$ grades students are expected to learn how to fit equations to scatterplots. ${ }^{2}$ PIN is designed to help students master these skills through practice and application to new situations in a cross curricular unit. A unit test and individual interviews were used to document if students have gained these skills.

This study also seeks to show that students also gain both nature of science knowledge and science process skills, as well as improving in their attitude towards science. Many students have the misconception that science is specific content rather than a general discipline. If this unit can simply teach the correct use of the adverb 'scientifically' it should be considered a success. The reality is that teaching the nature of science is now

\footnotetext{
2 "In grades 9-12 all students should be able to display a scatterplot, describe its shape, and determine regression coefficients, regression equations, and correlation coefficients using technological tools" From NCTM Standards and Focal Points, 2011, online at: http://www.nctm.org/standards/content.aspx?id=318
} 
advocated on the national level in new standards and should be included in any science classroom. ${ }^{3}$ PIN is modeled after the way science researchers practice science to make the process more visible and familiar to the students. Students are explicitly told that they are doing science, they follow the process and they reflect upon their results. This technique is recommended by those researchers who have extensively analyzed studies about the Nature of Science (Lederman 2006). Providing a universal technique that can be applied to many different types of investigations may help enlighten students to the broader process of science. Measurements in this area were made with a pre and post survey concerning epistemological beliefs about physical science and interview questions developed to probe students' scientific knowledge.

To understand the data gathered from the students, this study uses a new method of educational research. Design-based Research (DBR) is a technique used by researchers who are developing classroom materials that can lead to the improvement of teaching practices to the unit itself. Formally published by Ann Brown in 1992 (Brown 1992), this emerging research method is designed to incorporate the complexities of the classroom environment rather than attempt to control a multitude of confounding variables. For example, imagine a teacher researching a particular teaching method in their classroom. If one teaching method does not work for some students, because it would be

\footnotetext{
${ }^{3}$ The National Science Teachers Association strongly advocates for the inclusion of the nature of science in the new, Next Generation Science Standards online at: http://www.nsta.org/about/standardsupdate/recommendations2.aspx
} 
considered unethical to simply let a student fail, the teacher might try other methods such as meet with them after school, or enlist help from another teacher to ensure that the students learn the material. All of those unplanned additions to the curriculum become confounding variables when those students are tested for what they have learned as a result of the new teaching strategy, becoming part of the strategy itself. In this method of research, it is acceptable for the treatment to change as the investigation is carried out.

One of the major advantages of design-based research technique is that each iteration of the unit will lead to more improvements, and therefore the study will have no real ending point; the treatment can be evaluated and improved simultaneously. If enough is learned about the successes and failures of the Patterns in Nature unit in relation to multiple classroom environments, it can be prepared for successful use in more schools. That is why this unit will be analyzed using a lens of a cyclical, design-based research approach.

In summary, this study evaluates the Patterns in Nature unit to add to the body of literature on instructional strategies in physics and design-based research. The question to be addressed is: How does the Patterns in Nature unit help high school students relate mathematical functions to scatter plots of real data? Subsequently, how does this treatment affect students' knowledge and views of the process and nature of scientific 
investigation?

Page | 8 


\section{Literature review:}

The Patterns in Nature (PIN) unit was not developed in response to any specific research; rather it came from observations to meet standards and to fit the circumstances. However, it does relate to studies in different areas such as Physics Education Research (PER), graphing, math modeling and the Nature of Science (NOS). Although no studies could be found relating to the data-driven decision making part of the PIN unit this study should help to fill that gap in the literature. Additionally, it will augment literature about Design-Based Research (DBR) helped to guide the methodology and data analysis of this study. By conducting this study, the PIN curriculum can be added to the list of developing research-based teaching strategies in physics and science in general.

\section{Research-based physics teaching methods:}

Henderson and Dancy (2009) conducted a comprehensive study, seeking to gather and summarize research on the dissemination of research based techniques for teaching in Physics classrooms. Research based techniques can be defined as an instructional strategy that is designed using information from published literature, and evaluated and improved using student data; these types of techniques are generally considered purposeful teaching. Inversely, traditional teaching is not based on data and more 
related to what a teacher thinks will work based on what they have seen or heard in the past. Often times this traditional type of teaching is lecture based, or taught out of a book because of the lack of planning time. Doing research on teaching methods is difficult and requires much hard work. Henderson and Dancy sought to investigate the awareness of existing research-based strategies in this study.

The researchers administered a web survey about pedagogical knowledge and practices in physics to physics faculty members at various colleges and universities around the country to determine the approximate usage of research-based strategies in the classroom. The survey also asked how the teachers felt about their students' ability to meet their instructional goals and their students' responsiveness to these strategies. The authors had an adequate response rate of $50.3 \%$, which was better than some similar web-based surveys. Their sample size represented an estimated five percent of the total of all the physics professors at schools in the United States.

Findings showed that instructors were familiar with some strategies, but normally not all of research-based strategies that were in the survey. As a point of reference, about 60 percent of faculty members had knowledge of all 24 strategies listed, and the highest percent of current usage for any instructional strategy was $29 \%$ among instructors who were aware of it. The results showed that much of the time the instructional strategies mentioned were initially used and then discontinued for a variety of reasons. 
The authors concluded that most of the physics faculty members who were surveyed do not have the knowledge or means to customize the wide varieties of research-based instructional strategies and thus, better ways to support teachers need to be developed. Henderson and Dancy stated that there is adequate awareness of the strategies, but the knowledge of how to implement them into physics instruction is lacking. New studies need to include tests of instructional methods for implementation.

Patterns in Nature is both a teaching strategy and a curriculum. This study of PIN is designed to test the effectiveness of the unit as a teaching strategy in physics by using it in a classroom. Results will include recommendations for how to use it to increase student learning in multiple areas.

Redish and Steinberg (1999), physics education researchers at the University of Maryland, summarized the reality of teaching university level introductory physics and the need to pass on valuable information and skills to students in a short amount of time. Through surveys, the authors discovered that many students in their introductory physics courses never take another physics course. Therefore, students have little reason to gain the proficiency with the content knowledge that professors intend them to master. Redish and Steinberg claimed that physics teachers should concentrate on 
how students learn and not on what they learn to pass on valuable information that students may be able to use in other subjects.

Consequently, Redish and Steinberg (1999) researched and summarized several programs that attempt to emphasize the 'Hidden Curriculum' and make it visible to the students. The authors defined concepts, skills and attitudes that are not explicitly stated by the teacher as the 'Hidden Curriculum', and claimed that much of a student's learning comes out of this. Many of these programs studied were implemented by the researchers at their university in an effort to evaluate them. Professors collected data from surveys and administered content tests throughout their class. This data was shared with the researchers who analyzed the results and correlated them with the types of teaching methods used.

The findings showed that the research-based methods, like interactive demonstrations and discrepant events to name a few, outperformed traditional classes in concept comprehension and problem solving ability in addition to showing and improved attitude towards physics at the conclusion of the class. They encouraged additional evaluation in the field to find out exactly which teaching methods work and communicate them to others, because often teaching methods are shared without proper research and testing. 
As strategies similar to PIN are used and evaluated like this, changes can be recommended and adaptations for different types of students and environments can be made. This process results in a dynamic, adaptable, and continually improving teaching method.

Wieman et al. (2005), in Transforming Physics Education, made an attempt to explain how teachers can reach a larger fraction of their student population. A large body of research the authors examined showed that students in traditional classrooms did not gain a true understanding of physics and had trouble tying concepts to the world around them. The researchers discussed a potential solution to the issue of cognitive load limits in students linking new material to prior knowledge. Wieman et al. suggested that teachers should concentrate on 'why' and not 'what' when making links between topics. Research based techniques seem to be the most effective in making these links for the students. Wieman et al. recommended relating ideas to students in terms of real-world situations and utilizing new educational technology, including rapid response systems and virtual labs.

Focusing on the development of the mental structure of students' understanding was shown to be an effective instructional method. The authors concluded that students' 
beliefs about the subject depend on their motivation which in turn is contingent on their understanding of the material. Wieman et al. stated that the over-arching goal is for the students to approach expert thinking and understanding. To accomplish this goal the authors say that physics teaching needs to be reformed to use research-driven strategies in the classroom, and more purposeful teaching.

This type of reform is what drives the creation of the PIN unit and its evaluation. In this study the goal is to share the method itself while also inspiring others to evaluate and share their curriculum developments. The entire community of teachers and students can benefit from this fundamental change in the origin of new teaching methods.

\section{Graphing and mathematical modeling:}

The Patterns in Nature unit concentrates on graphing data and modeling the pattern mathematically. Literature about these subjects can provide ways to help strengthen the unit's ability to effectively teach these skills to students.

Leinhardt et al. (1990) conducted a comprehensive study about teaching graphing. The authors suggested that graphing is the most basic knowledge of symbolic systems and that it affects the students' understanding of science and math for years afterwards. Furthermore, functions and graphs are communicative systems that cannot exist independently. Each one symbolizes the other. Therefore, a comprehensive study of 
the research related to teaching these skills is warranted to decide what steps need to be taken towards increasing student comprehension. This article is a review of approximately 50 research studies related to teaching and learning functions, graphs, and graphing for students aged 9 - 14 .

After looking at studies from the fields of both math and science education, Leinhardt et al. noted that the techniques used by mathematics instructors emphasized real world applications to deepen the students' understanding of the abstract mathematical concepts. Conversely, science instructors emphasized the use of graphs and analytical tools to discover underlying patterns. The authors proposed that an approach combining the methods of science and mathematics teachers would logically be the most effective.

They were critical of many research studies in the literature that paid little attention to the nature or form of the variables associated with the tasks given, which could confuse students. The authors classified the types of variables that they have seen as static or dynamic, specifying that both types can exist simultaneously in a problem.

They also classified the types of tasks that were given in these research studies as: prediction, classification, translation, and scaling. The authors found that $75 \%$ of the articles reviewed included implications for teaching but focused more on assessment of 
tasks and variables rather than on teaching methods. For example, researchers generally designed their tasks for the students around extreme or confusing situations to check if students had a true understanding and were not distracted by irrelevant information.

Leinhardt et al. concluded that there are many different ways to assess graphing ability, but it is more important to better understand the instructional sequences and how they affect the learner at different age levels. This, like the Henderson and Dancy (2009) and Redish and Steinberg (1999) studies, requests that researchers make their findings and results more applicable to instruction than assessment. What follow are some studies with instructional strategies about teaching these skills.

\section{Graphing and mathematical modeling instructional strategies:}

Like the following studies, PIN teaches and tests specific skills that can be used with a variety of different content topics.

Clement et al. (1985) wanted to determine if middle school students could produce correct graphical representations of various situations. This study involved a preliminary study with a small class of college students and followed with a primary study of $257^{\text {th }}$ and $8^{\text {th }}$ grade students. For their assessment, the authors chose several 
situations involving different types of graphs and content areas in an effort to counteract the students' lack of content knowledge of the subject of the problems. The data was gathered from taped clinical interviews with all of the students. After analyzing the data, Clement et al. noticed several common errors that were confined to particular problems and that these were similar to errors that occurred when the preliminary study was done on the small population of college students.

The researchers categorized the major errors students made as 'confusion with graph as picture' and 'slope versus height confusion'. Clement et al. states that 'confusion of graph with picture' occurred when students thought that the graph visually resembled a time lapse picture of the situation. For example, a distance versus time graph of a ball being thrown up in the air will resemble the path of a ball being thrown up in the air at an angle. The authors say that confusion of slope versus height occurred when there were two lines on a graph that did not start at the same point. This commonly resulted in students choosing the one with greater height when looking for the greater slope. In the conclusion, Clement et al. recommended further study on the subject to determine whether their results were typical. 
McDermott et al. (1987) found similar errors to Clement (1985), and documented more common errors in graphing. The researchers noticed that students seem to lack the ability to use graphs to impart or extract information about a physical investigation. The authors sought to illustrate common errors in interpreting graphs with some examples taken from kinematics.

The study was descriptive, spanned a period of several years, and involved hundreds of university level students at the University of Washington. The authors tested students as they participated in an introductory level laboratory-based Physics course. Two skills were examined by the study: connecting graphs to physical concepts and connecting graphs to the real-world. Throughout the physics classes examined, student data was taken from written problems and laboratory experiments.

Looking summarily at the findings, students had little problem with the plotting points and slopes, but could not easily apply that skill to physics situations. The researchers noticed that the mistakes related to producing graphs commonly occurred in problems that required an analysis using inferred methods and not memorized steps. Many students lacked the deeper understanding necessary for certain problems involving making or analyzing graphs. When more than memorized patterns or procedures are required, many students struggle. 
The researchers pointed out that many of the difficulties they described do not come up in typical instruction, because typical instruction and assessment tend to use algorithmic approaches to data and graphing. The errors also did not occur in any particular group, but were evenly distributed among various gender, racial, and economic populations. This finding suggests that these problems are widespread and not isolated to particular environments or backgrounds. They used their findings to design an instructional model on kinematics and also extended the testing of graphing to topics taught in a latter part of their current physics course.

In addition, the authors also give their arguments for teaching about the powerful tool of graphical analysis in multiple contexts, "to develop a general ability to work with graphs that may be useful to students long after they have forgotten much of their physics, and to take advantage of the increased depth of understanding that comes from using the same procedures and reasoning in several different contexts." (McDermott, 1987, p. 512) The researchers concluded that literacy in graphing does not spontaneously develop and that the ability to work with graphs is likely to be more useful in the future life of the student than specific topic knowledge.

These early studies focused on the difficulties students had completing a task that was important for multiple contexts. They noticed that students had trouble tying graphical 
representations of data to real-life, but did not look into better methods of teaching those skills.

Doerr (1995) provides an example of a teaching strategy designed to improve students graphing skills. The researchers conducted a classroom study on Integrated Mathematical Modeling and described it in a paper written for the National Council for Teachers of Mathematics (NCTM). The goal of their study was divided into three categories: 1) having students build relationships from physical phenomena, 2) having them use a simulated environment to explore their conjectures, and 3) having them use an iterative process of developing and validating solutions using computer based tools ( in this case, a program called 'Interactive Physics' and a function fitting program). Two teacher teams taught a class of 17 students at an alternative public high school a unit, lasting 35 instructional days. The unit focused on reconstructing physical phenomena using math and technology. The teachers used the context of an inclined plane to investigate the model building process in their classroom involving the students in an iterative process where they continually revisited and reused the models that had been made. The guiding question of the unit was "How will an object behave when rolling down a ramp, and can we predict its behavior given any angle?" It was then further broken down into sub-problems focused on specific issues. 
To treat the research properly and to leave room for students to learn independently, the teachers tried to remain as observers while the students worked. This unit also placed considerable emphasis on small and whole group discussion which became the setting for the content skills being taught. Data sources included: pre and post-tests, collected student worksheets, student submitted computer data, and video and audio evidence. A focus group of students was closely followed throughout the course of the unit.

Some developing themes were identified as a result of the study. Firstly, the researchers recognized the unexpected diversity in the way that students pursued the questions. Secondly, the researchers observed that time spent on incomplete models turned out to be worth the frustrating effort for the students, as it helped them piece together conceptual models over time. Lastly, the final major theme was the positive effect of the quick feedback that the students got from using the computer software tools. Doerr said that this was very valuable in particular when the physical experiment was inconclusive. However, the researchers had to be careful to guide students into simplifying and not overcomplicating the situations. The implications for teaching and the curriculum are made with those major themes in mind. 
The researchers mentioned that this process of open-ended inquiry was not without confusion, opening the door for unexpected mathematical difficulties. However, with the support of the tools to represent data and build simulations the students were capable of mastering the essential questions. It must be pointed out that the researchers were not sure that the students saw the value of their stumbling blocks, and a reflection element should be considered a good addition to their unit.

The author stressed that problem solving skills are acquired when students focus on indepth investigations and fewer concepts. The students' results on the force concept inventory suggest that they can still make large learning gains when using a curriculum of this modeling style. Modeling was not just an add-on, but "a more fundamental reformation of the curriculum that gave primacy to the students' construction of content knowledge through an inquiry process of experimentation, simulation, and analysis." (Doerr, 1995, p. 26)

This study happened early on in the modeling movement, when teachers had students closely study a physical situation and recreate it. However, not many researchers sought to identify and analyze the students' conceptual connections between the task and the mathematics. 
Sherin (2001) investigated the connections that students made in their modeling tasks. He conducted a study that attempted to find a way to teach for understanding and to move students away from memorization and meaningless symbol manipulation. Specifically this was a study relevant to the use of equations to understand physical phenomena, as when fitting curves to a scatterplot. The work focused on determining how Physics equations are understood. To do this, Sherin observed five pairs of university level students in a $3^{\text {rd }}$ semester physics course for engineers while they solved seven moderately difficult problems on a whiteboard. The students participated in four to six sessions each lasting about an hour and fifteen minutes. Sherin's data was largely qualitative and the discussions were transcribed from video tapes.

The researcher concluded that the students possessed inherent knowledge of symbolic forms and equations that are not directly related to physical principles such as parts of a whole, competing terms, multiplicative factors etc. Symbolic forms consist of two components: a symbol template (framework for an equation in which two things are equal) and conceptual schema (the overall idea to be expressed in the equation). Sherin showed that there can be a deeper understanding of physics equations using vocabulary elements called symbolic forms that bridge between physical principles. Mathematical relationships or graphical patterns (linear, inverse, quadratic, etc.) can be considered a type of symbolic form. Students, however, only understood those equations to a 
certain level of detail without tying them to physical concepts. The author's research supported the general movement that uses models as a method of physics instruction, and in the years after this study modeling has been extensively studied and developed into several published science teaching programs.

Halloun (2004) chronicled modeling theory in science education. This article written by Halloun is a synopsis of a book representing 20 years of modeling theory development as a pedagogical theory, designed for both teachers and researchers to be used as a major reference.

An important part of this reference is the definition and description of the theory. Modeling theory is described as a theory about scientific principles and practice that places models at the core of scientific philosophy. The book states that while science standards are traditionally content driven there also needs to be a drive for mastering process skills. Scientific Models can be generalized as conceptual systems mapped onto a specific pattern in the real world. They can serve either an exploratory function or an inventive function. Additionally the authors of the book say the benefits of a modeling related curriculum reach both students and teachers; it serves as a method for students 
to organize their work in a productive way and provides teachers a reliable way to plan instruction and assess student learning.

A particular modeling program was presented that has been systematically tested mostly in secondary school and university physics courses, but is now being adjusted for other scientific fields and educational levels. Results of the testing are shown, which supports the claim that this modeling method helps to narrow the gap between students at opposite ends of the competence spectrum creating a more equitable learning experience.

The program, championed by Arizona State University, possessed some similarities and differences to the Patterns in Nature unit. While it concentrates on connecting scientific disciplines and principles with an inquiry task that involves modeling data, it does not talk about students using their models to make predictions and conjectures like PIN does. Regardless, the authors show that students can develop conceptions of scientific theories and essential skills of scientific inquiry through the affordable and efficient framework that modeling can provide. 
Sins (2005) conducted a study to determine what distinguishes successful from less successful student modelers, and which reasoning processes are difficult for novice modelers to perform. The process of modeling (using mathematics to mimic reality) is widely advocated as a way to offer students a deeper understanding of complex phenomena, but the process itself is complex and requires scaffolding. Constructing a model is a difficult task, and novices tend to encounter problems in areas like the task perception, the content addressed, and the tools used.

The study involved 38 students from $11^{\text {th }}$ grade science classrooms. The students worked in pairs that they chose themselves. Students started with incomplete models and changed values to complete tests and finalize their models. The results are given in the form of case studies of pairs.

A high performing pair was described as engaged, systematic, elaborate, and critical. They were very thoughtful and reflective in a process where they struggled to fit their data to a mathematical relationship, but they broke it down into parts and evaluated each relationship separately before making their final decisions with high quality reasoning. A medium performing group was also monitored and described. They mainly analyzed and identified just individual elements without elaborating on improvements that could be made. This medium performing group, however, did express concern about their model being a realistic representation of the phenomena. 
Lastly, a low performing group was followed. The students constructed a poor model and frequently asked for guidance from the experimenters. These students tried to evaluate the degree of the model fit but did not know how to revise their model because they had trouble explaining why they chose particular values. The main differences in scoring between these three groups were in the reasoning and explaining categories.

In conclusion, the researchers found several characteristics that differ between novice and expert modelers. The more successful students justified their reasoning with prior knowledge, and typically regarded the model as a whole. However, the less successful students spent a lot of time manipulating parameters and mostly considered only one quantity at a time. Generally, inductive reasoning with prior knowledge seemed to be the difference between effective and ineffective models. The less successful groups were more concerned with model curve fitting than the successful ones. They used it as an artifact rather than a method to comprehend complex phenomena. A top down approach, from general to specific, seemed to be more successful when revising a model, with students keeping the whole picture in mind.

Even these upper high school students experience difficulty with complex modeling tasks because some have the proper background and others do not. Patterns in Nature seeks to provide the content independent framework that could aid students in 
situations like this. PIN could be considered a pre-modeling unit with an emphasis on the basic mathematical modeling skills and a validation of them at the end.

\section{Data-driven decision making:}

This phrase describes how students use the information that they find in their experiments. Within the field of research there is a lack of any specific studies on lines of best fit, in terms of their predictive power. While some articles talk about integrating a use of technology into graphical analysis (Jackson, 2006), none of them go to any great lengths about how to use it to make data-driven decisions. The concentration is on using the programs to evaluate data, not using the trends to make a prediction for future measurements.

Scientists collect data for the purpose of predicting repeated experiments to a certain degree of accuracy. PIN intends to use data driven decision making as a connection for students between the classroom and the real world. So much of the science and technology people know and use only works because it was tested in a lab and a predictable relationship was found and recorded. Through this part of the process, students can better understand the Nature of Science.

\section{The Nature of Science:}


It is necessary to accurately analyze the meaning of and views surrounding the Nature of Science (NOS) because of its important role in new educational practices and standards. Nature of Science can be described, by first defining science. According to Lederman (2006) Science is three things: a body of knowledge, a method, and a way of knowing. The epistemology surrounding the topic of science usually refers to the Nature of Science. This is the beliefs, views, and means of understanding the body of knowledge or characteristics surrounding Science. However, like scientific knowledge itself, Nature of Science is a moving target and has evolved over time.

Lederman (2006) conducted a review of the literature to describe the NOS and its role in the past, present, and future of education. Despite being mentioned in the literature for over 100 years, those studies continually state that our students still do not seem to have adequate understanding of the Nature of Science, thus NOS is gaining increased attention in the science curriculum. The author of the review states that there are many questions still to be asked and answered about the topic. Lederman's goal is to help synthesize those questions and answers from the previous literature and then share them with the science education field. To accomplish this he describes research studies done on both students and teachers, in the framework of both classical and contemporary studies. 
Lederman shows that studies have been done on students' conceptions of NOS. A wide variety of instruments used in studies for over 20 years concluded that students do not possess adequate conceptions of the Nature of Science. Studies on teachers' conceptions of the nature of science also showed a lack of adequate understanding as well. However, none of these earlier studies made an attempt to solve the problem, they simply confirmed that one existed. Classic studies that attempted to address the issue that teachers' views affected students' met moderate success, but they were very simplistic. Contemporary studies, after 1980, are more complex and comprehensive. They show that teachers' and students' views are only linked if there is explicit instruction on the Nature of Science. The few studies that attempted to justify the importance for teaching NOS showed that an understanding is important because it contributes to individuals' decision making.

Some researchers reviewed by Lederman have argued against the validity and reliability of Nature of Science assessments. Early assessments focused on quantitative data that led to easy analysis, but the methods of assessment have changed just as educational research design has over the years. Lederman has compiled a list of all the different standardized NOS assessments since 1954 and analyzed them. Most assessments concentrate on students' abilities and skills regarding the scientific process of making judgments regarding data. Half of the assessments deal with students' values and feelings or appreciation of science. Few of them placed emphasis on the development 
of scientific knowledge in an epistemological way. Additionally, Lederman found that successful studies validated their assessment instruments used by comparing them to qualitative data from interviews. This affected the way that PIN was to be assessed and the instruments chosen. A survey about the Nature of Science was chosen because it cited Lederman's work and the questions from that survey were compared with similar questions.

Overall, in his conclusions Lederman asserts that much work is needed to determine the underlying mechanisms that drive Nature of Science learning in both teachers and students, as well as the relationships that are tied in with knowledge transference.

According to Lederman, both the teacher and student views and prior knowledge affect a student's ability to learn. This complicates a research study and adds to the long list of variables that need to be accounted for. Traditional scientific research methods do not suit educational research well. It was necessary to investigate effective ways of designing a research study to most successfully evaluate the PIN unit.

\section{Design-based research:}

Brown (1992) sought to design a reliable and repeatable way to conduct studies in the rich, complex, and constantly changing environment of the classroom that is based on theoretical descriptions. The author describes her personal history with educational 
theory and what brought her from developmental psychology to the point of conducting research in the classroom. She notes that a fundamental shift began, taking research about how people learn out of the laboratory and into the classroom. More subtle methods were needed and developed to collect information without affecting the subjects thought processes. A multitude of new methodologies were developed and incorporated into her research. She describes her current research in $6^{\text {th }}, 7^{\text {th }}$, and $8^{\text {th }}$ grade science classrooms.

In these classrooms the researchers have set up a community of learners that differs from a traditional classroom in the active roles that students and teachers take. Students engage in self-reflective learning and critical inquiry and are monitored using many different types of formative assessment. Teachers serve as role models and guides through the discovery learning process. The students, teachers and researchers are all subjects of the study, as they all have an impact on the measured outcomes. Every person involved will show up in the data, thus everyone must be considered an integral variable in the study. The sources of data generated by students in the classes monitored by Brown's research team are extensive. In addition to the standard outcomes measured from assessments, they collect data in the form of transcripts, observations, and portfolios of work. They have audio and video tape of individual, group, and full classroom settings. Brown explains that they have "no room to store all of the data, let alone the time to score it." They gathered excess data as a safeguard in 
the situation that the research question changes as a result of unforeseen complications in the study.

The data was collected, but at the time of this article it was not organized into any specific findings. Rather, the researchers have concentrated their effort in this study on the methodological issues of conducting research in a classroom that they are simultaneously designing. The conditions are constantly changing, causing issues in data collection and analysis.

A preliminary result shows that outcomes on standard assessments improved significantly; however, Brown seeks to learn about the students thinking from the extensive qualitative data. Selected interviews with students showed that they can improve their thought processes after participating in the learning community classroom. She mixes and matches qualitative and quantitative methods, using the classroom to inform lab decisions and the lab to inform class decisions. Brown seeks to justify her non-traditional experimental approach through the development and description of a new classroom setting method, design-based research. This and other complex methodologies must be developed to capture the systemic nature of learning, teaching and assessment. Brown wrote the following as a definition for the research approach saying it is "a paradigm for the study of learning in context through the systematic design and study of instructional strategies and tools." Design-based 
research can help create and extend knowledge about developing, enacting, and sustaining an innovative learning environment.

Ketelhut, Clarke, and Nelson (2010) conducted a study where they claimed to have used design-based research methods. The authors developed a computer-based simulation, a multi-user virtual environment, centered on skills of hypotheses formation to provide teachers with a platform for implementing authentic science inquiry experiences. They employed a design-based research approach to the iterative development of their inquiry curriculum. The focus was on scalability as they were looking to move to large scale implementation.

Studies were set in the classrooms of public schools where relationships with teachers have been established and the intervention could be used in 'natural settings'. Over 15,000 students and 100 teachers were considered in the scope of this study. Studies were conducted in large, urban school districts.

The program is called "River City" and involves the biological and ecological investigation of a city set in the 1900s. The computer simulation used in the study was created to address a specific part of scientific inquiry, investigations that involve 
hypothesizing and testing, collecting and analyzing data, and making inferences. Development started with identified problem areas and suggested solutions from teachers. The students worked collaboratively within the virtual environment, where they could interact with the environment and each other. Lab notebooks were provided to help the students build towards mastering the inference and scientific investigation. The curriculum corrected the students' naïve view that there are correct, easily discernible answers to problems in science. The researchers described the development of the program in detail and the important changes that they have made, specifically modifying the lab notebooks and the program to provide a more authentic research experience.

Over the past eight years of the project design and implementation the researchers have developed new insights into student learning, design, and instructional strategies. They cite the use of design-based research, an iterative process, as a major part of their project's success in understanding students' inquiry learning through the collection of a variety of data types. River City classes did not always perform better on the assessments than the control classes. However, these results sparked changes to the curriculum to allow for increased engagement and accessibility for more types of students. 
Their virtual learning environment seemed to have a large impact for students who were identified as low performers in a traditional classroom curriculum. They witnessed many students who were inattentive to their teachers, but highly engaged in the virtual world of "River City". These types of students exceeded their teachers' expectations, interpreted the data insightfully and finished their projects in a timely manner. The researchers conclude that virtual scientific inquiry environments can have a valuable role in the classroom, allowing for learner-centered collaborative inquiry learning. The project continues as the authors perfect the design and development of the tool using a DBR approach. This study provides an excellent model for others pursuing designbased research.

From this study, the parallels between the "River City" program and Patterns in Nature unit can be seen. They are both developing curriculums trying to move towards a large scale implementation and continued improvement. While they are at very different stages in development, and about different content, both programs focus on collecting data and using the scientific inquiry process. "River City" is a good model of designbased research for PIN to follow in its design and evaluation as more studies are done.

\section{Summary:}

The fact is that, for many students, traditional lecture-based teaching is not effective. There are an increasing number of researchers and teachers that support scientific 
inquiry and various other methods of stepping away from the traditional lecture style of teaching. However, not every method is necessarily better all the time and these methods need to be researched and tested before they are deemed successful. A research-based strategy was developed by consulting the literature, tested with students, and modified using the results. The more these strategies are tested, the more effective they become. Henderson and Dancy (2009) established that there were a lot of research-based techniques out in the teaching community, but many teachers struggle when they try to implement them in their classrooms because of a lack of direction given by most research. Redish and Stienberg (1999) implemented several research based teaching strategies in their university level classrooms and confirmed that their students outperformed control groups in concept comprehension, problem solving ability and attitude towards physics. The researchers claim that in every classroom there is a 'Hidden Curriculum' that the teachers want the students to get from the lessons. Often this includes material about the process of science. Teachers need to make an effort to have the hidden curriculum be visible and explicit to their class if that want students to truly understand what it is they are supposed to take away from the lesson. Units like PIN, are designed to specifically focus on and test the experimental process, rather than have it be an assumed outcome from the class.

Some suggest that for students to make connections with the information they are learning it must be linked to their previous knowledge and also allow for easy links to 
new knowledge. (Wiedman 2005). Teachers can do this by creating cross-curricular connections and making those connections explicit. Patterns in Nature combines the common mathematical activity of modeling and links it to physics experimentation. This teaching method advocates for science as a process and guides students repeatedly through that process. The students are finding mathematical patterns and testing the limits of those patterns, an important part of the Nature of Science. It is a very relatable process that students can use as a framework for other activities.

There are some parallels between the Patterns in Nature unit's methodology and others that have tried to teach similar skills. Studies that have concentrated on teaching about graphing consistently found that students had difficulties developing a deeper meaning of the information they represented in graphical form (Mcdermott, 1987, Clement, 1985). A review of the graphing literature (Lienhardt, 1990) found that the students' graphing abilities was largely age dependent, concluding that teachers need to concentrate on the instructional strategies behind graphing starting earlier in a student's development. This supports the idea to use PIN curriculum in early high school. Doerr (1995) concentrated on in-depth instruction and fewer concepts, seeing a greater student understanding through an integration of math and science. This was near the beginning of the development of a specific method referred to as modeling, where students basically mimic physical phenomena. Halhoon (2004) follows the development of this method to widespread use in science classrooms. However, the 
method is not perfect, and students encounter difficulties using tools and recalling the correct mathematics (Sins, 2005). PIN is different than modeling in that it prepares students to model by providing the conceptual framework of the process. The students can then relate the process to real science by making data driven decisions. This is designed to enforce their understanding of the Nature of Science.

The Nature of Science (NOS) has been a focal point since the formalization of science education research and it is an important part of the current national standards in science. A study (Lederman, 2006) reviewed almost 100 years of research on the Nature of Science established that students are still not as successful at understanding NOS even after all the changes that have been made to the teaching process. Some argue that existing instruments are not even able to measure NOS gains effectively enough to tell for sure. Recent studies are more complex, showing that teacher and student conceptions of the Nature of Science are only connected when there is explicit instruction on the subject. However, the exact mechanisms that drive NOS understanding in students are not yet understood by science education researchers. It is obvious that more work needs to be done to understand how the Nature of Science should be taught. The hope is that the study of this unit, Patterns in Nature, will add another successful method of teaching NOS to the current body of knowledge. 
Challenges exist when conducting research in a classroom environment. Research clearly shows that there are new methods of investigation, collectively identified as design-based research, that have emerged to aid in classroom-based studies. Even though one may not be able to isolate all of the variables and there may be changing treatment as the study progresses, researchers can still conduct a valid and reliable study using a variety of data sources. (Brown, 1992) Other studies have successfully used design-based research to evaluate and improve their treatment. (Ketelhut, 2010) Researchers can trace the changes they have made to specific instances of implementation and subsequent analysis. Long term tracking can allow for deeper analysis of the effects of the unit. Design-based research will aid the analysis and further developments in Patterns in Nature. 


\section{Methods:}

\section{Overview:}

The purpose of this study is to evaluate the effectiveness of the Patterns in Nature (PIN) unit by measuring the impact of the unit on students. The research question to be answered is: How does the Patterns in Nature unit help high school students relate mathematical functions to scatter plots of real data? Subsequently, how does this treatment affect students' knowledge and views of the process and nature of scientific investigation? Both quantitative and qualitative data have been collected in order to answer these questions and define what changes may need to be made with the unit.

The primary study was conducted at a small charter school with a small number of students. Those students were subjected to content tests, surveys, interviews and the treatment. Data was taken in the class during the first grading period before, during and after the PIN unit was enacted. The aggregate results from that class were compared to the pre and post test results from a large school with a large class and a different instructor (Bradford Hill). In the year prior to the study, observations were made and instruments were piloted in Mr. Hill's class. Only the summative assessment on the content of the unit was used in his class, whereas all of the evaluative 
instruments were used in the primary study class. The experimental format is as follows with both classes taking approximately five weeks for the unit.

\begin{tabular}{|l|l|l|l|l|l|l|}
\hline $\begin{array}{l}\text { Primary Study Class: } \\
\text { Instructor - Chris } \\
\text { Sheaffer } \\
\text { (Met once per week) }\end{array}$ & $\mathrm{S}_{\text {NOS }}$ & $\mathrm{O}_{\text {Content }}$ & $\mathrm{X}_{\mathrm{PIN}}$ & $\mathrm{O}_{\text {content }}$ & $\mathrm{S}_{\text {NOS }}$ & $\mathrm{I}$ \\
\hline $\begin{array}{l}\text { Secondary Study Class : } \\
\text { Instructor - Bradford Hill } \\
\text { (Met every day) }\end{array}$ & & $\mathrm{O}_{\text {Content }}$ & $\mathrm{X}_{\mathrm{PIN}}$ & $\mathrm{O}_{\text {Content }}$ & & \\
\hline
\end{tabular}

Table 1: A time table comparing the instruments given to the students in the two classes studied.

$$
\begin{aligned}
& \mathrm{I}=\text { Interviews } \\
& \mathrm{S}_{\text {NOS }}=\text { Survey on Nature of Science } \\
& \mathrm{O}_{\text {Content }}=\text { Unit assessment on Content } \\
& \mathrm{X}_{\mathrm{PIN}}=\text { Treatment- Patterns in Nature }
\end{aligned}
$$

\section{Treatment:}

Patterns in Nature (PIN) was developed for use with $9^{\text {th }}$ grade students in a class that meets every day with a high student to teacher ratio as high as 40 students to one teacher. The unit being studied has been taught before in this format in the Beaverton School District and many adaptations have been made to optimize student engagement and proficiency. One distinct difference between previous iterations of PIN and this trial is the context in which it is taught. Contextual differences include the meeting frequency, the class size, the amount of material covered each class, and the different prior knowledge of the students. This difference is important because it will help to determine how transferable PIN is between different contexts. The new class is at a 
small charter school in the Oregon City School District. Here the student to teacher ratio is much lower, six students to one teacher. Students at this school mostly come from homeschooling backgrounds and they only receive grades in their classes once they reach high school. Their individual background knowledge can vary tremendously. In this setting the unit is taught to a class of seven students that meets one day per week, three hours per day. In this format, the unit is only five class periods. Because of this, adaptations had to be made, but the themes and methods remained the same.

The technical way to refer to Patterns in Nature would be mathematical modeling of data gathered from investigations of natural phenomena. The essential question of the unit is "How do we use patterns in nature to predict the future?" This statement is designed to engage the students and encourage them to think about the experiences that may have developed their prior knowledge. Through this question the teacher can relate all their experiences, from gravity to cell phones, to patterns that scientists have found when investigating phenomena in nature.

The unit begins with an inquiry investigation entitled the "Inquiry Cube", from the National Academy Press (NAP). It takes one class period. In this activity students are introduced to the concept of inquiry and how it can relate to science. In addition, the activity also introduces the idea of unknown answers and encourages students to evaluate their confidence in guesses as they predict what they will find on the bottom of 
the cube based upon the patterns they discover. They must first make a prediction before looking at the bottom, then as the students look at the mystery side they can see how close they were. An adaptation to the NAP activity is made by changing the bottom so that all squares follow the pattern, but different groups discover a different result when they look at the unknown side. This opens the door for a discussion about how results on the same experiment can differ based on the accuracy of the instruments used.

From here the unit leads to four experiments where the students discover four different patterns; one experiment per day is done in this particular enactment of the unit. Throughout these experiments the students learn about the Nature of Science while improving their experimental method skills. Conducting these experiments, finding patterns, and testing their predictions, the students can see how scientists learn about phenomena and construct the body of knowledge that we call science. This process helps to improve the students' views about the Nature of Science.

The first experiment investigates the pattern followed when a spring stretches with different masses hung on it. The format for the first experiment is very explicit to guide the students through what is expected of them in their future experiment write-ups. The goal is to emphasize that they take data, graph it, find a pattern and then use that pattern to make judgments about what the result would be if another point were taken. 
The students are also encouraged to make a statement about their confidence. The writing of their conclusions is scaffold using a fill in the blank format, requiring a statement about the pattern and their prediction. In general the students should explicitly see the difference between making a wild guess, and a data supported prediction. This particular activity reveals a linear pattern, and helps the students become familiar with the data gathering process and the analysis tools available to them. In this case they use Logger Pro and Microsoft Excel to analyze their data and model it mathematically. To expand upon the first experiment, students who finish early are given the task of investigating amplitude versus period, and mass versus period, both leading to constant flat line relationships. They report their findings back to the whole group and learn from each other through a discussion, another important part of the scientific process.

The second experiment is a pendulum period versus length investigation where the students discover a quadratic relationship. To keep things as efficient as possible the students must choose the simplest line of best fit that goes through their data point error bars. Simplest best fit keeps the math from becoming unnecessarily complicated. This relates to the notion that the simplest mathematical explanation is more advantageous to share and use. With the equation of the line of best fit the students can see the connection between math and science, and then use it to make predictions. 
The third experiment takes a break from physics content and involves a simple paragraph printed on a page. The students examine how changing the width restriction in the document affects the height of the text thereby discovering an inverse relationship. They must do more of the work individually, making the data table and taking data without a group to help them. The methods the students use from their first experiment are the same. They start with a wild guess, take data, find a pattern, use it to make a data-informed prediction, and then finally test the prediction.

The last experiment is an inverse squared pattern revealed through the investigation of how the shadow area of an index card relates to its distance from a light source. Students can conceptualize, through performing this experiment, that doubling the distance decreases the shadow size by four. Using the same methods, the students must write their own conclusion, without scaffolding, following this experiment. After this experiment the students should be ready to design and investigate a phenomenon on their own.

The unit concludes with a summary of the patterns followed by a unit test. Although the PIN unit ends here, the physics instruction for the remainder of the class uses the same experimental technique as the students learn physics content in a traditional sequence that proceeds from Newtonian to modern physics. 
Appendix B includes a collection of the PowerPoint slides for each day

\section{Participants:}

Preliminary studies were done at Southridge High School, a medium-sized school with approximately 2000 students in the Beaverton School District, situated in the suburbs of Portland, Oregon. The instructor, Bradford Hill, originally developed the unit at Southridge. His school operates on a trimester schedule where each trimester is 12 weeks long and he will be teaching the Patterns in Nature (PIN) unit for the second year. In 2012 , he taught the unit to a $9^{\text {th }}$ grade class of 35 students with the majority of students in 9th grade and some repeating the class. Those students will be compared with the ones in the primary study through reports of their grades on the unit test .

The primary study took place at a small charter school in Oregon City, Oregon called Alliance Charter Academy (ACA). The school operates on a college-like schedule with physics classes meeting once a week for three hours each meeting. The physics course is a year-long course designed to prepare the students for college science classes. Most of the students at the school come from home-schooling backgrounds and nontraditional science learning. There were seven students in the class aged 13-18. These students were taking classes above their grade level, with a few in the talented and gifted programs taking college-level math classes. The advantage of using this school as the primary study is the small class size and the ability to pay close attention to each 
student. Below is a short description of each student and their math and science backgrounds. Names of these students have been changed using pseudonyms to protect their identities.

Aaron is an $8^{\text {th }}$ grade student placed in all high school classes at the school. He was in Algebra 2 at the same time as Physics, and was one of the strongest students in that class. Although he had not taken any high school science classes before, Aaron had a strong background in science. He was always bringing in projects that he was working on. There were several robots that Aaron was building, programming, and competing in competitions with. His electronics knowledge was very extensive and he taught some of the other students during that unit. Although, Aaron was still working on his study skills and organization, he was always quick to solve any problems that the class had and correct mistakes from the teacher.

Spencer is a $10^{\text {th }}$ grade student taking both Algebra2 and Geometry at the same time he was in the Physics class. He came into the class with the lowest math skills. In science, he was taking a Bioethics class and had previously taken a physical science class. He was excited about science and it showed in the questions that he asked throughout the class. His interest in science fiction usually came up in the questions he would ask. After describing something that he had seen in a movie or read in a book, he would ask "Is this possible?" He found it challenging to conduct research or perform an 
experiment on his own. He had the interest in science, but needed to work on the skills required to pursue it.

Andy is another $10^{\text {th }}$ grade student who was taking a Pre-Calculus class at the same time as the Physics class. Although he had skipped Algebra 2 course, he was preparing to take Calculus the following school year from the community college. He had taken Physical Science and Chemistry the previous year. Andy had a great interest in computers, computer graphics and programming. At several points during the physics class, he instructed the class how to make visualizations of certain phenomena and even helped put together a video on energy. Andy always brought his laptop and i-touch to class, and tried to avoid writing things by hand whenever possible.

Nathan is a $10^{\text {th }}$ grade student in the same Pre-Calculus class as Andy. He had skipped Algebra 2 as well and was preparing to take Calculus the following year. Although Nathan and Andy had the same background, they had different personalities. Nathan had to write everything that he was doing down. He originally thought about going on to study mathematics in college, but eventually switched his interests to engineering. When doing an experiment, Nathan was always the first one to propose new studies by saying, "What if we did this?" or "Can we try this?" 
Quinlan is an $11^{\text {th }}$ grade student who was taking a Pre-Calculus class at the community college while enrolled in the physics class. She had also taken the Physical Science class and the Chemistry class. She took most of her classes in 2011-2012 at the community college. Quinlan was a little quiet and did not like to give her opinion in front of others. She was a hard working student and always the recorder for her lab group, organizing the information in a neat way.

Emerald, a $12^{\text {th }}$ grade student, entered the class with the highest math skills and executed her independent experiment at the beginning of the unit very well. Her interest is in music and dance, instead of science where she possessed much of the skills needed to be successful. Despite some effort to integrate art into math and science learning, Emerald could not see the two things together. She was an excellent student in the traditional sense, but had trouble seeing the bigger picture of how the scientific process affects our daily life.

The instruments described in the next section were only applied to the small charter school in Oregon City. Only general comparisons were made with the school in Beaverton through data shared by the instructor. Only aggregate unit test scores will be presented from the students in Beaverton to compare with data on a similar test from the Oregon City class. 


\section{Instruments:}

Described below are the sources of data from the students at the charter school in Oregon City, Oregon. The instruments used in this study include: A) a survey assessing student views of the Nature of Science; B) a content knowledge test (pre and post) on the subject of modeling data using graphs; and C) an interview with a subset of students in order to check the validity of the other instruments and obtain more in depth answers regarding the students' knowledge, skills and perspectives.

\section{A. Survey: Epistemological Beliefs Assessment for Physical Science (EBAPS)}

This survey was developed and validated by Elby, Schwartz, Frederiksen, and White at the University of California, Berkeley (Elby, 1999). It is a forced choice survey that is designed to look at student's epistemologies of science or, in other words, their views about the nature of knowledge and learning in the physical sciences. The authors intended the survey for college and high school students in an introductory physics, chemistry, or physical science class with an algebra-based background. This survey was chosen because it has been detached from a specific course, unlike many other surveys that were researched EBAPS focuses almost exclusively on the epistemology and nature of learning in science. This survey is an excellent fit with the concentration of the Patterns in Nature unit on science as a process. 
There are five different dimensions that the survey investigates as subscales of epistemological beliefs. The EBAPS survey probed students in the following areas:

\begin{tabular}{|l|l|}
\hline $\begin{array}{l}\text { Structure of scientific } \\
\text { knowledge: }\end{array}$ & $\begin{array}{l}\text { Do the students see science as a structured, unified whole, or } \\
\text { a collection of disconnected facts and formulas? }\end{array}$ \\
\hline $\begin{array}{l}\text { Nature of knowing and } \\
\text { learning: }\end{array}$ & $\begin{array}{l}\text { Does learning science mean absorbing facts, or constructing } \\
\text { knowledge from prior knowledge, working with materials, and } \\
\text { reflecting? }\end{array}$ \\
\hline Real-life applicability: & $\begin{array}{l}\text { Can science apply only to a classroom or laboratory, or does it } \\
\text { apply more generally to real-life? }\end{array}$ \\
\hline Evolving knowledge: & $\begin{array}{l}\text { Is knowledge absolute, evolving as often as peoples' beliefs, } \\
\text { or changing in a structured, research-based manner? }\end{array}$ \\
\hline Source of ability to learn: & $\begin{array}{l}\text { Does being good at science result from natural ability or can } \\
\text { most people become better at learning and doing science? }\end{array}$ \\
\hline
\end{tabular}

Table 2: The five dimensions investigated by the EBAPS survey

Each question is scored on a scale of zero to four. The forms of questions are mixed between Likert-scale and specific multiple choice response type questions. A score of zero is considered less sophisticated thinking and a score of four is more sophisticated thinking. A score of four on a question corresponds with an expert's level of thinking. Items are ordered in a randomized way, and the method of scoring is non-linear to take into account question to question variations. Some of the questions incorporate neutrality as more sophisticated and some as less sophisticated. Scores are reported in each sub-category and overall by calculating the average. 
The instrument was validated by the authors based on pilot studies and informal feedback. One hundred community college students took the survey and included written reflections for each item on the assessment. Those responses helped to reword the questions to focus on epistemology rather than other issues.

In terms of reliability, the authors tested to make sure that items in the same subcategory probe the same beliefs. They emphasize that despite questions being placed in the same dimension by a researcher, this may not be the case in the students' minds. There may be two different ideas in their heads that are activated based on different contextual clues; therefore a negative emphasis cannot be attached to a student answering differently in two similar questions. The authors conclude that the categories should be used as teaching targets rather than categories of students' beliefs.

Therefore, to test reliability in this study, results of the survey will be tied to results from one on one interviews and the context of the Patterns in Nature unit.

Appendix $C$ includes a copy of the EBAPS

Preliminary study survey: "Student views about science"

For the primary study, a survey was created to measure students' understanding of the Nature of Science and piloted in Mr. Hill's class. Ultimately, after giving the survey to 
Mr. Hill's students and analyzing the responses this survey was not used in the main study because scoring it was unreliable. However, individual students' responses from this survey were used to uncover some of the ideas about science they were developing as a result of the unit. Therefore, a description of the development of the survey is still included.

This instrument used questions selected from two different validated sources and was adapted for the needs of this study. Neither of the studies examined would have worked alone because they included several questions not addressed by the unit, and they were longer than the allotted class time.

Views of Nature of Science (VNOS), Lederman et al. (2002)

Views of Science and Education Questionnaire (VOSE), Chen (2006)

Lederman et al. (2002) explained that the "VNOS was tested for construct validity (i.e., capacity of the instrument to measure what it intends to measure)". The researchers administered the VNOS to two groups, a novice and an expert group, of nine participants each. After performing interviews in addition to the pencil and paper survey, researchers discovered clear differences between the experts' and novices' responses concerning the nature of science. As a result, the instrument was modified and expanded. Then a panel of five experts examined the items for content validity and 
the items were modified accordingly. Profile comparisons indicated that interpretations of participants' views as elicited by the VNOS were congruent to those expressed by participants during individual interviews.

Chen (2006) wrote that the test-retest reliability of the VOSE is high because the questions are derived from actual student views instead of experts' opinions. When the VOSE was given to 24 college students who voluntarily chose to take the test again three months later, a test-retest coefficient of .82 was achieved. The assessment was validated by two separate panels of experts and interviews with the students who were retested showed that only two of VOSE's 85 questions, neither of which was taken for the 'Student Views of Science' assessment, were interpreted differently from the researcher.

For the preliminary study, some questions from those two surveys were adapted to fit a 'yes or no' format, with space left for the students to explain themselves. Half of the questions concern the classroom environment and the other half relate to the scientific community. Two unit specific questions were developed and added to the adapted questions. These were deigned to document if the students' views of the relationship between graphs and equations changed. 
After the 'Student Views of Science' survey was developed it was examined for validity by three experts and determined to be measuring what it intends. However, this questionnaire used in the preliminary study did not prove to be reliable in its measurements or in its scoring method when actually used with students. Therefore, more reliable, more extensively validated study (Epistemological Beliefs about Physical Science, described in the previous section) was chosen and used in the primary study.

Appendix C includes a copy of the adapted assessment used in the preliminary study.

B. Patterns in Nature unit summative content knowledge and skills test:

To fully evaluate the unit, this study looked at how effectively the unit teaches the skill of data analysis. Specifically, the study looked at students' use of graphical methods and students' abilities to apply these methods to different physics principles. This was achieved by using questions drawn from the assessment normally given at the end of the unit.

Results from this test were compared to the assessment given at the beginning of the unit that shows the students' prior knowledge. 
This unit summary assessment had been used for two previous trimesters in a total of 12 different sections. The test has been examined by three different teachers and found to be valid. Similar grade distributions have been found in all of the classes that use this particular assessment, rendering the test reliable.

Appendix D includes a copy of the pre/post-test for the Patterns in Nature section.

\section{Interviews:}

Qualitative data was taken in the form of a one-on-one interview following the teaching of the unit. Interviews were conducted midway through the course, more than a month after the PIN unit, and involved all of the students in the class. Questioning began with broad and open-ended queries and gradually became more specific in order to avoid inadvertently directing the students to specific answers. Each interview lasted approximately 15 minutes and was recorded via digital audio recorder. Some questions from the EBAPS survey were repeated and transcripts from the interview have been compared to those students' answers on the surveys. 
The students were asked to apply their new knowledge of mathematical modeling and data-based decision making to previously unstudied situations in physics and other subjects. Two sets of data involving graphs were given and the interviewees were encouraged to answer various questions about the mathematical modeling and experimental process involved in the represented experiments. The students were also asked to evaluate the class and speculate how they may use the information in their future lives.

Appendix E includes the line of interview questioning that was asked following the unit.

Observations:

Observations were taken throughout the class and used to help analyze the data gathered. They were written down during teacher reflection before the next class occurred. These observations were subsequently coded into categories related to the learning goals of the unit and aspects relating to the students beliefs about science. 


\section{Data and findings:}

The results are integrated with the analysis for easy understanding. First, the results of the preliminary study are detailed, followed by the primary study.

\section{Preliminary studies:}

The results from instruments piloted in the preliminary study, during the 2010-2011 school year in Mr. Hill's class, guided the choices that were made for the current study in Oregon City. The "Student Views of Science" survey that was created and tested was not deemed an effective way to judge students' views of science as a process. There is no way to tell the degree of a student's judgment in its present 'yes' or 'no' format. Additionally, because the students were forced to one side of the arguments, explanations of their answers were often short and difficult to understand, usually just repeating the question. This meant that they were not triggered into sophisticated thought by the question and answer format and subsequently caused a lack of reliability in evaluating answers. An already validated survey, Epistemological Beliefs about Physical Science (EBAPS), was chosen to replace it and used unmodified. The EBAPS survey was researched and determined to be sufficient to use for the study in its published form. 
Interview questions tested in Mr. Hill's class were found to be effective and were used again, unchanged, in the current study. This data was collected and shared via Mr. Hill, allowing for comparisons between his students from 2010 in Beaverton and the students in 2011 in Oregon City. Students were able to understand the questions and answer them. The preliminary study interviewed two students at a time, but it was found that some of the shyer students just agreed with their partners' answers instead of providing their own thoughts and views about the questions. As a result, individual interviews were performed in the primary study, isolating students' thoughts from each other.

\section{Primary study:}

The findings are split up into the two aspects of the unit that are being evaluated: A) the skills of finding mathematical patterns in real data and B) the Nature of Science views.

\section{A. Patterns unit content:}

Pre-test modification:

A pre-test, identical to the final test, was given to the class, but the Oregon City students did not respond well. Students were frustrated and asking, "What does this mean?" and "What am I supposed to do here?" They did not know how to answer the questions and consequently were not providing any information about their prior knowledge. 
Explaining the questions in detail would have biased their answers rendering the item unconnected to their prior knowledge. To prevent disengagement at the beginning of the unit and risking that attitude carrying through the rest of the class, this test was stopped. A last minute change was made to the unit plan and the original pre-test was thrown out and replaced with a new type of pre-test.

Instead, the students were instructed to perform an investigation on their own as homework after the first class. Their assignment was to show what they think experiments involve and find their own pattern in nature and then share their findings with the rest of the students. It was designed to act as a diagnostic assessment of their experimental skills. This task was met with excitement from the students and provided much more information about their prior knowledge than the content test. A list of the students' experiments and findings is found in Table 3. The rest of the class consisted of the students working through the inquiry cube activity.

A simple process to assess the students' level of initial knowledge of mathematical modeling was developed. Three categories were examined as each student presented their experiment and each category was evaluated on a scale of zero to two. Zero represents no current knowledge, one represents some current knowledge, and two represents adequate current knowledge. The categories are: A) explanation of process, B) documentation of results, and C) analysis of data. 


\begin{tabular}{|c|c|c|c|c|c|}
\hline Student & Experiment Performed & Findings & Notes & Level & Overall \\
\hline Aaron & $\begin{array}{l}\text { Direct distance to a } \\
\text { dot vs. distance on a } \\
\text { monitor when being } \\
\text { filmed }\end{array}$ & & $\begin{array}{l}\text {-Elaborate Experiment } \\
\text {-Difficulty explaining } \\
\text { process } \\
\text {-No data to display }\end{array}$ & $\begin{array}{l}A-1 \\
B-1 \\
C-1\end{array}$ & $3 / 6$ \\
\hline Emerald & $\begin{array}{l}\text { Using a hydrometer to } \\
\text { measure salinity vs. } \\
\text { amount of salt added }\end{array}$ & Exponential & $\begin{array}{l}\text {-Well documented } \\
\text { process } \\
\text {-Data presented in } \\
\text { graphical form }\end{array}$ & $\begin{array}{l}A-2 \\
B-2 \\
C-2\end{array}$ & $6 / 6$ \\
\hline Nathan & $\begin{array}{l}\text { Amount of water vs. } \\
\text { amount of time to boil }\end{array}$ & & $\begin{array}{l}\text {-Explained process } \\
\text {-Only verbal data }\end{array}$ & $\begin{array}{l}A-1 \\
B-1 \\
C-1\end{array}$ & $3 / 6$ \\
\hline Andy & $\begin{array}{l}\text { Measuring } \\
\text { temperature of water } \\
\text { on a stove vs. time. }\end{array}$ & $\begin{array}{l}\text { Linear } \\
\text { (with an } \\
\text { upper limit) }\end{array}$ & $\begin{array}{l}\text {-Explained process } \\
\text {-Data in graphical form }\end{array}$ & $\begin{array}{l}A-1 \\
B-2 \\
C-2\end{array}$ & $5 / 6$ \\
\hline Spencer & $\begin{array}{l}\text { Basketball drop height } \\
\text { vs. bounce height }\end{array}$ & & $\begin{array}{l}\text {-Explained Process } \\
\text {-Presented gathered data } \\
\text {-Speculated pattern }\end{array}$ & $\begin{array}{l}\text { A - } 2 \\
B-1 \\
C-1\end{array}$ & $4 / 6$ \\
\hline Quinlan & $\begin{array}{l}\text { Number of ice cubes in } \\
\text { water vs. volume } \\
\text { change }\end{array}$ & Linear & $\begin{array}{l}\text {-Well documented } \\
\text { process } \\
\text {-Data in table form }\end{array}$ & $\begin{array}{l}A-2 \\
B-1 \\
C-0\end{array}$ & $3 / 6$ \\
\hline
\end{tabular}

Table 3: Diagnostic Test Experiments

Although not all of the students made it past the point of collecting data, this task

provided an opportunity to discuss the experimental process and possible ways of analyzing data. Only two of the students presented their data in a graphical form to analyze the pattern. The others only speculated about the pattern from the data or from their feelings about the experiment. None of the students fit an equation to their collected data by hand or using technology. The class discussion involved talking about finding patterns in the data and then using them to predict inside and outside the range of the results. This proved to be an interesting conversation considering two of the 
students had data that was bound by a limit. The class tackled the question "Can an experiment follow more than one mathematical pattern?"

The discussion ended with a talk about the reliability of the data. As a group, the class brought up possible variables that might have affected the results and the ability to use those findings to predict new results. Generally, the students were quick to come up with other variables that they could have controlled, but they were uncomfortable speculating about how their data could be modeled. The students did not seem to fully understand how their data could be used to make predictions about future results.

After summarizing this pre-test/diagnostic assessment, the students possess some experimental method skills, but not mathematical modeling skills. Despite the major differences between the new assessment and the post test, results from the post test can still be compared generally to this data to show student growth in both the areas of experimental skills and mathematical modeling. The new method of assessing prior knowledge turned out to be a good way to increase student learning as well and it may be advantageous to use this type of a post-test as well.

The Pattern In Nature unit was also taught by Bradford Hill, the developer of the unit, in the spring trimester of the same year as this study. He was able to give his standard pre-test to his students without any difficulty. The large class size may have played a 
role in this different outcome. Large classes create more of a lecture room atmosphere where students can feel discouraged from asking questions. It is also possible that the standard pre-test from this class does not accurately represent his students' actual prior knowledge either. More studies would have to be conducted using both types of assessment to know for sure.

Post-test:

Data from Bradford Hill in Beaverton:

Aggregate data from Mr. Hill's class shows the grade distribution from his pre and posttest. His class included scores from 36 students. He was able to give very similar pre and post-tests without any issues, allowing for a simple comparison. The change is clearly visible in the graph. The number of C's, D's and F's decreased while the number of A's and B's increased. This shows that in his classroom environment the students are gaining the content skills that Patterns in Nature seeks to teach. 


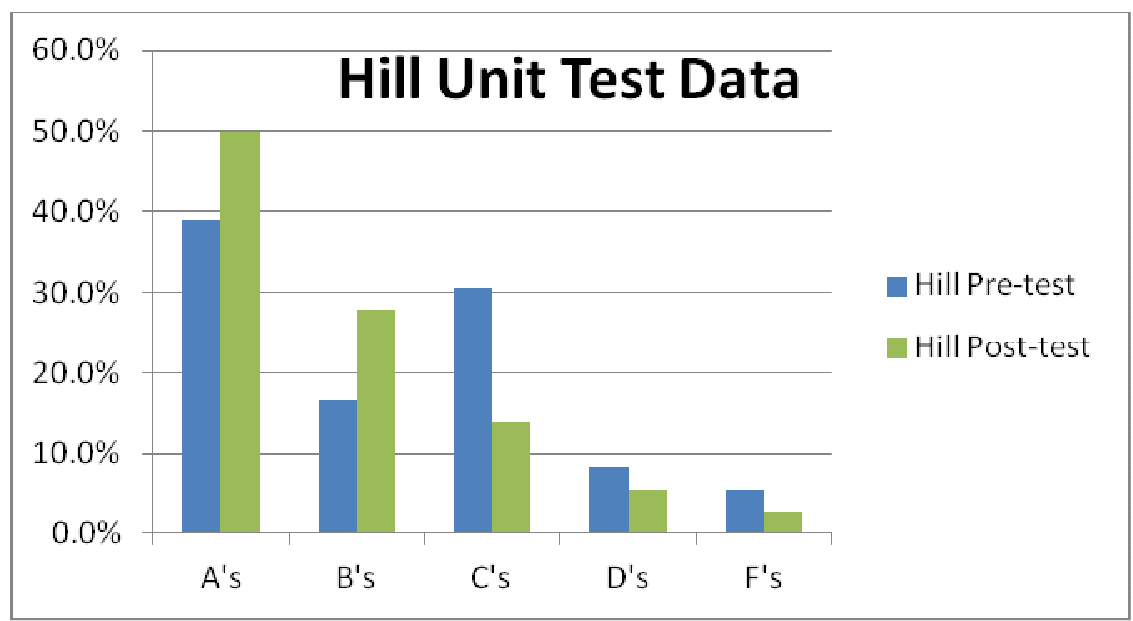

Figure 1: Pre and Post-test scores of students on the Unit Test from Mr. Hill's class.

Inter-class comparison:

The post-test from Mr. Hill's class and the primary study class were nearly identical, and only differed by a few questions concerning conversions, which was not a specific learning goal of the PIN unit. Therefore it can be assumed that similar knowledge gains happened in both classes. However, the scores from the two classes cannot be directly compared because of the discrepancy in sample size.

The primary study class only had scores from six students, as opposed to the 36 students in Mr. Hill's class. Despite this, the number of A's and B's in each class were greater than the number of C's, D's and F's. Additionally, both of the classes were graded using a ten point scale and did actually have the same average grade of $81 \%$.

These similarities support that PIN was taught effectively in two different classes by two different teachers, but exact knowledge gains are difficult to show. 
Pre/Post-test comparison in Oregon City:

Once again, in the primary study, the pretest was replaced by a diagnostic assessment of the students' experimental method and data analysis skills. Due to the drastic differences in the type of assessment these two items cannot be easily compared. However, it is valid to make a general statement about how well the students did on each instrument and compare the overall scores.

Most students that scored well on the pre-assessment also scored well on the post-test. Some of the students showed greater change than others, but the two tests are overall difficult to compare directly. The two tests were in a very different format and did not quite test all of the same aspects of mathematical modeling and scientific investigations. The most important finding from the pre-test is that none of the students represented their data graphically or developed an equation to fit the data and predict future measurements.

\begin{tabular}{|l|r|r|}
\hline Name & \multicolumn{2}{|l|}{$\begin{array}{l}\text { Diagnostic } \\
\text { Assessment }\end{array}$} \\
\hline & $\begin{array}{l}\text { Points } \\
\text { (out of 6) }\end{array}$ \\
\hline Aaron & 3 & $50 \%$ \\
\hline Emerald & 6 & $100 \%$ \\
\hline Nathan & 3 & $50 \%$ \\
\hline Andy & 5 & $83 \%$ \\
\hline Spencer & 4 & $67 \%$ \\
\hline Quinlan & 3 & $50 \%$ \\
\hline
\end{tabular}

\begin{tabular}{|r|l|}
\hline \multicolumn{2}{|l|}{ Post-Test Scores } \\
\hline \multicolumn{2}{|l|}{$\begin{array}{l}\text { Points } \\
\text { (out of 18) }\end{array}$} \\
\hline 13.5 & $75 \%$ \\
\hline 17.5 & $97 \%$ \\
\hline 15.5 & $86 \%$ \\
\hline 15.5 & $86 \%$ \\
\hline 11 & $61 \%$ \\
\hline 14.5 & $81 \%$ \\
\hline
\end{tabular}

Table 4: Pre and Post content test scores for each student. 
Post-test results in Oregon City:

When looking at just the score on the post test, one student's score was lower in comparison with his peers. This can say one of two things: either everyone in the class except that student showed a knowledge gain, or everyone maintained a constant level of knowledge while that student showed a decrease in knowledge. A conjecture like this can be made assuming there was no knowledge increase from the student, and that the other students did not decrease their knowledge. Knowing the results of the pretest, the first option seems like the best choice. Spencer came into the class with the lowest level of math background, and seems to have also left with the lowest level of math modeling performance. However, this is an oversimplified view and one needs to look at the specifics of the test to see exactly where these students struggled. Figure 3 shows results from each question on the test.

Post-test item analysis:

Overall, there were five questions where every student answered correctly. The rest of the questions had at least one student answer incorrectly. What follows is a breakdown of the exam by question. The results will be used as a guide to identify which areas of the curriculum need to be strengthened for the next iteration. 


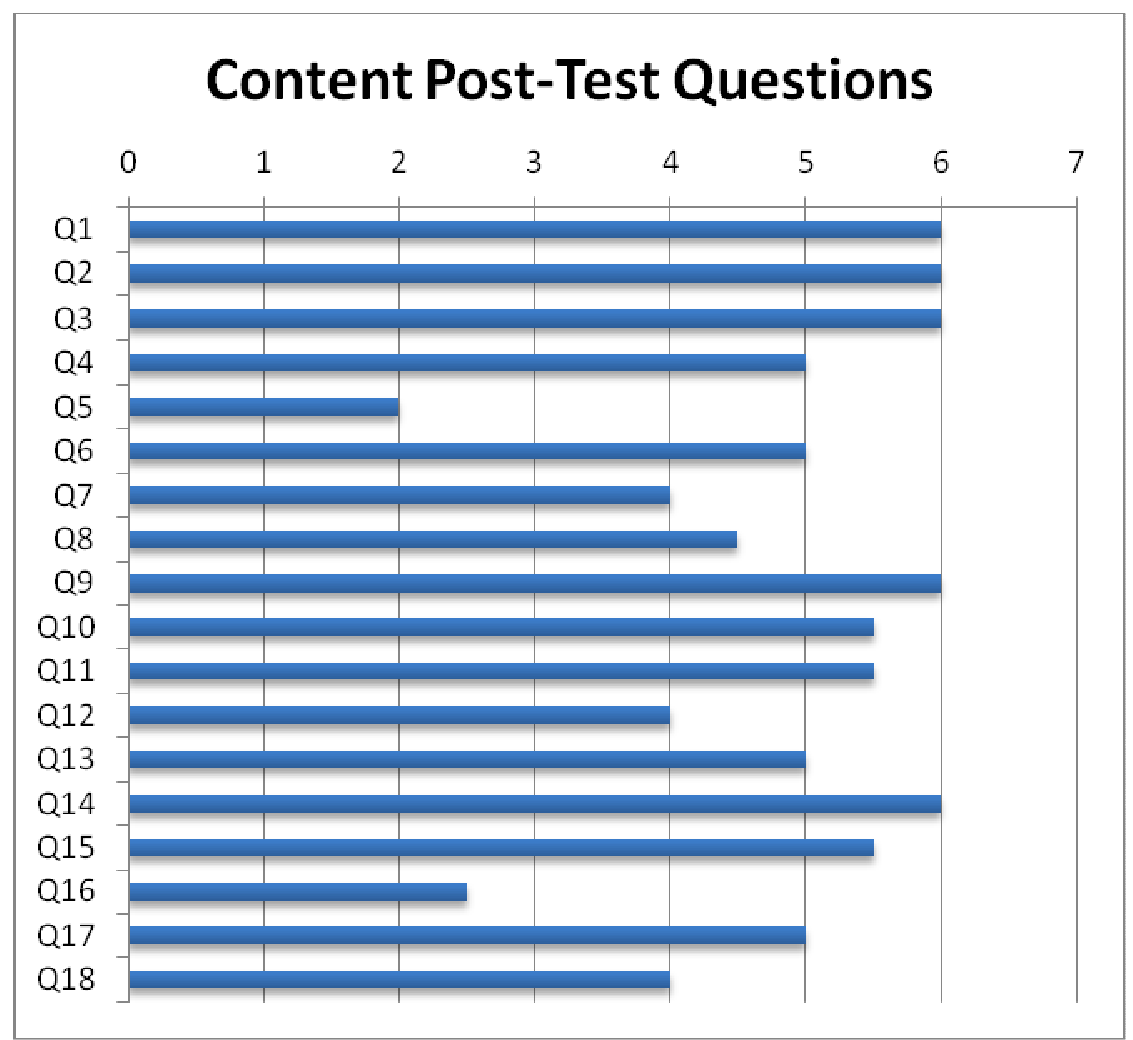

Figure 2: Content test results, the number of correct answers by question.

For the content test graphic, one point was given per question; there were six total students tested and a score of six means all of the students got that question correct. Half points were awarded for some of the questions.

Table 5 shows the topics of each question on the content test, and summarizes the changes recommended as a result of student performance. A copy of the test showing all of the questions can be found in Appendix C. 


\begin{tabular}{|l|l|l|}
\hline Questions & Topic & Future Change \\
\hline $1,2,3$ & Variable Types & None \\
\hline 4 & Average and Uncertainty & None \\
\hline 5 & Plotting Data and Uncertainty & $\begin{array}{l}\text { Add specific tasks where the students draw } \\
\text { their own uncertainty lines. Needs to be done } \\
\text { at the beginning and end of the unit. }\end{array}$ \\
\hline 6 & $\begin{array}{l}\text { Best fit Line, Pattern } \\
\text { Identification }\end{array}$ & $\begin{array}{l}\text { Complete cross-curricular lesson on drawing } \\
\text { graphs from data and equations. } \\
\text { To assess, give equations to graph and match to } \\
\text { the data identifying which of the given } \\
\text { equations is the best fit for the data. }\end{array}$ \\
\hline 7 & Data Based Conclusion & $\begin{array}{l}\text { Possibly require students to make a prediction } \\
\text { for a value of a new data point taken either } \\
\text { inside or outside the data. }\end{array}$ \\
\hline 8,9 & Pattern Description & Emphasize that variables have units. \\
\hline 10,11 & Pattern Identification & None \\
\hline $12,13,14$ & Conversions & $\begin{array}{l}\text { Make different graphs where only the units are } \\
\text { changed, observe differences and similarities in } \\
\text { shape and scale. }\end{array}$ \\
\hline $15,16,17,18$ & Pattern Create and Describe & $\begin{array}{l}\text { Provide more opportunities to describe } \\
\text { mathematical relationships using words. }\end{array}$ \\
\hline
\end{tabular}

Table 5: Content test questions categorized by type of knowledge, accompanied by a summary of potential changes.

The first mathematical question, (Q4) had the students find the average and uncertainty of given data. Only one student answered this question incorrectly, but when required to graphically represent that data other students also had difficulties. The following question (Q5) asked the students to graph the previously given data. They were required to show the data points and the error bars. Four out of the six students lost points on this question. The most common mistake was forgetting to draw in the error bars with the data. 
Based on the results of these questions, the students do not quite see the connection between keeping track of uncertainty and showing it on their graphs. Throughout the unit, the students keep track of both their data and uncertainties on their tables, but the program 'Logger Pro' places them both in the graph. While the students are told to make the best fit that they can manually, there is still a mysterious quality to the way that the computer produces an equation. It is possible that this prevents them from making a connection between their data uncertainties and the ones on the graph. Perhaps when they make their predictions the students should be told to incorporate their uncertainty values in the predicted outcome. While teachers cannot avoid using computer software to make appropriate mathematical models for this grade level, they can try to make a smoother connection between the real data and the equation produced.

Another troublesome question (Q16) occurred in the last section of the test where the students were required to describe all four patterns in multiple forms: graphically, mathematically, and in words. All of the students except for Spencer correctly recalled the mathematical descriptions of all four patterns. There were more difficulties on the descriptions of the patterns with words than anywhere else. As a group, the students had the most trouble on the quadratic pattern, the subject of Q16. Here two of the six answered correctly and one student received half credit. Most of the students who 
answered incorrectly went on to make similar mistakes with all of the following questions in this section.

A summary of individual results of Questions 15-18 describing the patterns in words can help to conceptualize the way that the students understand the mathematical relationship that they are working with. Here it is clear that they understand the difference between increasing and decreasing, but they do not quite understand what is happening as the rate is increasing and decreasing. From these descriptions one can tell that recalling symbolic relationships does not mean that the students can comprehend what is happening to the two variables. Admittedly, this is difficult to do without a physical relationship to relate to, but that is part of the reason for asking the question this way. In this format, the students need to bring in the physical relationship on their own. 


\begin{tabular}{|c|c|c|c|c|}
\hline \multicolumn{5}{|c|}{ Question format: As $x$ increases in regular intervals, then $y$} \\
\hline Student & $\begin{array}{l}\text { Question } 15 \\
\text { (linear) }\end{array}$ & $\begin{array}{l}\text { Question } 16 \\
\text { (quadratic) }\end{array}$ & $\begin{array}{l}\text { Question } 17 \\
\text { (inverse) }\end{array}$ & $\begin{array}{l}\text { Question } 18 \\
\text { (inverse squared) }\end{array}$ \\
\hline Aaron & Gets larger & Gets much larger & Gets smaller & Gets much smaller \\
\hline Andy & Grows linearly & $\begin{array}{l}\text { Grows at a } \\
\text { squared rate }\end{array}$ & $\begin{array}{l}\text { Decreases by a } \\
\text { steadily } \\
\text { decreasing } \\
\text { amount }\end{array}$ & $\begin{array}{l}\text { Decreases by a } \\
\text { squared } \\
\text { decreasing } \\
\text { amount }\end{array}$ \\
\hline Nathan & Gets larger & Doubles & $\begin{array}{l}\text { Halves / Gets } \\
\text { divided by the } \\
\text { same as } x\end{array}$ & $\begin{array}{l}\text { Gets divided by } \\
\text { the square of } x\end{array}$ \\
\hline Spencer & $\begin{array}{l}\text { Straight line, } \\
\text { Grows x } 2\end{array}$ & $\begin{array}{l}\text { Gentle curved } \\
\text { line, Grows x } 4\end{array}$ & $\begin{array}{l}\text { Backwards } \\
\text { gentle slope, } \\
\text { Shrinks x } 2\end{array}$ & $\begin{array}{l}\text { Don't know, } \\
\text { Shrinks x } 4\end{array}$ \\
\hline Quinlan & Gets larger & Doubles & $\begin{array}{l}\text { Decreases by } \\
\text { half }\end{array}$ & $\begin{array}{l}\text { Decreases by one } \\
\text { fourth }\end{array}$ \\
\hline Emerald & $\begin{array}{l}\text { Increases at the } \\
\text { same rate }\end{array}$ & $\begin{array}{l}\text { Increases to the } \\
\text { square of } x\end{array}$ & Is divided by $x$ & $\begin{array}{l}\text { Is divided by } x \\
\text { squared }\end{array}$ \\
\hline
\end{tabular}

Table 6: A comparison of answers from different students to the last 4 questions of the content test.

As a note from this test, although most of the students did well on writing the conclusion based on the data (Q7), they were given the option to use a scaffold conclusion and fill in words and values, or to write the conclusion in their own words. All of the students used the scaffold conclusion to describe the results. Perhaps this supports the fact that students lack the ability to sufficiently describe the resulting mathematical pattern in words, or maybe the students just chose the option that involved less work. Nevertheless, describing relationships between variables in their own words was also a common difficulty for students during the interview. 
Interview questions on Patterns in Nature unit content:

Table 6 shows students' answers to the questions in the interview regarding the pattern identification. They were asked to look at one of two scatterplots that included a line of best fit and then required to answer a few questions about what they saw. Originally, the students were going to answer both questions listed below, but time only permitted one per student. Different questions were asked of different students in an attempt to confirm that students understood both simple, logical and more complex, unfamiliar mathematical patterns. The question that was asked of each student is shown by the number beside the name in the table.

1) - Here is a plot developed by a computer scientist trying to determine the relationship between the number of words and the number of pages in a book, each point on the graph represents a different book.

(a linear relationship)

2) - An engineer is developing a crane equipped with a magnet for lifting wrecked cars. Here is her plot of the weight of the car vs. the distance between the magnet and the car to lift it off the ground.

(an inverse relationship) 


\begin{tabular}{|c|c|c|}
\hline & $\begin{array}{l}\text { What sort of relationship does this line } \\
\text { represent? }\end{array}$ & Describe it in plain words. \\
\hline $\begin{array}{l}\text { Andy } \\
\text { (1) }\end{array}$ & Linear... & $\begin{array}{l}\text { If one of them changes in the positive } \\
\text { direction, the other one changes in the } \\
\text { positive direction. }\end{array}$ \\
\hline $\begin{array}{l}\text { Spencer } \\
\text { (1) }\end{array}$ & $\begin{array}{l}\text { It would be a linear fit because all of them } \\
\text { are pretty much close to each other going in } \\
\text { the same direction. (- What do you mean by } \\
\text { that?) } \\
\text { They are all really close to each other as } \\
\text { they all travel along the line. }\end{array}$ & $\begin{array}{l}\text { It doubles, it just goes up and up and } \\
\text { up and up. }\end{array}$ \\
\hline $\begin{array}{l}\text { Aaron } \\
\text { (1) }\end{array}$ & $\begin{array}{l}\text { Pretty much a straight line. Starting at }(0,0) \\
\text { and going up. A positive relationship. }\end{array}$ & $\begin{array}{l}\text { If you double the number of pages, it } \\
\text { [the words] would probably double } \\
\text { too. }\end{array}$ \\
\hline $\begin{array}{l}\text { Quinlan } \\
\text { (2) }\end{array}$ & It looks kind of like an inverse & $\begin{array}{l}\text { It would get doubly smaller. It is hard } \\
\text { to tell... If it is heavier it will get twice } \\
\text { as small. }\end{array}$ \\
\hline $\begin{array}{l}\text { Emeral } \\
\mathrm{d}(2)\end{array}$ & $\begin{array}{l}\text { I remember lines of best fit, but not the } \\
\text { name... Maybe inverse? }\end{array}$ & $\begin{array}{l}\text { ' } \mathrm{X} \text { ' is the weight of the car, ' } \mathrm{Y} \text { ' is the } \\
\text { magnet distance. (- As the weight of the } \\
\text { car increases, what happens to the } \\
\text { other variable?) } \\
\text { Decreases. (- If you double the mass, } \\
\text { using your inverse relationship, what } \\
\text { happens to your magnet distance?) } \\
\text { It is divided by...2. }\end{array}$ \\
\hline $\begin{array}{l}\text { Nathan } \\
\text { (2) }\end{array}$ & I would say an inverse equation... & $\begin{array}{l}\text { It would decrease by } 1 / 2 . \text { So like if the } \\
\text { distance was } 10 \text { meters, it would go to } \\
5 \text { meters. }\end{array}$ \\
\hline
\end{tabular}

Table 7: Students' answers to two of the mathematical patterns questions in the interview.

Among the students' responses there was no uniform description. While all of the students correctly identified the relationship that existed between the two variables, many experienced difficulty describing exactly what that meant in plain words. In response to the question the students were expected to make a statement along the lines of 'If the $x$ variable does ___ then the $y$ variable does__,' filling in the blanks 
with the correct mathematical words. However, they struggled to articulate exactly what was happening in real-life.

For instance, Emerald, who is one of the students with the strongest math skills had trouble remembering the name of the relationship, and then had to be led to the description of the relationship in words. This confirms that complete mathematical modeling understanding, in terms of literacy, is a possible weakness in the PIN unit. If the interview had included a question about a quadratic or an inverse squared relationship, the areas where the students had the most trouble on the unit test, it can be safely assumed that the students would have had even more difficulty articulating the relationship. They simply need more practice writing descriptions of relationships between variables.

From observations during the first few days of class, whenever the students discussed other patterns they noticed in the world around them, they most commonly named linear patterns. There were even several misconceptions about what a linear pattern was. Much of the relationships that the students understand are simply increasing or decreasing, and they often do not think about the rate of change varying. Considering this, it makes sense that there would be more difficulties with the unfamiliar patterns that form curved lines like quadratic, inverse and inverse squared. 
Summarizing the results of the content test brings to light the ability of the students to quickly identify patterns visually, but also shows how they seem to lack the capacity of describing relationships in their own words. The simple solution is more practice.

Throughout the unit students are introduced to each pattern individually so they have a specific experiment to remember when they are identifying patterns in data. The students come up with a conclusion, identifying the relationship between the variables and predicting a future measurement, but results show that they do not get enough opportunities to describe the mathematics of the relationship in words. The student conclusions need to explicitly include an emphasis on describing what is happening to the independent and dependent variables and they need to be given more chances to do so. The unit could additionally incorporate mathematical and scientific literacy, or an emphasis on vocabulary, to instruct the students how to explain a mathematical relationship verbally.

Regardless of what these results hint at, they are uncertain enough that it is necessary to develop better ways of testing the skills taught in the unit. A more authentic type of assessment, similar to the diagnostic assessment, might shed more light on the students' difficulties in the aspects of the Patterns in Nature unit. The students could be given two related variables and told to investigate and describe the relationship between them. The observation and written evidence of the students' experiment provide the evidence of learning. Authentic assessments like this have the advantage of 
providing much more information about students' thoughts. If a teacher has the time and a small enough class, then they would certainly learn more about the students by using this assessment at the end of the unit.

\section{B. Nature of Science and science process findings}

Epistemological Beliefs Assessment for Physical Science survey (EBAPS):

The survey was given on the first day before any instruction, and also on a date following the unit before the interviews. Table 5 shows the compiled results of all the students averaged. The surveys consisted of 30 questions all assessed on a scale of one to four, where four is the ideal response, all of these scores were then averaged together.

\begin{tabular}{|l|r|r|r|}
\hline & $\begin{array}{r}\text { Pre } \\
\text { Test }\end{array}$ & Post Test & Difference \\
\hline $\begin{array}{l}\text { Whole Group } \\
\text { Average }\end{array}$ & 2.79 & 2.98 & 0.19 \\
\hline
\end{tabular}

Table 8: Averaged results from all of the students on the EBAPS survey before and after the unit.

The overall performance improved from the beginning to the end of the unit. As a group the students were closer to expert-level thinking in the nature of scientific knowledge and investigation after they experienced the Patterns in Nature unit. The 
improvement was slight, but noteworthy. Statistical significance was not tested due to the small sample size.

The EBAPS survey also categorized the questions in terms of five interlinked dimensions.

These categories were created by the authors as a way to describe specific issues that students may be facing in their beliefs about science. Some questions on the survey are included in multiple categories, and a few are not included in any of these categories.

Table 6 is a brief summary of the ideas covered by each category. Figure 4 is a graphic of how the class performed in each category.

\begin{tabular}{|l|l|}
\hline $\begin{array}{l}\text { Structure of scientific knowledge: } \\
\text { Q2, } 8,10,15,17,19,20,23,24,28\end{array}$ & $\begin{array}{l}\text { Do the students see science as a structured, } \\
\text { unified whole or a grouping of disconnected } \\
\text { facts and formulas? }\end{array}$ \\
\hline $\begin{array}{l}\text { Nature of knowing and learning: } \\
\text { Q1, } 7,11,12,13,18,26,30\end{array}$ & $\begin{array}{l}\text { Does learning science mean absorbing facts or } \\
\text { constructing knowledge from prior knowledge, } \\
\text { working with materials, and reflecting? }\end{array}$ \\
\hline $\begin{array}{l}\text { Real-life applicability: } \\
\text { Q3, 14, 19, 27 }\end{array}$ & $\begin{array}{l}\text { Can science apply only to a classroom or } \\
\text { laboratory, or does it apply more generally to } \\
\text { real-life? }\end{array}$ \\
\hline $\begin{array}{l}\text { Evolving knowledge: } \\
\text { Q6, 28, 29 }\end{array}$ & $\begin{array}{l}\text { Is knowledge absolute, evolving as often as } \\
\text { peoples' beliefs or changing in a structured, } \\
\text { research-based manner? }\end{array}$ \\
\hline $\begin{array}{l}\text { Source of ability to learn: } \\
\text { Q5, 9, 16, 22, 25 }\end{array}$ & $\begin{array}{l}\text { Does being good at science result from natural } \\
\text { ability or can most people become better at } \\
\text { learning and doing science? }\end{array}$ \\
\hline
\end{tabular}

Table 9: Categories for EBAPS questions. 
Elby, Schwartz, Frederiksen, and White (1999) stress that these categories should only be used to inform teaching strategies and not to analyze student thinking. In the students' minds the ideas on similar questions may be divided differently by contextual clues.

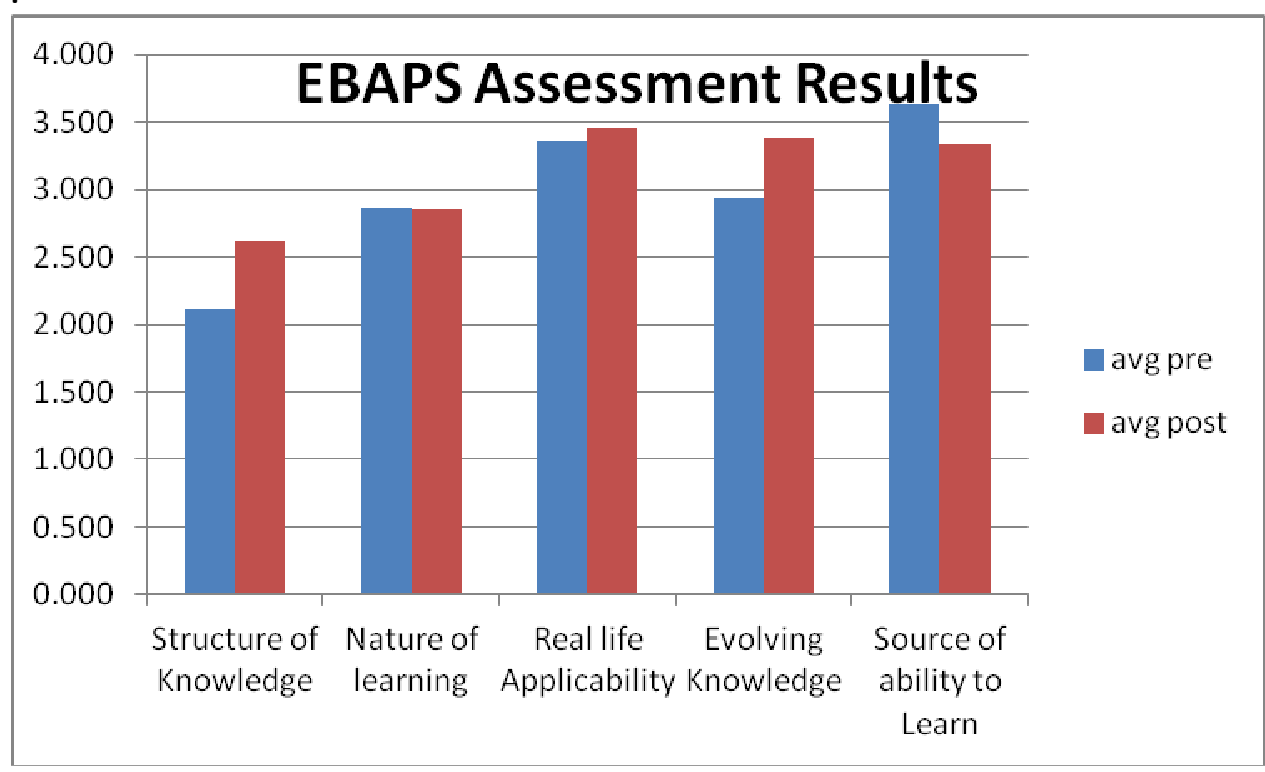

Figure 3: Average scores of the class in each category of the survey on a scale of zero to four.

The EBAPS test key, organized by category can be found in Appendix C.

Although the students did not average very close to the expert-level thinking in any of the designated categories, the students seemed to maintain or gain in every category except one. In the 'Source of ability to learn' category the students averaged a high score, but the overall average of the students declined slightly. In the 'Structure of knowledge' category the students averaged the lowest score, but improved the most. To understand both of these results fully, a closer look needs to be taken at the questions in each category. 
EBAPS item analysis: 'Structure of knowledge'

On the survey, this category contained more questions than any other. Ten out of the 30 questions belonged to this subset (questions: $2,8,10,15,17,19,20,23,24$, and 28). The structure of knowledge is important to the researchers who created the EBAPS and it is also important to the Patterns in Nature unit, which is designed to highlight the structure of mathematical relationships that provide the connections between physics topics. Almost all of the students showed improvement in this category. Only Emerald showed a slight decrease in the category. Although there are too many questions in this category to look at individually, there are several aspects which merit special attention.

An important question in this section was Q15. It asked the students to agree or disagree in a statement that said knowing methods to solve specific types of questions is important for most regular problems while knowing the big ideas are not. Three students disagreed with the statement on the pre-test, and then changed to agree on the post-test. Andy went from neutral to disagree, and Nathan disagreed on both tests. Emerald on the other hand was neutral on the pre-test and then agreed on the posttest. For her, somehow the big ideas were devalued during the course of the unit and now she agrees that they are not very important in most physics problems. 
Another question in the category (Q23) asked the students about the best way for a teacher to see how much they know. Students have to choose between a large number of short-answer and multiple choice questions, each covering a different topic, or a small number of longer questions that cover multiple topics. Ideally the student should choose the latter, but in answering this question many of the students favored the multiple choice questions. This is most likely because there are several of the students who are in large community college classes where they use that style of questioning on their tests. When looking who answered that way, it was Emerald, Andy, Nathan and Quinlan, who were all in community college classes at the time of the unit.

One final question to look at in this 'Structure of knowledge' section was one that talked about the structure of science textbooks (Q24). In the question two students have a debate and those answering the question are asked to choose who they agree with. One student says that they should not treat each chapter as a unit because they are not really all separate, while the other student says that they chapters are different topics that do not have much to do with each other. Most students agreed with the first opinion, that science topics are interrelated, on both the pre and the post-test. However, on the pre-test Nathan and Spencer both thought that chapters in a science book should not be interwoven, and then changed to agree with the rest of the students at the end of the unit. This result helps to show that at the end of the Patterns in 
Nature unit, all of the students in the class can see how all of the topics in a science class are interrelated.

In this category, students generally improved the most because the majority of them saw the importance of the big ideas and interconnectedness of all the topics in the textbook. Some students could not see why longer questions covering more than one topic in physics would be a more effective way for the teacher to assess their knowledge. This might be related to the other types of classes that they are enrolled in, but when looking at the assessments in PIN, there are not a lot of these types of questions. Multiple choice questions are non-existent and most of the questions are short, one topic questions. This may support changing the types of assessments used in Patterns in Nature.

EBAPS item analysis: 'Source of ability to learn'

Looking at the test, five of the 30 questions fit into the 'Source of ability to learn' subset (questions: $5,9,16,22$, and 25). The first question (Q5) talks about the ability of studying to make a difference in a student's understanding of the material. All students agreed with this statement on the pre-survey, and only two changed their answer on the post-survey. One student changed from 'strongly agree' to 'somewhat agree', and 
another did the opposite, changing from 'somewhat agree' to 'strongly agree'. Results from that question support the notion that students believe anyone can learn science through studying.

The second question of the section (Q9) reiterated the point of Q5, saying that someone who doesn't have natural ability can still learn in a physics class. Once again, most students agreed with the statement, and kept their opinion the same from the pre-test to the post test. One of the students changed their answer from 'somewhat agree' on the pretest to 'neutral' on the post test. This student, Emerald, had the best grade in the class and very good work habits, but for some reason still changed her beliefs. Before the PIN unit she thought that someone without natural ability could still learn physics, but following the unit she is not sure that someone who does not have the right background could succeed in physical science. A closer look will be taken later at Emerald. Overall, she seemed to lack confidence in her scientific abilities at the end of the class.

When considering the answers of everyone but Emerald, it seems that the class has direct influence on maintaining a student's belief that scientific knowledge does not depend on natural ability. 
The next question, (Q16) in the 'Source of ability to learn' series (Q9), once again asked the same thing in a slightly different way. The question states that "Given enough time, almost everybody could learn to think more scientifically if they really wanted to." This question gets at the heart of the issue by eliminating the constraints of classroom from the students' thought processes. Results were very similar, and all students agreed with the statement on the pre-test; however, on the post-test one student drastically changed her opinion from 'agree' to 'strongly disagree'.

All other students answered as they did on the pre-test, but Quinlan did not. According to her answers, she no longer thinks that almost anybody can learn to think more scientifically if they have the time. Her answers of agreement to the previous questions suggest that she thinks that people can learn to do well in a physics class through studying even if they do not have a natural ability. This disagreement in results can either show that she did not answer all of the questions carefully and truthfully, or that she does not believe that there is a correlation between physics class and scientific thinking. She thinks that in the classroom anyone can succeed and learn (Q5), but when the classroom aspect was eliminated from the question she disagreed (Q9), thinking that not everyone can learn to think scientifically. If that is the case, then the Patterns Unit did not accomplish all of its goals with Quinlan because she cannot see the connection between the classroom and the real world. However, her score in the category 'Real life applicability' did improve slightly and this complicates our view of her 
thought processes. In the interview results a closer look will be taken at Quinlan's answers to support this statement.

Continuing with the EBAPS results, the next question in the subset (Q22) was asked in a different manner. Students were asked to choose between a series of statements that compared the roles of hard work and natural ability to being successful at science. Almost all said that hard work was more important than natural ability, except for two students. Quinlan stated on both the pre and post-test that hard work and natural ability are equally important. It does not appear that the unit changed her opinion at all and she still considers natural ability an important part of science success. While it is debatable that this may or may not be true, the correct response favors hard work, and favoring natural ability is not the result that one would expect from a student after experiencing a unit about the scientific process where it is clearly stated that all students can be successful in science. Spencer, another student, also considered hard work and natural ability equal influential factors in science success on the pre-test. His opinion however, changed on the post-test. After experiencing the Patterns in Nature unit, Spencer now believes that hard work is more important than natural ability. Spencer was a hard working student that did not have as much mathematical background as the other students. Perhaps the successes that he experienced throughout the unit influenced his opinion of his own scientific learning. 
The last question relating to 'Source of learning ability' (Q25) talks about exactly the same issue as the previously discussed question. In this question, a conversation between two students is described where they debate the role of hard work and natural ability in career success. One student takes the side of hard work, and the other sides with natural ability as they discuss how Kay Kinoshita (a well renowned particle physicist) became such a good physicist. Once again, most students sided with the student arguing that hard work was most important, but two students changed their opinion on the post test. Spencer went from favoring hard work to 'neutral', and Quinlan went from favoring hard work to favoring natural ability. Spencer's change in opinion shows the exact opposite change from pre to post as Q22, possibly influencing the reliability of his answers. However, it is clear that there is still some debate about the issue in his mind. Quinlan, on the other hand, has changed her answers from favoring hard work to favoring natural ability two times. She had some negative influence in this area over the course of the unit and shows this on the survey.

It seems as though most students in this class understand the importance of good study strategies and hard work, agreeing that with the appropriate amount of effort any student can succeed in science. One student in the class, Quinlan, did not see the value of her hard work, after progressing through the Patterns unit. She now believes that natural ability can play an important role in science learning. This is the opposite result that is expected after experiencing the Patterns in Nature curriculum. In certain 
circumstances in the real world this may be true, but teachers cannot support this view if they want to give their students every chance to succeed in their classroom. It is important to note that PIN encourages all students towards science success through hard work. Quinlan may have been answering the questions about her own performance, or the performance she observed from others in the class. The exact reasons for her answers are not known, however, the result shows that not every student interprets success in science in the same way. Teachers need to make sure they highlight the successes of every student throughout the teaching of any unit. Additionally, teachers need to make sure they are explicit about showing the success that can come from hard work and that scientists are not the only people that use science. In the future it may be helpful to make this clearer in the survey. In summary, while natural ability may be a head start for some students, it alone does not govern a student's ultimate success in science and teachers need to help them see that.

\section{EBAPS item analysis: Other categories}

In the survey there are a few other questions to point out where there were some varied opinions among the students' answers. 
One question where the students' responses did not match up to the EBAPS assessment's standards was Question 2. This question asked them to agree or disagree with the statement, "When it comes to understanding physics or chemistry, remembering facts is not very important." Every student in the class disagreed with this statement on the post-test, while the test key agrees with the statement. Realistically, students can retrieve any information very quickly from various resources, and because of that teachers deemphasize memorization in the classroom. While the students do not need to memorize formulas and constants in Patterns in Nature, they do need to remember the basic relationships and patterns and apply that to what they see in the data.

It is possible that the meaning of 'facts' is different for the students and the authors of the EBAPS. The students are thinking more about overarching themes and concepts when they mention the word because that is what they needed to remember for the PIN assessments, whereas the authors are thinking about formulas, constants, and other information that would be fed to students in a more traditional science class. This question should be rewritten when this survey is used again, to define the meaning of the word 'facts' for the students as either laws, concepts, and relationships or as equations and constants. Including another question may help to explain this confusion between the survey authors' thoughts and the students' thoughts. 
The question that saw the most change from pre to post-test was near the end of the survey (Q29). In the question, a conversation was described where two people debated about the absoluteness of scientific theories and the students were asked to agree that scientists regularly change their theories or to agree that scientific theories are very rarely altered. The ideal answer was a balance between the two. This question sheds some light on the reason that the authors think that facts do not need to be memorized, because they see science as a field that can change. Answers from the students varied greatly and they all changed from the pre to the post-survey. Only Aaron maintained his opinion from the beginning to the end of the unit, believing that "while theories regularly change, advocates of the opposite opinion makes some good points." This is not exactly in the middle, but still a balance of the two opinions. The other students seemed to jump back and forth from one opinion to the other, neutral to one opinion, or one opinion to neutral. This subject is not made very clear in the Patterns unit, as there is not a lot of discussion about current issues in science. That is something that should be improved for future iterations.

EBAPS results summary:

Generally, the students improved the most on the questions that had to do with the structure of scientific knowledge. They are moving away from the view of science as weakly connected pieces and towards science as big ideas and themes that permeate 
multiple aspects of society. One of the main purposes of the Patterns unit is to provide a general scientific framework for students to use in future investigations, supporting science as a process. Without the view of science as an interconnected method of study, the unit would be nothing other than a few unconnected experiments. Here the mathematical pattern is the structure around which students build their views of science. The interview questions show how the different types of students make the connection between science and the rest of their lives.

\section{Interview questions on Nature of Science and science process:}

Highlighting the answers of two different students whose opinions of science changed in opposite directions, according to the EBAPS survey, and comparing them shows the differences that occur in the way two types of students beliefs are affected by the Patterns unit. Emerald was the only person to decrease overall; she showed an overall slight decrease in the sophistication of her answers on the survey from before the treatment to after. She was at 2.92 before the Patterns unit and 2.82 after, a decrease

of 0.10. Spencer showed the largest overall increase in the survey score. He, on the other hand, showed an overall increase from 2.42 to 2.85 , an increase of 0.43 . The following table compares their answers to the Nature of Science questions in their individual interviews side by side. 


\begin{tabular}{|c|c|c|}
\hline Question & Spencer's answer & Emerald's answer \\
\hline What is Science? & $\begin{array}{l}\text { An explanation of facts! It is } \\
\text { explaining things that previously } \\
\text { we explained in less sensible } \\
\text { ways. For example, when god is } \\
\text { angry lightning strikes. That } \\
\text { makes less sense than friction } \\
\text { caused by air masses moving } \\
\text { against each other. I view it as } \\
\text { explaining things and fueling our } \\
\text { curiosities. It is our tool. }\end{array}$ & $\begin{array}{l}\text { I don't like those kinds of } \\
\text { questions...I guess it is trying to } \\
\text { answer questions about the } \\
\text { world using experiments and } \\
\text { observations. }\end{array}$ \\
\hline $\begin{array}{l}\text { If you were to repeat the } \\
\text { experiment, would you } \\
\text { expect to come up with } \\
\text { the same results? Please } \\
\text { explain why or why not. }\end{array}$ & $\begin{array}{l}\text { Generally every time. If I don't } \\
\text { then either my original } \\
\text { experiment was flawed or I did } \\
\text { something wrong. }\end{array}$ & $\begin{array}{l}\text { Not the exact same. I would } \\
\text { hope for the same results. I } \\
\text { would not expect the exact } \\
\text { same results, because you have } \\
\text { that uncertainty and because of } \\
\text { human error. That would be } \\
\text { really hard, unless maybe you } \\
\text { have computers doing it for } \\
\text { you. }\end{array}$ \\
\hline $\begin{array}{l}\text { How is the information } \\
\text { given in a graph similar to } \\
\text { or different than the } \\
\text { equation of best fit? }\end{array}$ & $\begin{array}{l}\text { Well the best fit line just goes } \\
\text { straight through it. It is not } \\
\text { accurate to all of the points } \\
\text { exactly, it is accurate to the line } \\
\text { that all of the points make. }\end{array}$ & $\begin{array}{l}\text { If you had a margin for error, } \\
\text { like error bars, it would be } \\
\text { more true to life because the } \\
\text { best fit is just that. The line } \\
\text { does not give you the sense for } \\
\text { minor jumps or bumps in your } \\
\text { data, idiosyncrasies. }\end{array}$ \\
\hline $\begin{array}{l}\text { Why is it better for } \\
\text { someone to use these } \\
\text { graphs to make a data- } \\
\text { informed decision than for } \\
\text { them to simply make a } \\
\text { wild guess? }\end{array}$ & $\begin{array}{l}\text { Graphs are a very nice visual } \\
\text { aide. A guess has a very high } \\
\text { margin for error. }\end{array}$ & $\begin{array}{l}\text { Because they are more exact. (- } \\
\text { Why?) Because they use data } \\
\text { from past experiments to graph } \\
\text { how it will happen further along } \\
\text { in the future. I am no good at } \\
\text { this... (- You are doing great) }\end{array}$ \\
\hline $\begin{array}{l}\text { You have developed the } \\
\text { skill of interpreting graphs } \\
\text { as a relationship between } \\
\text { two variables. Can you } \\
\text { see yourself using this skill } \\
\text { in future? If so, how? }\end{array}$ & $\begin{array}{l}\text { My dad and I like to do random } \\
\text { science experiments about } \\
\text { anything from transportation to } \\
\text { light speed travel. If we actually } \\
\text { get to do something along those } \\
\text { lines and graph it, that could be } \\
\text { helpful for us learning how crazy } \\
\text { or super cool it could be. (-What }\end{array}$ & $\begin{array}{l}\text { I have to use it in math, and you } \\
\text { have to use it in business. I } \\
\text { don't plan on becoming a } \\
\text { scientist. (- Do only science } \\
\text { people use graphs?) } \\
\text { No, business people use graphs } \\
\text { too. Scientists use them more; I } \\
\text { don't think you use them very }\end{array}$ \\
\hline
\end{tabular}




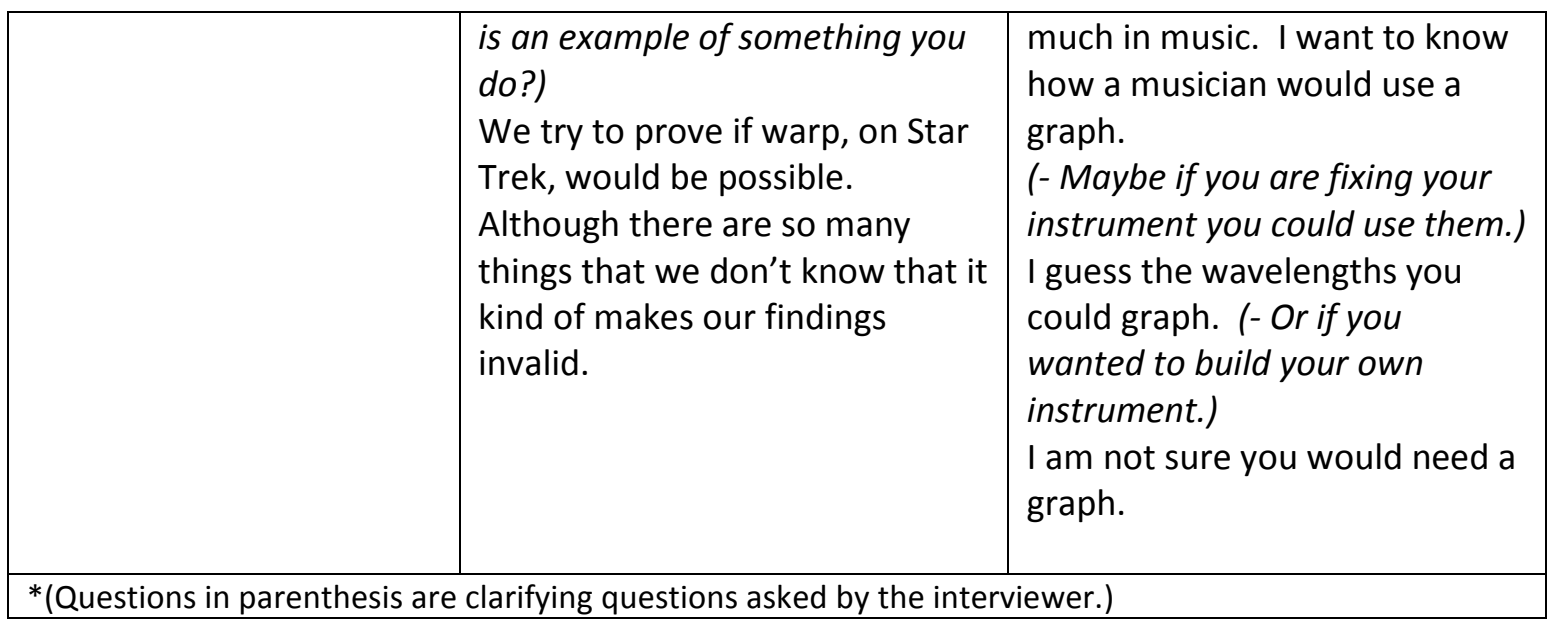

Table 10: Answers of two students to the Nature of Science questions in the interview.

A little background on each student will help understand the results. Referring back to the participants section, Spencer had low math skills and a high interest level in science, whereas Emerald had strong math skills and a low opinion of science.

The first question asks them to define science in their own words, and immediately the differences in their attitudes towards science appear. Spencer is excited to answer the question, while Emerald remarks that she hates those types of questions. Despite that difference, they both answer the question in the same basic way, defining science as a tool or method that we use to try to understand things about the world. They continue to answer the questions similarly each time, Emerald with a little more sophistication in her responses than Spencer; however, Emerald has a lack of confidence in her answers. The last question asks the students how they see themselves using the content that they learned throughout the PIN unit in the future. Spencer quickly made the comparison to 
something that he does often in his free time. Emerald had difficulty seeing this material used by anyone other than scientists, and she could not see herself using it in the future.

Quinlan, another student with a strong mathematics background, has similar results to Emerald on the interview questions. She also was unsure of her answers and took a long time to respond to questions. In the last question, about using PIN skills in the future, Quinlan showed an interest in a non-scientific career (business) and had trouble seeing how Patterns could play a role.

Despite specific applications to everyday life mentioned throughout the unit, such as miles per gallon graphs and words per page, a few academically strong students could not see how to use mathematical modeling in the future. Their interests in science remained low and they were not confident in their abilities. This is something that needs to be addressed in the next iteration of the unit.

This discrepancy found between students like Quinlan, Emerald and Spencer is a great example of why a mixed methods approach to educational research is necessary, and a great example of why educational research is necessary at all. Typically the only data that a teacher records is quantitative data from summative assessments. If they did that with these two students, the only thing that they would see is that Emerald 
performed 'well' before and after the unit while Spencer performed 'not so well' before and after the unit. The rich information that can be gathered from a survey or an interview can help to paint the detailed picture of what is happening in the students' minds. By analyzing that picture teachers can see what the students think about what they are learning. In a typical design-based research project, there needs to be multiple forms of data gathered and with the use of the EBAPS survey and the interview questions, statements about students' knowledge, understandings and views can be made.

\section{Summary of Results:}

The Patterns in Nature unit sought to teach the skills of mathematical modeling to high school physics students by enforcing the idea of science as a process. This study is an effort to see how successful the unit was at accomplishing this goal. Additionally, another goal was to see how the unit affected the students' beliefs about the Nature of Science. Multiple techniques were used to evaluate changes in students' beliefs. These included: a pre and post unit test, a survey administered before and after the unit, and an exit interview.

Patterns content knowledge: 
In terms of the summative unit test, students' performance on the pre-test and posttest were difficult to compare. Student test data from Mr. Hill's large public school class showed improvement from before to after the unit. In the small class at the charter school the students did not show their prior knowledge on the pre-test, and an adapted assessment was given to them. This adapted assessment was designed to show the students' experimental process, data analysis, and mathematical modeling prior knowledge. As a consequence, it could not be directly compared to the test at the end of the unit. That modified pre-assessment showed that students had little knowledge of applying patterns to data. Then, in the post assessment these students were able to quickly and accurately identify mathematical patterns in data and on graphs. Most were even able to remember the equations that go along with those patterns. However, of the students in the studied class, most had difficulties correctly creating and describing mathematical patterns that had a pattern other than linear. This is in agreement with studies, (Doerr, 1995; Sherin, 2001) which found that students had the most problems studying and understanding curved lines. A strong mathematical background helped in creating and identifying patterns, but not in describing them with words.

The interview supported those findings from the post-test as describing the relationship between the variables in plain words was difficult for the students. The conclusions where students were require to do this had strong scaffolding at the beginning of the unit, and by the end of the unit students are only beginning to write their own 
descriptions of their results. The unit provided only a few opportunities to practice doing this, and needs to provide more in order for the students to become literate with the patterns they studied.

Nature of Science and science process knowledge:

The Epistemological Beliefs for Physical Science (EBAPS) survey was administered before and after the Patterns in Nature unit. Results showed that the unit helped the students improve in their awareness about the structure of scientific knowledge, the nature of learning, the real life applicability of science, and the evolving aspect of science. The largest of those increases occurred in the structure of scientific knowledge, the essence of the Patterns in Nature unit. This is a positive result, as other studies (Wieman 2005) show the structure of students' knowledge to be an important part of their understanding of the content. The survey however, showed a decrease in the students' ideas of the nature of their ability to learn. This decline from pre to post unit was traced to two students who, in some questions on the survey, changed from believing that hard work was most important in learning to believing that natural ability plays a bigger role in science learning. After analysis it was found that they could see success in science class as different from success in science in the real world. This result is in contrast to Wieman (2005) who concluded that student beliefs about a subject are dependent upon 
their understanding of the material. Although these two students received good grades and understood most of the material, this did not help them see themselves as successful scientists. It is difficult to tie this result to any particular part of the unit, but it likely shows a lack of confidence in the student's ability to learn science on his or her own. It is a goal for the PIN unit to show all students how they can succeed in science and this result needs to be corrected in future classes. The result could be related to how difficult they found the class, the lack of independent work that was required of them, or their views of real world science.

Interview questions concerning the Nature of Science and science as a process were also asked at the end of the unit. Students responded in similar ways as they gave their own definitions of science and described the key aspects of the scientific process, showing that they possessed adequate knowledge in the area. There was some variance in students' answers to questions about how they would use the skills which they had learned in the PIN unit later in their life. Some struggled to see the connections to real life. Many associated the ability to mathematically model data and make predictions with scientific careers. Half of the students also mentioned computer science, mathematics, and business careers. A small number of students incorporated the use of this skill into their daily life activities. Work needs to be done to make the mathematics and science learning more relevant to the daily lives of the students and to convince them that science can happen in any career (Lederman, 2002). 


\section{Implications of results and recommendations for changes to Patterns in Nature:}

Every teacher teaches differently, even when they are using the exact same curriculum materials. Results show that students learn approximately the same percentage of the unit content in two very different class structures with two very different class sizes. Patterns in Nature has now had success across multiple learning contexts. Consistency in the different classroom environments may be attributed to time spent observing the unit being taught in its original setting. To maintain that sort of consistency between different teachers and teaching styles, a teacher training session is recommended. Before a large scale implementation of the PIN unit in Beaverton School District, a professional development session is being held for all who will be teaching it. They will get the opportunity to perform some of the experiments and ask questions directly to the person that developed the unit. However, based on the data gathered, there are some improvements in the way that PIN is taught and assessed that can be made it more effective.

Research-based physics teaching methods:

It is difficult to know how many different successful teaching methods have been realized in classrooms around the world because not every teacher has the time or 
ability to carefully track their students' progress and relate it to teaching strategies. Even if they are able to do that, many do not have the support to write up and share those strategies with the educational research community. The study byHenderson and Dancy (2009) showed that only $60 \%$ of surveyed teachers were even aware of a selection of researched and published teaching strategies, and of those teachers even fewer had implemented more than one or two of the listed instructional strategies. Problems mentioned were that many of the strategies did not include methods of implementation. Redish and Steinberg (1999) emphasize that teaching strategies need to be evaluated, a feat that can only be accomplished through implementation. This is why Patterns in Nature needs to be tried in different classrooms, modified, and shared with the community so that others . can contribute improvements. The hope is that PIN can reach the status of the Arizona State University Modeling curriculum (Halhoon, 2004). A curriculum advocated by a large university, with years of research and modifications, and published books sharing the strategy with the teaching community.

\section{Graphing and mathematical modeling:}

While assessment is important to deciding what students learned and is addressed by this study, the implications of the assessment findings are the most important (Lienhardt, 1990). Through the varied forms of assessment, this study was able to evaluate what aspects of graphing and mathematical modeling the students did not 
understand. This studied unit combined strategies from both math and science education by emphasizing real world applications and using mathematics to discover underlying patterns in data (Leinhardt, 1990). The tasks that the students were expected to complete throughout the progression of this unified strategy method varied from prediction, to classification, to analysis.

In the content of the unit, students could correctly identify patterns and state the mathematical relationship that exists between the variables, but they showed weakness in verbal and written explanations of these relationships of observed phenomena. They experienced difficulties when writing their conclusions with and without scaffolding, and also when describing what the mathematical equation between the two variables means. Other studies have recognized similar difficulties, but did not highlight specifically in what aspect of modeling they occurred (Doerr, 1995; Sherin, 2001). Here, regardless of the different backgrounds of students that were encountered in the classroom, this study found that the majority of students had difficulty with communicating descriptions and concludes that they all need more practice using words to describe exactly what their line of best fit on the graph means. This was contrary to the results of Sins (2005) who found that prior knowledge made the difference between successful and unsuccessful modelers in their classroom. The next step will be to investigate different ways to help students improve their abilities in this area which will provide them with better prior knowledge for their future classes. 
In order for this alteration to the PIN unit to be most effective, the students need to be explicitly told that mathematical modeling is one of the unit's objectives. Then as the curriculum provides more opportunities to examine different relationships and describe them, students will be aware of the teacher's intentions. This study recommends an interactive demonstration, similar to those tested by Redish and Steinburg (1999), showing each type of relationship that the students are introduced to in a new way. Based on statements from students stating that they enjoyed the various demonstrations during the course of the class, this would be one of the most engaging and effective features to add. At the conclusion of class, after finishing one of the pattern experiments, a short demonstration of new phenomena could be done and the students could be required to predict what will happen and describe how the relationship matches or differs from the pattern that they just studied.

There is nothing that needs to be omitted from the PIN unit and given the time constraint; there is not enough time in the course of the unit to add another experiment. Time permitting, the unit could certainly be made longer to include more patterns an experiments. Ideally, teachers would continue to use a research-based method as they moved through various physics topics and learned new mathematical patterns such as exponential and periodic. 
Data-driven decision making:

Students throughout the unit gather information from experiments and use it to predict results. In a typical modeling curriculum the students gather data and then use it to create a virtual mathematical representation of the experiment that they completed (Halhoon, 2004; Sins 2005). Patterns in Nature, however, asks the students to use that model to predict future measurements outside the measured range, testing their findings. That method may have helped to propel the students' improvement in the survey areas of 'Structure of knowledge', 'Nature of knowing and learning', and 'Reallife applicability'. An important part of the Nature of Science involves knowing how to use and evaluate the quality of data. Through the teaching of the PIN unit and the utilization of this data-driven decision making method, students have improved in many areas of their Nature of Science knowledge.

The Nature of Science:

Although the information in this subject has become a moving target over the years, the research defines the Nature of Science as the beliefs and views surrounding the body of knowledge, and a method or way of knowing the characteristics surrounding science (Lederman, 2006). Based on the findings on the surveys and in the interviews, the Patterns in Nature unit proved to be very effective at teaching science as a process. 
Students responded well to the repeatedly mentioned central theme that science is finding patterns in nature and using them to predict the future. They improved in that area of the survey and answered those interview questions well. Where a few of them had trouble was relating this process to their daily lives, as shown by some students believing that success in science requires natural ability. Those same students struggled to see how they could use scientific skills in their future as well. Most students had no trouble recognizing that this is what scientists do and that it produces much of the technology that is use every day, but some did not see where they could use this process on their own.

Understanding the scientific processes and where they occur within a civilization makes a student a better informed member of society (Lederman 2006). Requiring students to search for other instances of each pattern they learn somewhere outside the classroom might help. There was a lot of enthusiasm for the modified pre-test task that was assigned, where the students had to investigate a relationship between two variables on their own. Because of this positive response, the study recommends expanding the initial assessment by asking the students to revisit their initial experiment and use what they have learned to develop an explanation, as well as using that same type of task as a post-test for the unit. For additional out of class work that could aid student understanding of these mathematical relationships, homework assignments should be made by providing the pattern and having the students search for it outside the 
classroom. It may help them see where this method of investigation can fit into their daily lives.

There are various lessons and activities that could be brainstormed and added, but the reality is that a unit needs to be taught following a certain timeline. Teachers need to be intentional and strategically think about modifying parts that do not work before adding new content and assignments that need to be placed in the Patterns in Nature unit. Based on the collected data, the aspects of PIN discussed above are the areas that need the most improvement. As they are added in, they need to be carefully observed using a design-based research method and tested to see exactly how effective they are.

Design-based research:

In design-based research, a classroom environment is created that involves selfreflection from both the teacher and student (Brown, 1992). A repeating cycle of creations, evaluations, and modifications is what defines this type of research. Designbased research is typically paired with instructional strategies or tools that are made to be used over the course of a few days, so effective methods of evaluation are essential to diagnosing strengths and weaknesses. These evaluation instruments must gather both quantitative and qualitative data, from which the researcher or teacher could justify design changes to the treatment mid-study. 
Significant lessons were learned while attempting to effectively evaluate this unit about the limitations of the instruments that were used. The unit post-test did not effectively measure prior knowledge when used as a pre-test. Either the test needs to be modified to make the questions more appropriate for a student who had not just experienced the PIN unit, or replaced with a different type of assessment. The modified pre-test that was used to assess the students' experimental method could easily be used as a type of authentic assessment post-test at the end of the unit as well. If the teacher has the time and a small enough class to use this type of test at the beginning and end of the unit, this study recommends doing so.

The EBAPS survey used did a fair job of assessing the students' views about physical science, and many of their answers were reliable, as confirmed by interview questions. There are a few items that could be modified and made clearer. The questions about the role of natural ability and hard work in science success should be rewritten to define success in science or to use a term like 'aptitude' instead of 'ability'. When the survey asks about the necessity of memorization of facts in science, the term 'facts' needs to be properly defined to make this a more effective question. Another item to be modified is the questions about science as a changing field; wording should be made more specific to say to what changes the survey refers. 
With improved evaluation, necessary changes to PIN can be more easily identified. As the unit and the assessments become more effective, more can be said about how and why this method of teaching is worthwhile for students. These changes should be made and then tested in new classrooms. This study is just a small step in the creation, modification and publication of the Patterns in Nature unit. Here the research focus was on the effectiveness of the curriculum at teaching mathematical modeling, but in future studies the focus could shift.

\section{Limitations and future studies}

Aside from the grades that parents see on their child's report card, this research study was the first major attempt at documenting the students' learning through PIN. During a pilot study in Mr. Hill's classroom a survey and interview questions were tested, but no formal data was gathered. Improvements were made to those assessments before they were used in this study. The methods for assessing the effectiveness of this unit could still use some improvement before they are used on a large scale. Those recommendations are outlined in the conclusion. In the next iteration of PIN, the unit will be implemented through the entirety of the Beaverton School District ninth grade science classes. Effective assessments for content and Nature of Science will be very valuable in identifying the validity of the modifications mentioned by this study, and to identify necessary future modifications to be made to the unit materials. Additionally, this much larger sample size will provide more reliable data concerning student learning. 
This study recommends that those classes in Beaverton gather similar qualitative and quantitative data to what was collected in this study. The same assessments could be used if the outlined changes are made.

More research needs to be done on how this introductory unit might affect student's performance in the long term as they begin to learn specific physics topics. Studies here were restricted to the introductory Patterns in Nature unit; however, the purpose of teaching the unit is to make it easier for students in a physics class to understand those future topics. While the material that teachers use after the studied unit will likely differ, the goal is that they will use the experimental methods from Patterns in Nature to guide how they teach other physics topics like mechanics, waves and electricity. Ideally there would be a full course written that teachers could implement where even more mathematical patterns are introduced to the students. Including flexibility for different types of teachers and learners is encouraged, as long as it has been trialed and tested.

As long as data is continually collected from participating teachers, more improvements can be made the unit. Patterns in Nature effectively teaches most students how to model experimental data and use it to predict the results of future experiments. PIN also has a positive effect on students' views of the nature of science and science process. After the changes to the unit have been made, future studies with different 
schools, students and teachers will provide more data, guiding future improvements to Patterns in Nature and improving the quality of $9^{\text {th }}$ grade Physics education. 


\section{References:}

Angell, C. (2008). U. Phys. Educ., 43, 256. Retrieved 1/12/2011, from http://iopscience.iop.org/0031-9120/43/3/001/

Bonham, S. (2007). Graphical Response Exercises. The Physics Teacher, 45, 482-486.

Brown, A. (1992) Design Experiments: Theoretical and Methodological Challenges in Creating Complex Interventions in Classroom Settings. Journal of the Learning Sciences, 2(2), 141-178.

Chen, S. (2006). Views on science and education (VOSE) questionnaire. Asia-Pacific Forum on Science Learning and Teaching, 7(2), 11.

Chi, M.T.H. \& VanLehn, K. A. (1991). The Content of Physics Self Explanations. The Journal of Learning Sciences. 1(1), 69-105.

Clement, J. et al. (1985) Adolescents's Graphing Skills: A Descriptive Analysis. Technical Education Research Centers, 85(1).

Doerr, H. (1995). An Integrated Approach to Mathematical Modeling. American Educational Research Association: Annual meeting, San Francisco, CA (pp. 143150). Retrieved from http://www.eric.ed.gov/

Elby, A., Frederiksen, J., Schwarz, C., \& White, B. (1999). Epistemological Beliefs Assessment for Physical Science. Retrieved May 9, 2004, from http://www2.physics.umd.edu/ elby/EBAPS/home.htm.

Halhoon, I.A.(2004) Modelling Theory in Science Education. Klewer Academic Publishers.

Hill, B. (personal communication, April 18, 2012)

Henderson, C. \& Dancy, M. H. (2009) Impact of Physic Education Research on the Teaching of Introductory Quantitative Physics in the United States. Physical Review Special Topics, 5, 020107. 
Izsak, A. (2000). Inscribing the Winch: Mechanisms by which Students Develop Knowledge Structures for Representing the Physical World. Journal of the Learning Sciences, 9(1), 31-74.

Jackson, D. F., Edwards, B. J. \& Berger, C. F. (1993), Teaching the design and interpretation of graphs through computer-aided graphical data analysis. Journal of Research in Science Teaching, 30, 483-501.

Ketelhut D., Clarke J., \& Nelson, B. (2010) "Chapter 4: The development of River City". Designs for Learning Environments of the Future. Washington, D.C. Springer Science. 89-111.

Lederman, N. G., et al. (2002). Views of Nature of Science Questionnaire: Toward valid and meaningful assessment of learner's conceptions of nature of science. Journal of Research in Science Teaching, 39(6), 497-521.

Lederman, N.G. (2006). Nature of Science: Past, Present, and Future. Curriculum and Assessment in Science, 827-876.

Leinhardt, G. et al. (1990). Functions, Graphs, and Graphing: Tasks Learning and Teaching. Review of Educational Research, 60(1), 1-64.

McDermott, L. C. et al. (1986). Student Difficulties in Connecting Graphs and Physics. American Journal of Physics, 55(6), 503-513.

McClain, K. and Cobb, P. (2001). Supporting Student's Ability to Reason About data. Educational Studies in Mathematics, 45, 103-129.

National Research Council. A Framework for K-12 Science Education: Practices, Crosscutting Concepts, and Core Ideas. Washington, DC: The National Academies Press, 2012.

National Council of Teachers of Mathematics Standards. (2012) Retrieved from http://www.nctm.org/standards/content.aspx?id=16909

Redish, E. F. \& Steinberg, R. N. (1999). Teaching Physics: Figuring Out What Works. American Institute of Physics, 52, 24-30.

Redish, E. F., Saul, J. M., \& Steinberg, R. N. (1998). Student Expectations in Introductory Physics. American Journal of Physics, 66(3), 212-224 
Sherin, B. L. (2001). How Students Understand Physics Equations. Cognition and Instruction, 19(4), 479-541.

Sins, P. (2005) The Difficult Process of Scientific Modeling. International Journal of Science Education. 27(14), 1695-1721.

Wieman, C. and Perkins, K. (2005). Transforming Physics Education. Physics Today, 58(11), 36-37.

Windschitl, M. (2008) Beyond the Scientific Method: Model Based Inquiry as a new Paradigm. Wiley InterScience. Retrieved from www.wiley.interscience.com

Working Group on Teaching Evolution, National Academy of Sciences. "Chapter 6: Activities for Teaching about Evolution and the Nature of Science Inquiry Cube." Teaching About Evolution and the Nature of Science. Washington, DC: The National Academies Press, 1998. 
Appendix A: Patterns unit description by Bradford Hill 


\section{Using Patterns as the Right Step-size to Get Student to See Science as a Process and use Data/Graphs to make Decisions \\ By Bradford Hill}

I have developed two exciting projects for my freshman physics course. The first involves getting students to understand "science as a process" and to help them explicitly see science not as reading a book and memorizing formulas but rather as "finding patterns in nature and using them to accurately predict the future"1. The second is an engineering project wherein students use inquiry to create to graphs and then use those graphs to make engineering decisions on how to best build a bridge.

I start the class with an Essential Question: "How do we find and use patterns in nature to predict the future?' Day 1 is the Inquiry Cube (from the National Academy Press) that emphases looking for patterns to make predictions and how confidence grows as we find more evidence or patterns that lead to the same conclusion. Then, I discuss how we all know one pattern in nature very well: objects on earth, when unsupported, fall. We have named this pattern gravity. And we can predict that tomorrow if you were to hold up a marker then let it go, that marker would fall to the floor. I then quickly scale up to discussing how scientists and engineers have discovered many patterns and have gone as far as creating a device, from materials found in the earth's crust, that if tomorrow you touch in a certain way and then talk towards it a loved one can hear your voice miles away! We, of course, call this amazing combination of stuff from the ground a cell phone. I like this because it puts it out there that we are taking steps towards understanding things they use and have questions about in their own lives.

I must interject a story here to properly explain an important reason I structure the activities as I do. A student of mine once was off by only $0.05 \%$ on $\mathrm{g}$, as I took in a breath in order to tell them good job they said "science experiments never work" this experience has stayed with me as I realized students often don't have the background knowledge to decide if there results are supporting the idea that science works or that it works for scientist, but not for them, or worse yet, it doesn't seem to work at all. So following my motto of Be Explicit, Model, Guide, Step Aside, I specifically have students start every experiment with a wild guess. Then we take data, use mathematics to find a pattern, then create a scientific, data-informed prediction about the future and finish with an explicit discussion about how this science process really produces superior results.

\footnotetext{
${ }^{1}$ It is worth adding "science is finding patterns in nature and using them to accurately predict the future or understand the past', but I found adding understand the past deemphasize the important point that we must test our claim against new data and it was difficult to adequately explain how things in the past could be considered new data.
} 
So now on to the actual four experiments. The first experiment centers on stretching a spring and has the focus question "how does the amount a spring stretches depend on the mass hung from it?" Students' start with making a wild guess about how much a $0.5 \mathrm{~kg}$ mass will stretch a spring. Then we put a $100 \mathrm{~g}$ mass on the spring and roughly gauge how much it stretched. Having the 1 rough data point we sketch out a graph of stretch vs mass hung and hypothesize where the data point would be if we doubled the mass, then tripled the mass, and do a thought experiment about where would the data point be for zero mass be. Student draw a simple trend line to fit their points and write out in words the hypothesized relationship that has emerged from their sketched graph (with the aim of reinforcing the message that graphs can aid our thinking). Then we find the independent, dependent, and controlled variables and draw our experimental set-up (at this point I am Being Explicit and giving them all this information to let them know what I will expect in their future Experiment Reports). We then create our data tables and start taking data. They get lots practice making graphs in hand-in homework assignments, but for these four experiments they directly enter their data in Logger Pro with error bars. I wasn't sure how freshman would do with error bars but for all the complexity one might think it adds, it is quite natural and has huge benefits. With their data with error bars, we then proceed to find the simplest best-fit line that goes through all their error bars. They determine it is Linear. We then write-up their conclusion:

Since the best-fit line of our data is linear, we conclude that there is a linear relationship between how much the spring stretches and the mass hung from the spring. This can be represented mathematically:

Stretch of Spring $=0.053^{x}$ Mass Hung.

So I predict that for a $500 \mathrm{~g}$ mass my spring will stretch

And we review their wild guesses and test their scientific, data-informed prediction, which nearly everyone accurately predicts to within $3 \mathrm{~mm}$ ! This makes it very tangible to some of the students that science works. But it takes until the next experiment to really make it believable.

Next up is the pendulum experiment. Again we start with a wild guess for a 4 meter pendulum. We go through the hypothesized graph exercise - many trace out a linear graph - and then write our hypothesis in words. We then determine the variables, set-up the experiment and data table, collect data, and enter it in Logger Pro. They are surprise that a line is close but clearly does not go through all their error bars, so they go to the next simplest best-fit line a quadratic function $^{2}\left(y=a x^{2}+b x+c\right)$. I simply tell them this is an intro class and we will only

\footnotetext{
${ }^{2}$ We follow the rule of thumb to plot the independent variable on $\mathrm{x}$-axis, unless you have a good reason not too. For instance we often plot time on the $\mathrm{x}$-axis even when it is the dependent variable.
} 
study quadratic functions where $\mathrm{b}$ and $\mathrm{c}$ are 0 , and they will have to take IB Physics if they what to take on that complexity - not perfect, and at times I do say what a physics interpretation of $b$ and $c$ can be which is the best solution I have at the moment. We then sketch the graph and write down the best-fit line in the generic form $y=a x^{2}$ from math class and as it applies to our graph

Length of Pendulum $=0.27^{\star}$ (Period of Pendulum $)^{2}$

This helps a lot of students who haven't really gotten that a graph of data tells you about the world or for that matter that formulas are a short hand way of expressing relationships found in data. I can't overstate how many students miss this connection between math and science, even for student who can solve difficult multi-step problems. We then write-up our conclusion and use both the graph to extrapolate the time of a 4 meter pendulum and our formula from the best-fit line, as shown above. We get it to within 0.2 seconds and most to within 0.1 seconds. Now, nearly every student is starting to see the power in the ability of science to predict the future. They thought it was hopeless during the wild guess at the beginning and showed open dismay when I said part of their grade would depend on them accurately predicting to within 0.2 seconds the time of pendulum after taking data. Many just didn't think they could get there in 45 minutes of class time, but they do - for example, all 39 students in my $5^{\text {th }}$ period did, working in groups of three or four. (I run this in three classes of 37,37 , and 39; nearly all freshman and a few others who are retaking the course after failing it previously.)

The third experiment follows the same structure, but now students must create the data table and take data individually. To make it feasible with the class sizes I have, I use a simple focus question "how does the width of a paragraph effect the height of the paragraph". Again the wild guess, data, find a pattern, use it to create a scientific, data-informed prediction and test it. The pattern is inverse ${ }^{3}$. height $=71 \mathrm{~cm}^{2} /$ width

It works again (when you have the paragraphs chosen right, so you don't have half hanging sentences - but this simplification is something we always do when teaching beginners - we'll build in complexity as they progress further into science). And again they get the height to within millimeters. Now they start asking what else can they predict if they take measurements, it is only a few students asking this but I must say that is one of proudest moments in my teaching career to have it come so naturally from our classwork and it is only the $2^{\text {nd }}$ week into the term!

We finish off with holding a square postcard in front of a light source and find that if you double the distance the size of the shadow goes down by a factor of 4 . In this Shadow Experiment students must now create their own data table and write

as in a d vs $t$ graph, here too I have them plot length vs period so that the best-fit line is a quadratic function rather than a square root function.

${ }^{3} 71$ is area of paragraph which is constant for a given font and text. 
happen 4 times (in very explicit and obviously understandable ways - the pendulum swings back and hits your hand when the stopwatch reads your predicted time) and lays the groundwork for it to happen for every experiment in the class, not to mention, using graphs from other scientists and making predictions based on them.

Further, this pattern approach blooms once you move into motion, forces, and energy. It makes many questions have natural, understandable answers. For instance when taking data on constant acceleration a student asked how much data to take. Looking on Logger Pro their data was bunched up and had relatively large error bars, so both a line and parabola would fit the data. I pointed this out and ask if you were going to take another data point where would it be impactful? The easily recognized to have it far from the others, as then if was high on the graph it would indicate a quadratic relationship but if it was low than only the line would fit. Then I put it back to the student was there data adequate, did they need to take more data, and if so how much more should they take? This was a simple, straightforward discussion that truly is sophisticated science but was natural and understandable to the $9^{\text {th }}$ grade student. This discussion also easily led into discussions like these: How do we know things through science? How far can you extrapolate? Once you find a pattern does that mean the world is actually that way? Could further evidence refine the pattern to be more complex? A teacher can take this as far as they want.

My second project that flows well with this, but could be done separately, is a more authentic engineering project. We created a Project-Based Learning unit wherein students are cast as engineers who are submitting a proto-type bridge to win a bid to rebuild an old historic bridge. With cost and historical landmark laws as constraints we analyze the forces involved in the simple bridge and realize there is tension and compression and for our given simple bridge design we are able to calculate the max load each member will experience (and use a $2 x$ safety factor). Next we analyzed our building materials (a manila folder) for their tension and compression properties. The students perform experiments on how the width of paper is able to withstand tension and generate a graph (linear pattern). Then engineer the paper to better withstand compression by folding into circular, triangular and rectangle columns and test them. Due to ease of construction, rectangular wins out, and we experimentally determine the size to max compression graph. As engineers do, we use their force analysis along with these graphs to make data/graph based decisions on how to construct the cheapest bridge that meets all of the engineering constraints - and it works. The bridges are only tested to the safety margin, there are no bonus points for over building the bridge. They then go on to an interview in which they must orally explain why they used the widths of tension strips and diameter of columns that they chose, and why the customer should believe they have a handle on how to build bridges. 
the conclusion by themselves. Again the wild guess, data, find a pattern, use it to create a scientific, data-informed prediction and test it. The pattern is inverse square.

$$
\text { Shadow Size }=71 / \text { (distance from light source })^{2}
$$

So we now have Linear, Quadratic, Inverse and Inverse Square and this is powerful. Before continuing, let me review where we are at: we are three weeks into the course and students have done the inquiry cube, been given a focus question, can identify independent, dependent, and controlled variables, practiced taking data over six times and gauged uncertainty from measurement tools and through averaging multiple trials, identified errors in labeling data tables, processed raw data by averaging and drew by hand the graphs with error bars, learned how in Logger Pro to input data, add constant and variable error bars, found the simplest best-fit lines, completed four experiments, and written four full lab reports with guidance (Be Explicit, Model, Guide, Step Aside - Step Aside is coming soon), and read Chapter 1 of Hewitt's Conceptual Physics.

Now that they have some experience with the four Patterns: Linear, Quadratic, Inverse and Inverse Square ${ }^{4}$, we create posters and write it in a toolbox ${ }^{5}$ flap each pattern expressed Mathematically, Graphically, Visually, and in Writing (see picture below). Further, we than compare and contrast the patterns and work on connecting the mathematics with the science.

What is the payoff? As I already mentioned, students get explicit exposure to how science really works. They literally experience that if you take careful data and find a pattern, you may be able to accurately predict the future! Also, they see that the formulas in science come from past data - this may seem obvious but I do not think it is to most students. It also makes clear the connection between quality data and quality predictions/results - if you want a better prediction/results you need to get better data. It places the emphases of experiments on patterns not the minutia of conformation ${ }^{6}$ of a proiri known values that without extremely careful experimental set-up will usually lead to students getting the wrong meta-message - science doesn't work for them, it doesn't work period, or you just redo measurements until they come out the way you know they should, all of which are not very authentic science experiences.

Additionally, it is near universally recognized that one benefit of a science education is it trains you to use evidence/graph based decisions - yet, how often is that actually happening in science classrooms? This Patterns Unit has it

\footnotetext{
4 We also have "Flat Line", which comes out of amplitude vs period in the pendulum experiment that indicates they two variable are independent or have a constant relationship.

${ }^{5}$ Tool box is simply 3 sheet of paper folded over to create a staggered panel of 6 flaps and each major unit in the class gets a flap - this is so, so that students have in a concise single location all the big ideas of the class.

${ }^{6}$ Conformation experiments do have their place in science education but I think should not be the bulk of a student experimental experience.
} 
I want to finish with a list of what I think students get from this Patterns approach:

- Students explicitly experience that science works.

- Students explicitly experience how mathematics aids reasoning and scientific predictions.

- Students get multiple opportunities to make and test data/graph based decisions.

- Students experience inquiry.

- Students progress towards learning the tools of science to perform inquiry on their own questions.

- Students engage in understandable ways with broader questions about knowledge through induction (experiments) and certainty of knowledge.

- Students explicitly experience that engineering works!

- Students explicitly experience that engineering often involves breaking a large problem into smaller components, analyzing those smaller pieces, and then integrating it all back together to create a solution.

- Students again get multiple opportunities to make and test data/graph based decisions in an engineering context and see that engineers use graphs to make decisions.

- Students experience making a proto-type as a step in the engineering process. 
Appendix B: Inquiry unit slides

Page | 119 


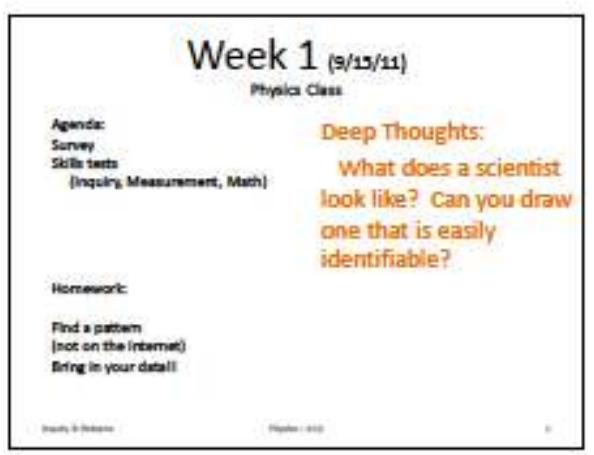

Science is...

- What qualities do scientists have?

- How do scientists do their work? How would they describe a scientific invertigation?

trat. $-\infty$ $+$

\section{Inquiry Cube}

- Form research groups for the second invertigation.

Do not touch, turn, lift, or move the cube in any way.
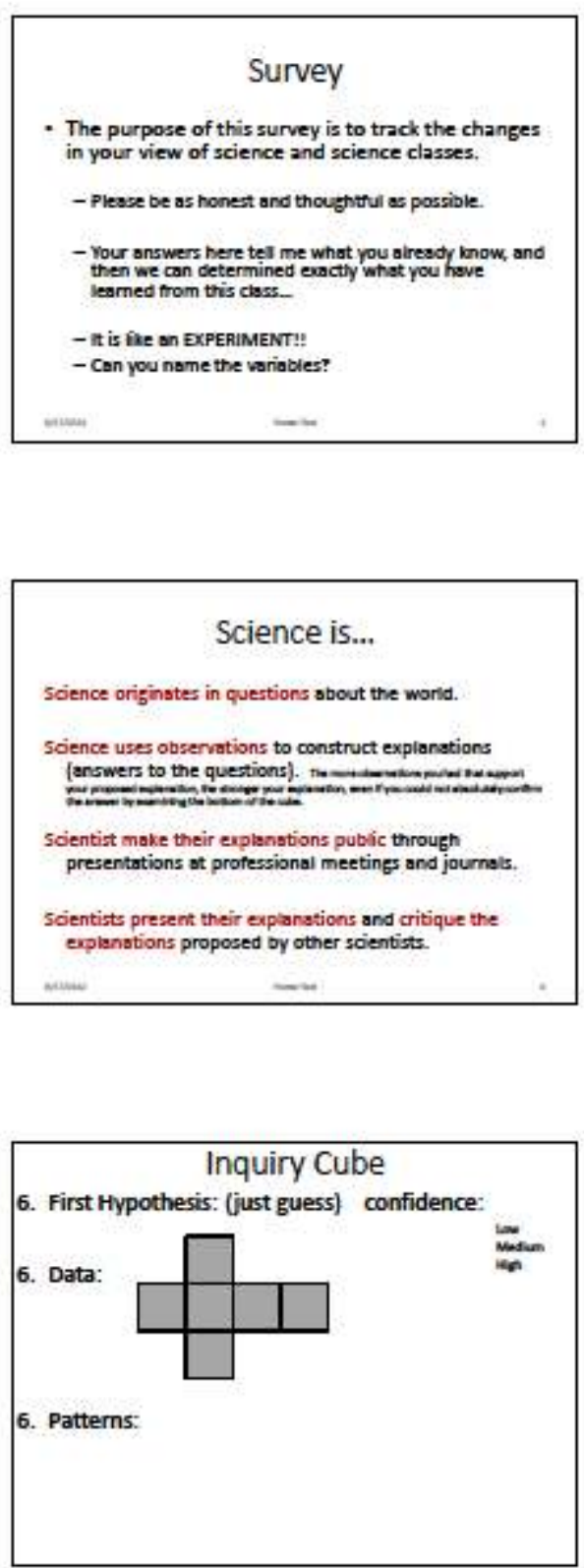


\section{Inquiry Cube}

- Research groups publicly share your explanations

9. What is the benefit to hearing other research

groups' ideas?

- What is another test we could perform to

determine with even more confidence (less error)

what is on the bottom?

\section{Inquiry Cube}

Scientist use patterns in data to make predictions and then design an experiment to assess the accuracy of their prediction. This process can also produce additional data.

10. Use your observations (data) to make a prediction of the number in the upper-right corner of the bottom.

\section{Inquiry Cube}

- with your limited funding you are able to purchase a small amount of technology and other equipment in order to test your prediction.

\section{Inquiry Cube}

- 11. Final Hypothesis

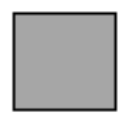

confidence:

low

\section{Inquiry Cube}

- *12. Describe how your confidence changed from first hypothesis and final hypothesis and why?

- 13. How is this activity like real science?

- '14. What about science doesn't this activity capture? 


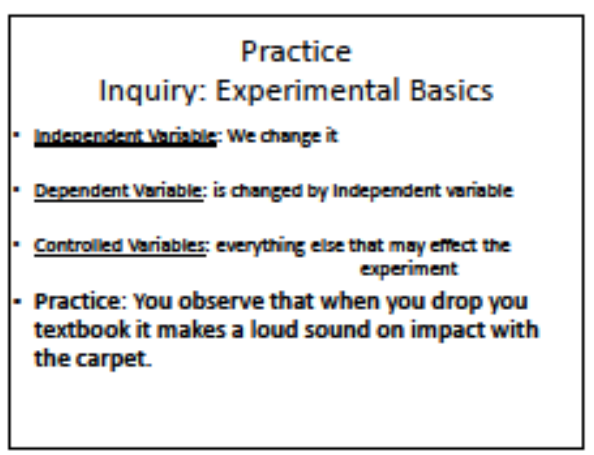

Example
- "How does the breaking strength a column of
- Whent depend on its diameter?"
- What is the independent variable.
- What are the controlled variables? (i.e. what must
you keep constant?)

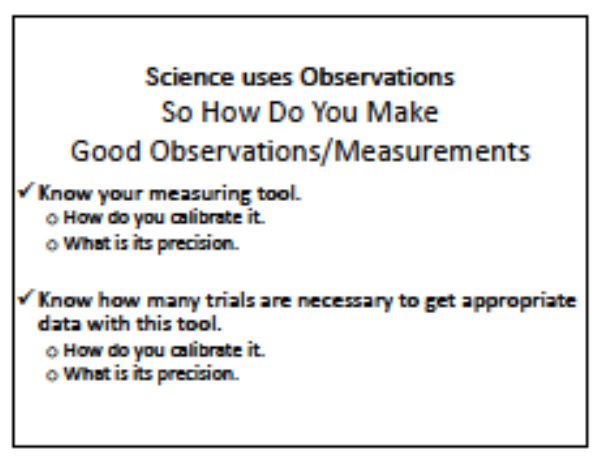

\section{Example}

- You notice a book dropped from different heights creates a sound of different intensity. So you ask "How does the height of the book is dropped from affect the intensity of sound when it hits the ground?".

- The independent variable:

- The dependent variable:

- What are the controlled variables:
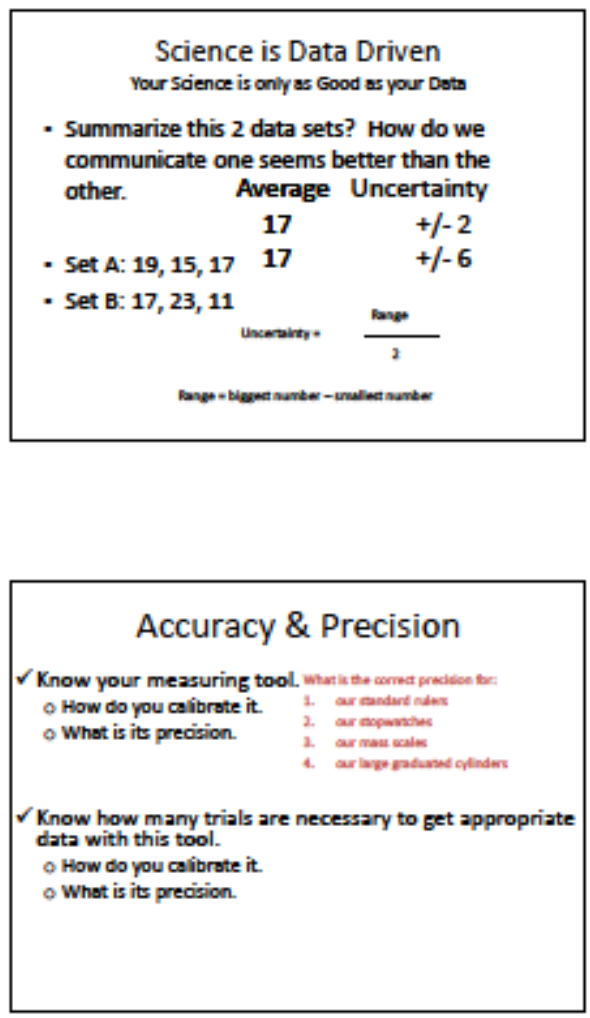

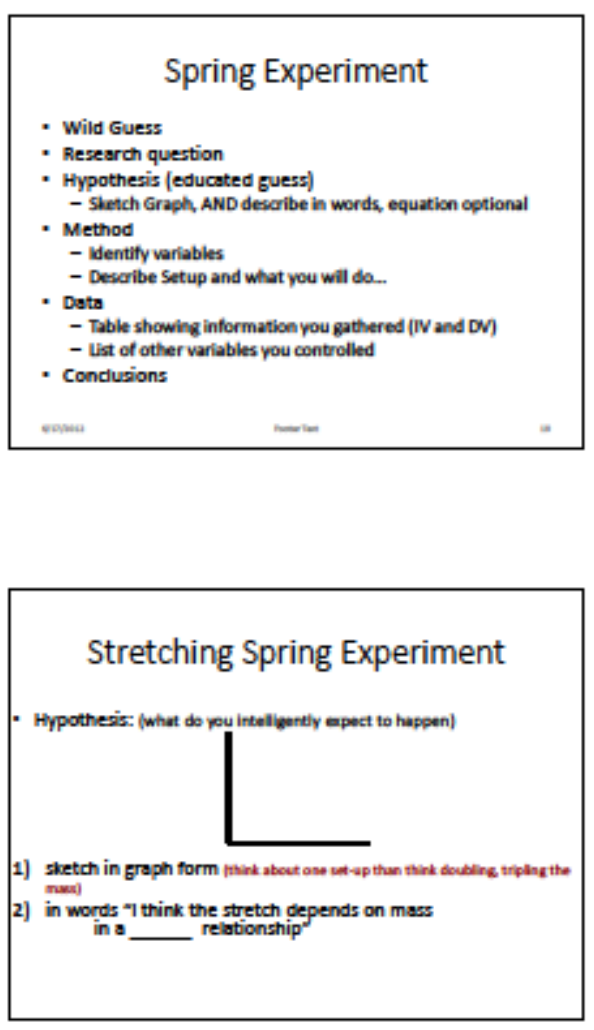

Stretching Spring Experiment

- Method:

1. Experimental set-up

2. How will you change the independent: variables

1. How will you control the controlled variables

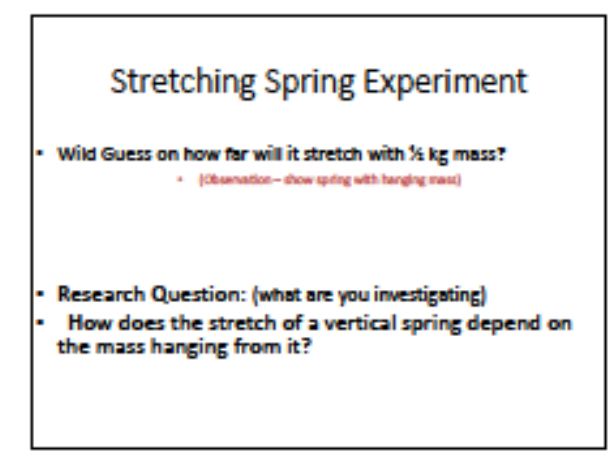

Stretching Spring Experiment

- Variables:

1. identify and list independent variables /the ones you are changing)

2. identify and list dependent variables

1. Identify and list the controlled variables_all variables not list above)

Stretching Spring Experiment

- Data:

1. List values of controlled variables

2. Create a table with a column for the independent variable and a column for the dependent variable, and 7 rows, one for column labels (name and units) and 6 rows for each mass measured:

-

$0,5,10,15,20,25$ grams. 


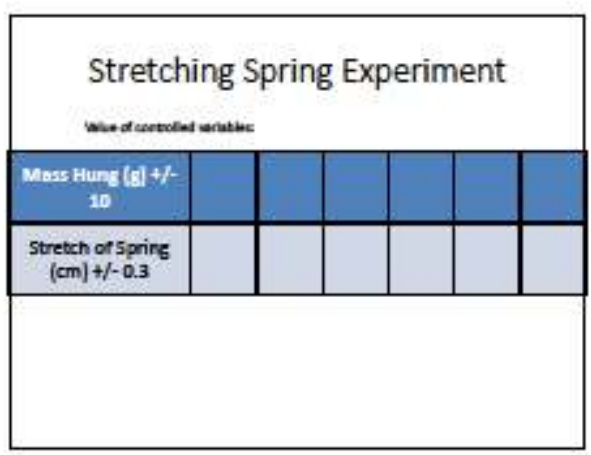

\section{Graphing the Data:}

1. We will use Logger Pro.

1. Set-up columns (name, unit) for mass, overage stretch

2. Under the DATA tab add nax manupl colvunn for

uncertainty of average stretch and fillit out.

Go back to average stretch, under aptions check error bars and use column uncertainty

4. Enter data in esch column

3. Graph Options (Add tive, cheok point protectors, uncheck: connect points]

6. Find simplest best-fit line

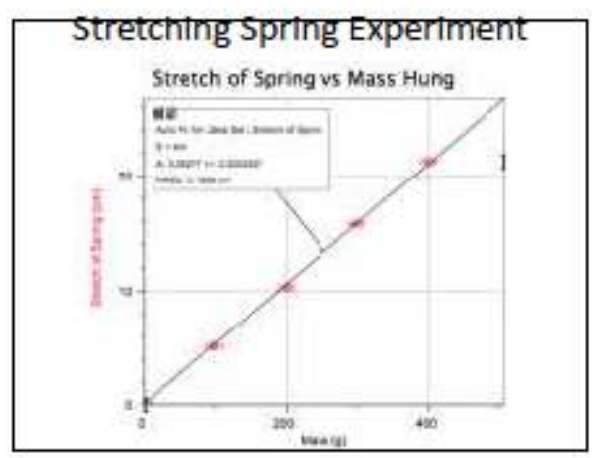

Stretching Spring Experiment

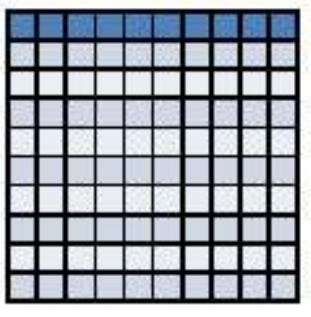

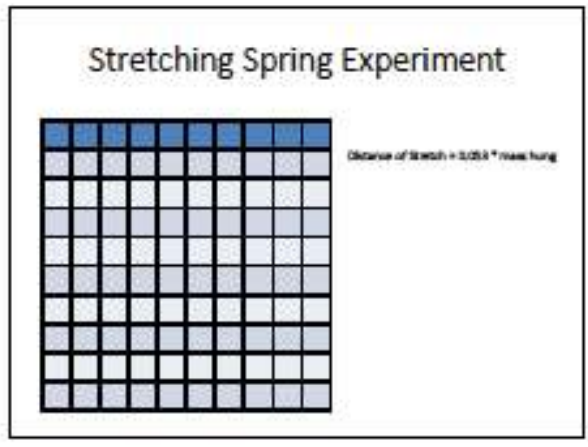

Stretching Spring Experiment

- Condusion:

- Since the best-fit line of our data is linear, we conclude that there is a linear relationship between how much the spring stretches and the mass hung from the spring. This can be represented mathematically

- Stretch of Spring $=0.053^{*}$ Mass Hung.

- $\quad 50$ I predict that for a $500 \mathrm{~g}$ mass my spring will stretch 

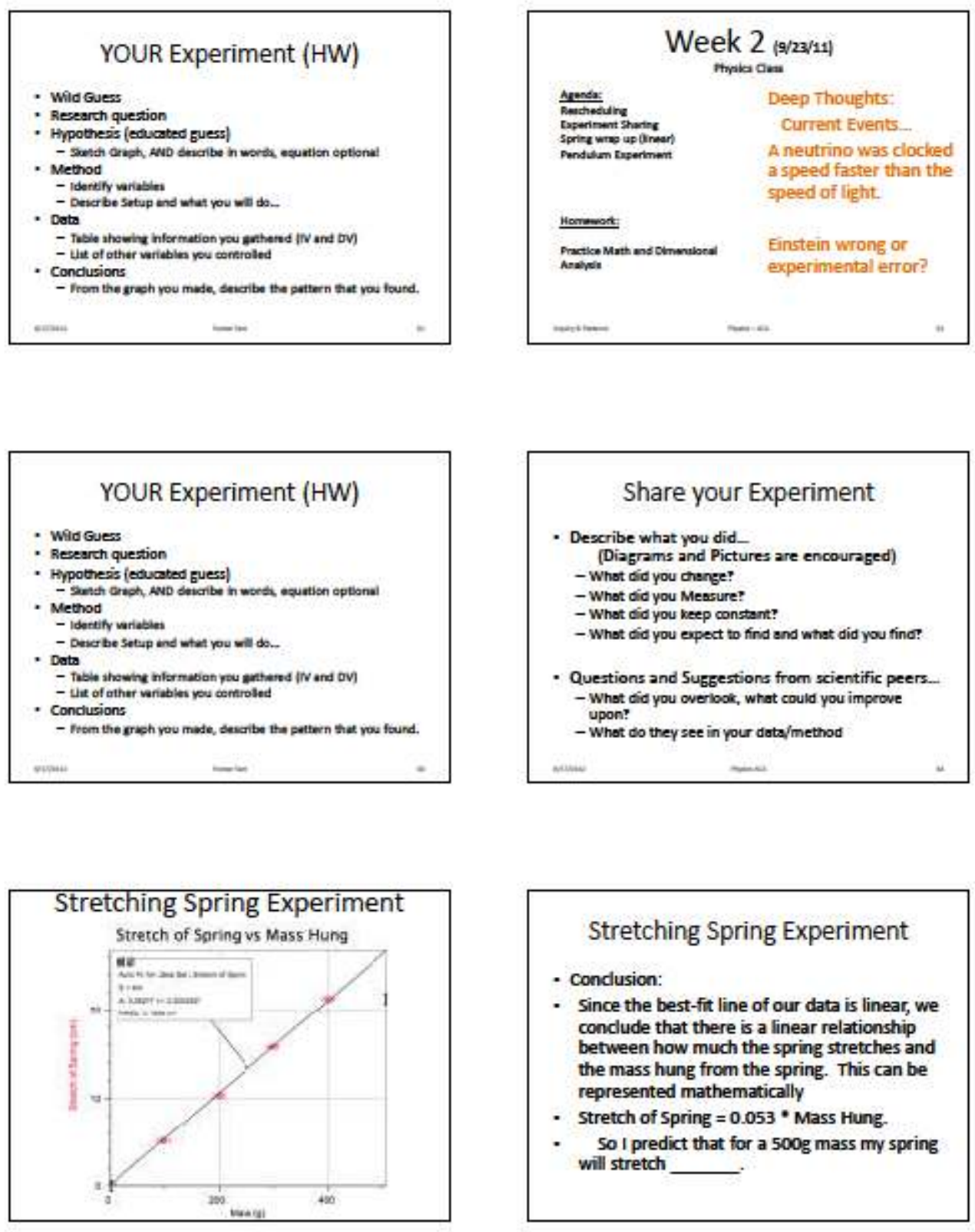

Stretching Spring Experiment

- conclusion:

- Since the best-fit line of our data is linear, we conclude that there is a linear relationship between how much the spring stretches and the mass hung from the spring. This can be represented mathematically

- Stretch of Spring $=0.053^{*}$ Mass Hung.

- So I predict that for a $500 \mathrm{~g}$ mass my spring will stretch 

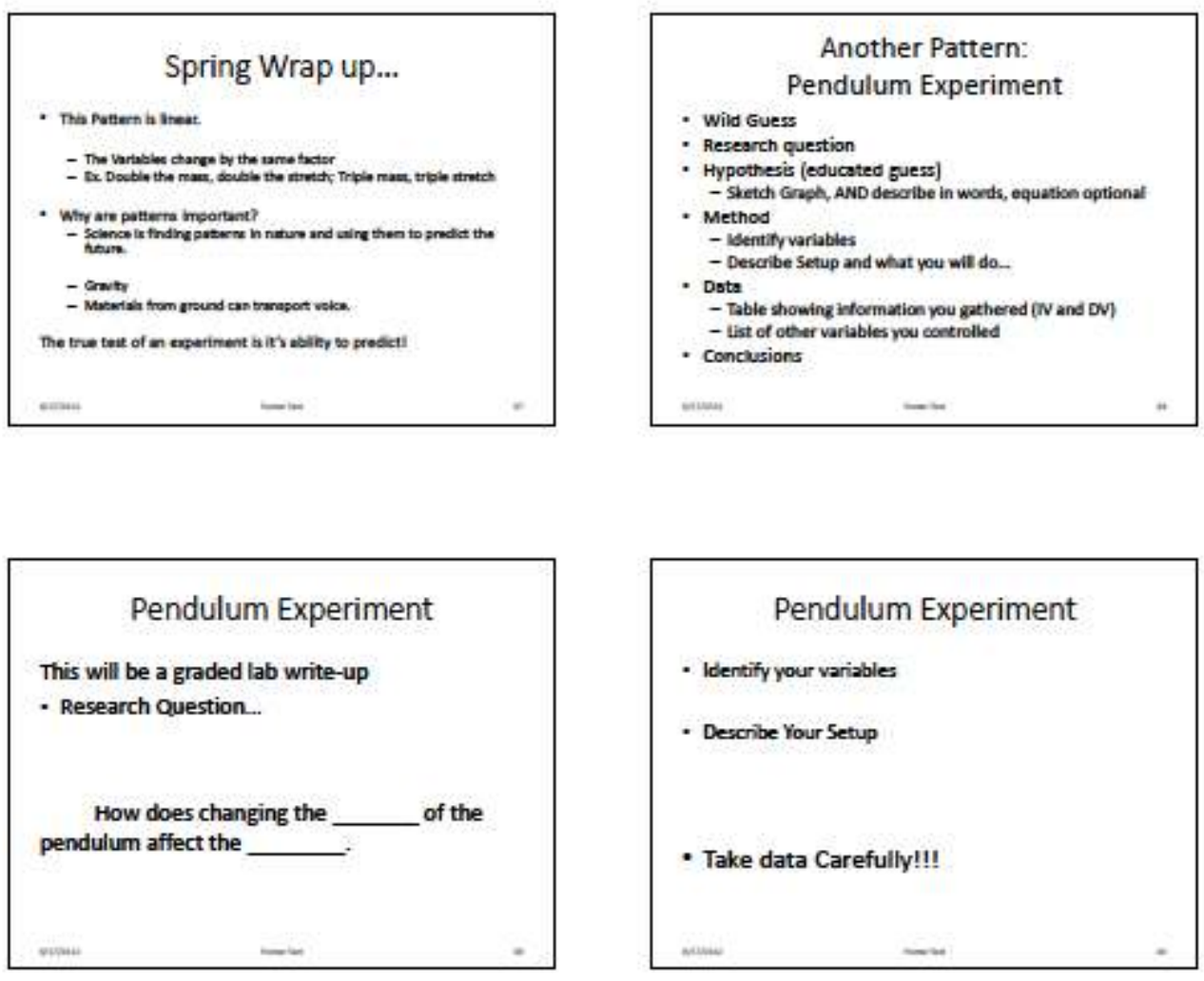

\begin{tabular}{|c|c|c|c|c|c|c|c|}
\hline \multicolumn{8}{|c|}{ Pendulum Sample Data } \\
\hline \multicolumn{8}{|l|}{ Data: } \\
\hline \multirow{2}{*}{$\underset{t i-61}{\lim }$} & \multicolumn{5}{|c|}{ 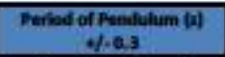 } & \multirow{2}{*}{ 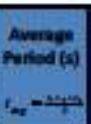 } & \multirow{2}{*}{ 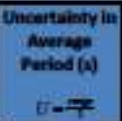 } \\
\hline & $\pi$ & $=$ & $\because$ & $\because$ & $\because$ & & \\
\hline$\infty$ & 0 & $\circ$ & 0 & 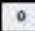 & 0 & 0 & 9 \\
\hline as & 18 & 4 & $\mu$ & 12 & 24 & $\square$ & 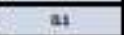 \\
\hline 10 & 12 & 28 & 19 & 22 & 24 & 20 & 42 \\
\hline 15 & 24 & 22 & 28 & 28 & 2.7 & 25 & 422 \\
\hline 20 & 29 & 28 & 27 & 29 & 27 & 28 & at \\
\hline 25 & 10 & 24 & 21 & 20 & 23 & 22 & 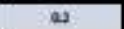 \\
\hline
\end{tabular}

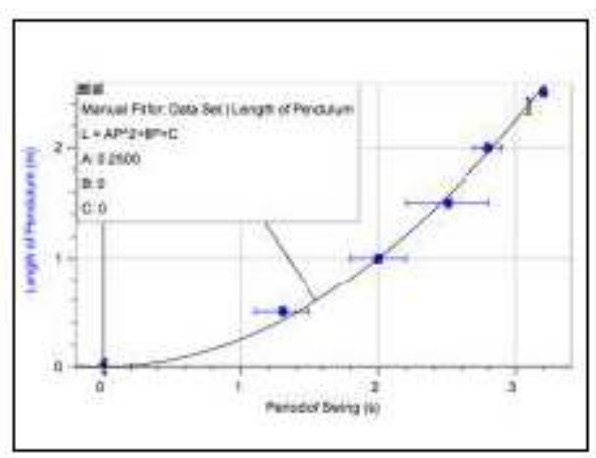



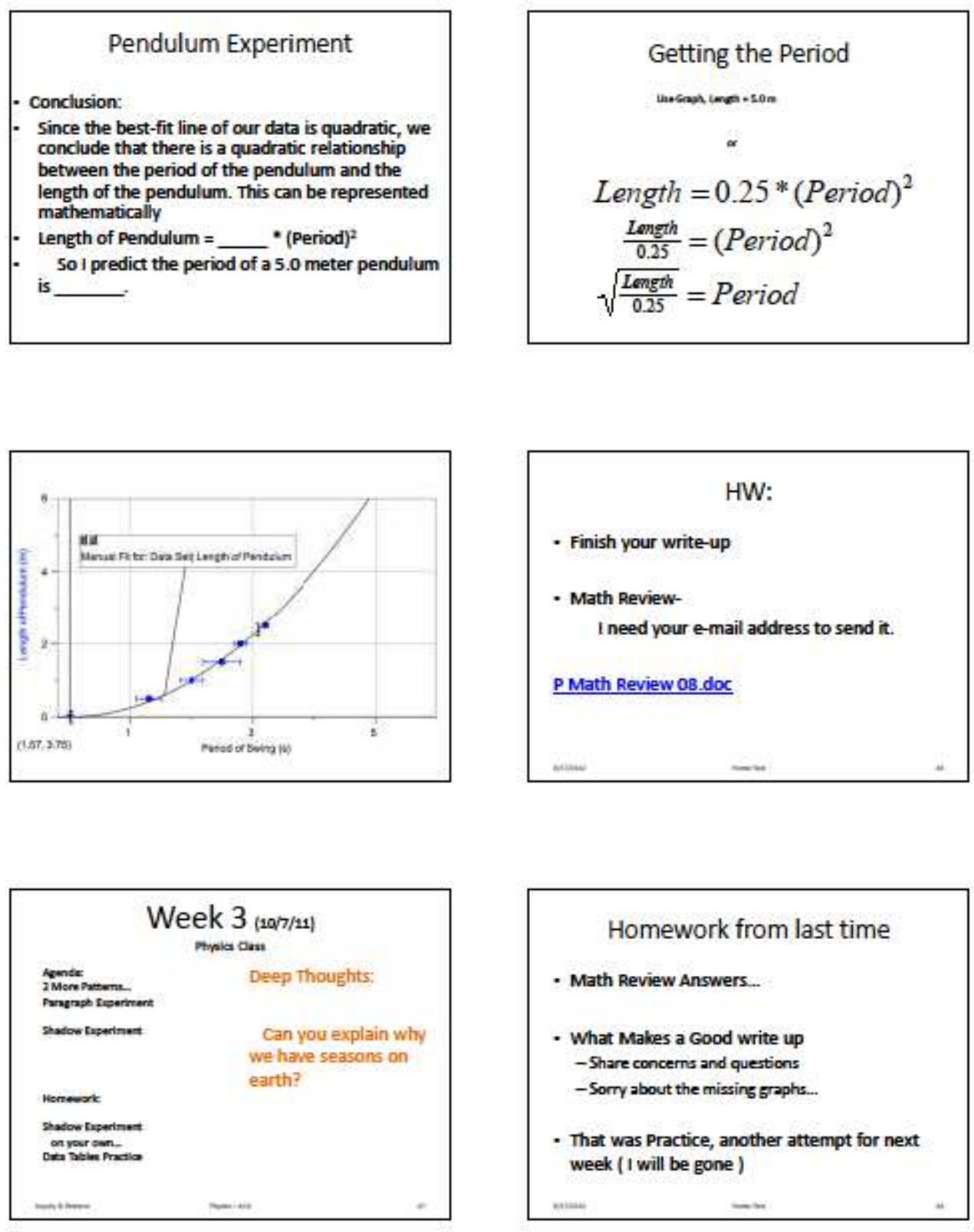

Homework from last time

- Math Review Answers.

- What Makes a Good write up

-Share concerns and questions

-Sorry about the missing graphs..

- That was Practice, another attempt for next week ( 1 will be gone) 


\section{Linear vs Quadratic}

Find 2 things similar about these patterns in nature

- Find 2 things different about these patterns in nature.

- Find another example of each pattern in nature.

\section{Text Experiment}

- Hypothesis:

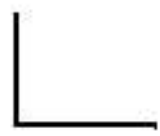

1) sketch in graph form (think about one set-up the non ssts than think doubling or halving the width)

2) in words "1 think height depends on width in a relationship"

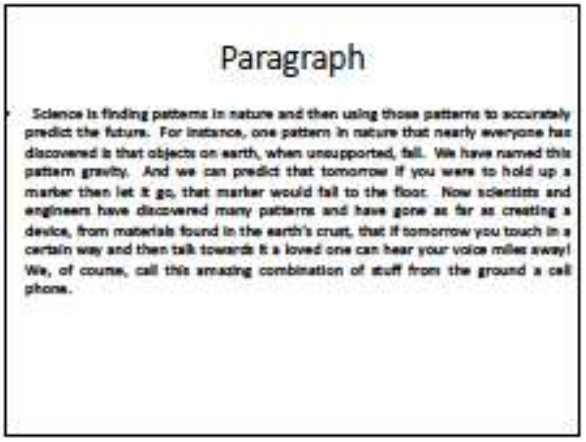

\begin{tabular}{|c|c|c|c|c|c|}
\hline \multicolumn{6}{|c|}{ Paragraph Experiment - Real Data } \\
\hline max & 1 & 2 & $=$ & . & 3 \\
\hline 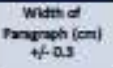 & ins & ss & 77 & 251 & S \\
\hline 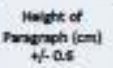 & $\omega$ & 120 & 25 & 20 & 4 \\
\hline
\end{tabular}
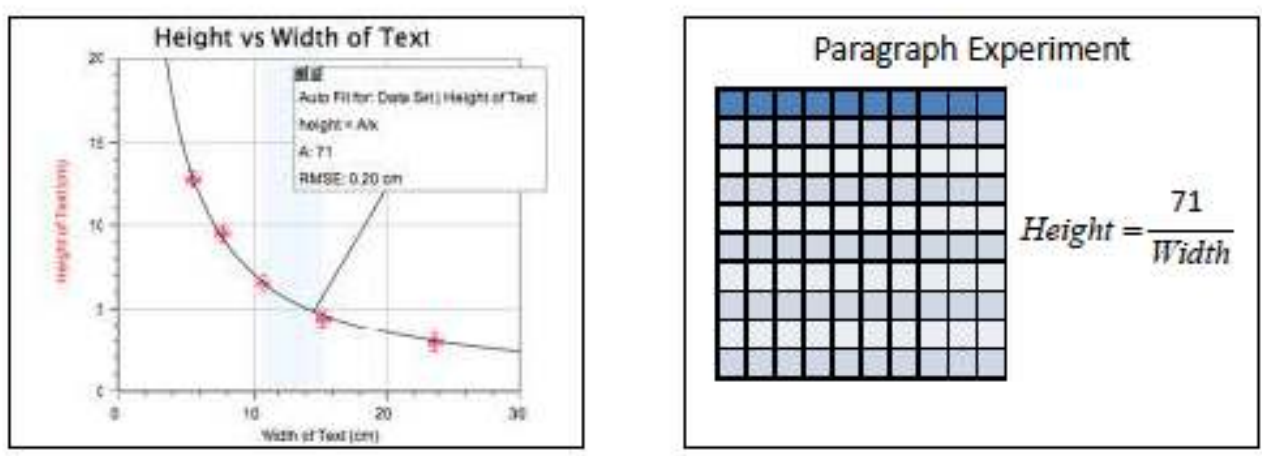

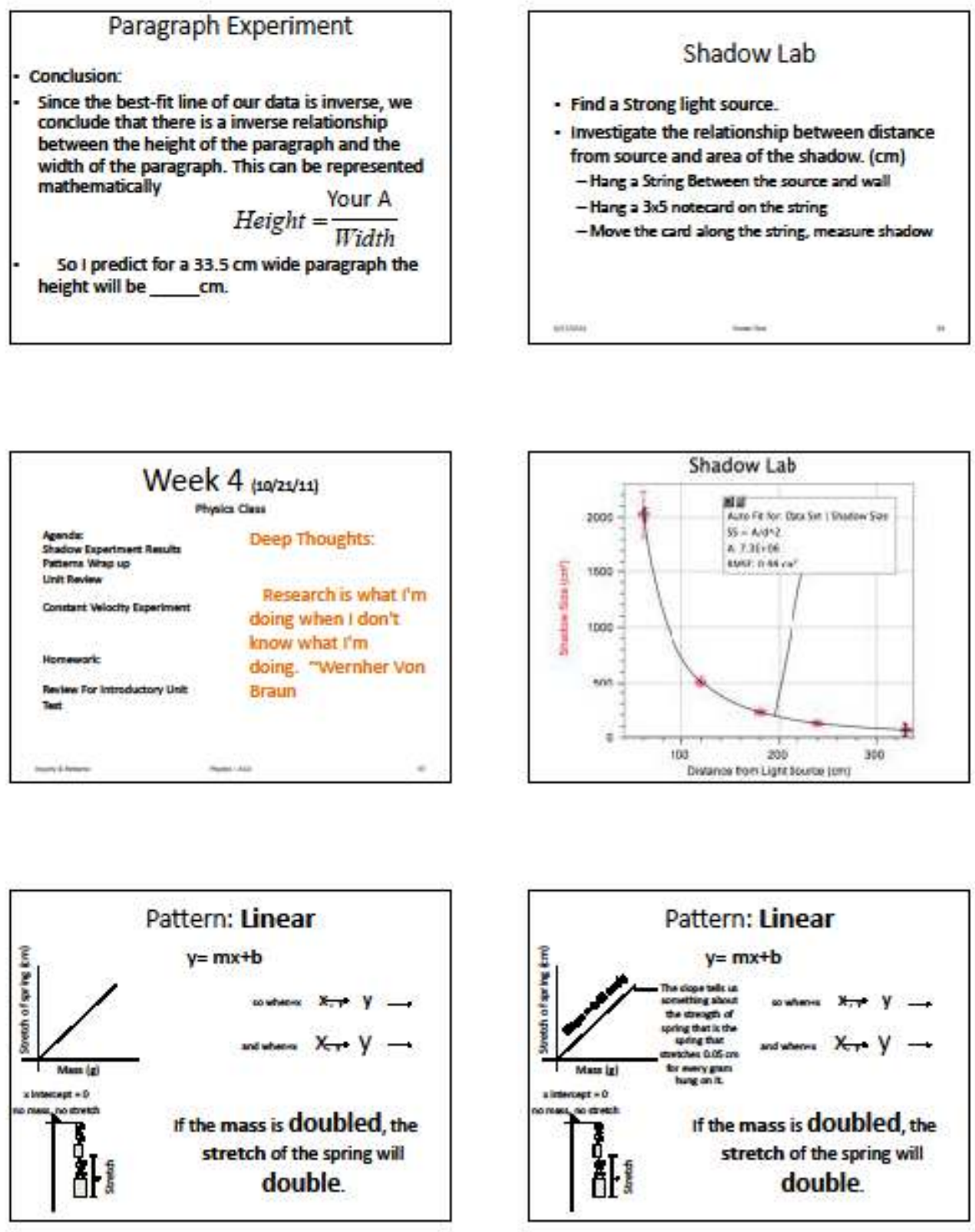

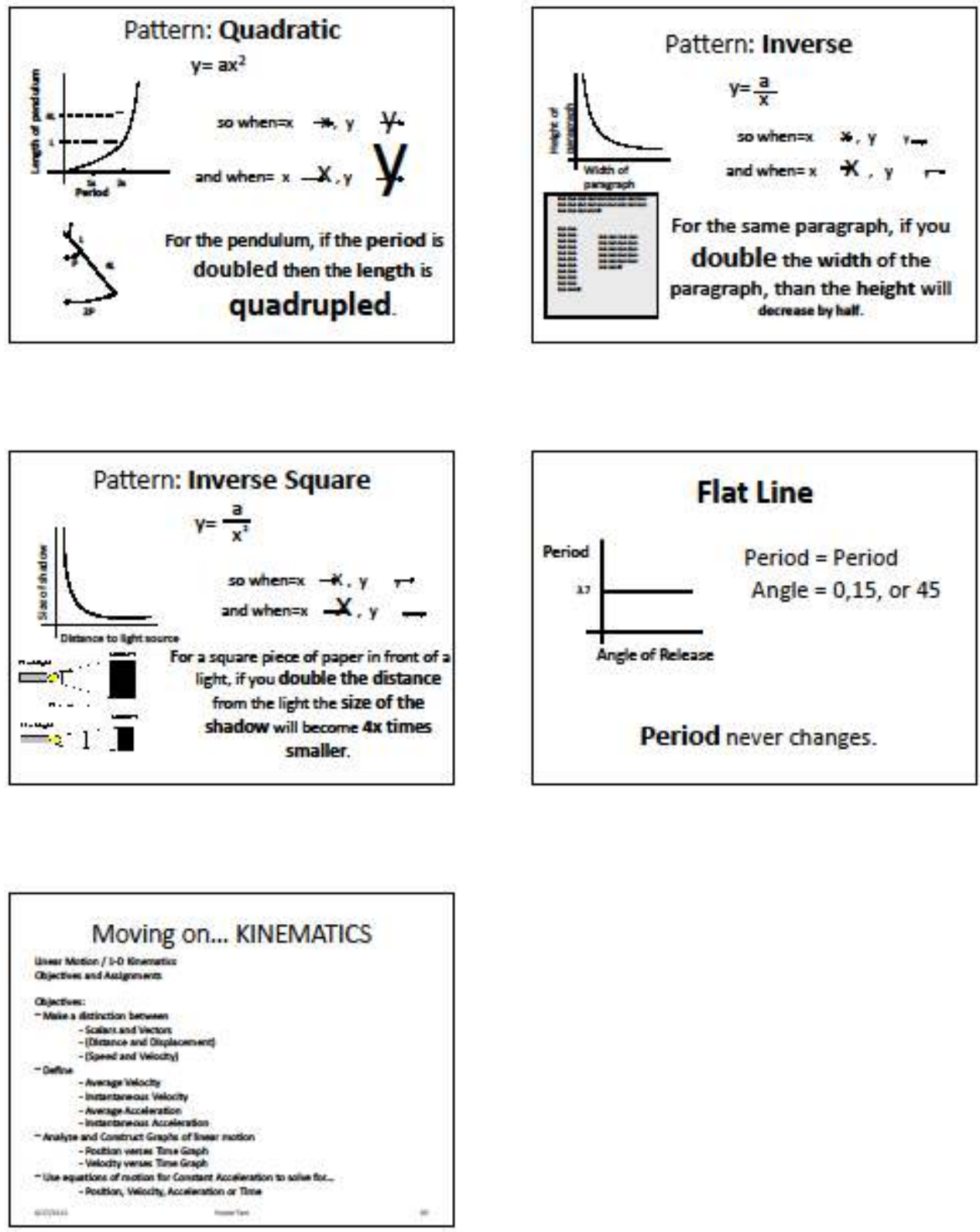
Appendix C: EBAPS survey with key and Views about science survey 


\section{Part 1}

DIRECTIONS: For each of the following items, plense read the statement, and indicate (on the scantron answer sheot) the answer that describes how strongly you agree or disagree.

\section{A: Strongly disagree $\quad$ B: Somewhat disagree $\quad$ C: Neutral $\quad$ D: Somewhat agree $\quad$ E: Strongly agree}

1. Tamara just read something in her science textbook that seems to disagree with her own experiences. But to learn science well, Tamara shouldn't think about her own experiences; she should just focus on what the book says.

2. When it comes to understanding physics or chemistry, remembering facts isn't very important.

3. Obviously, computer simulations can predict the behavior of physical objects like comets. But simulations can also help scientists estimate things involving the behavior of people, such as how many people will buy new television sets next year.

4. When it comes to science, most students either learn things quickly, or not at all.

5. If someone is having trouble in physics or chemistry class, studying in a better way can make a big difference.

6. When it comes to controversial topics such as which foods cause cancer, there's no way for scientists to evaluate which scientific studies are the best. Everything's up in the air!

7. A teacher once said, "I don't really understand something until I teach it." But actually, teaching doesn't help a teacher understand the material better; it just reminds her of how much she already knows.

8. Scientists should spend almost all their time gathering information. Worrying about theories can't really help us understand anything.

9. Someone who doesn't have high natual ability can still learn the material well even in a hard chemistry or physics class.

10. Often, a scientific principle or theory just doesn't make sense. In those cases, you have to accept it and move on, because not everything in science is supposed to make sense.

11. When handing in a physics or chemistry test, you can generally have a sense of how well you did even before talking about it with other students. 


\section{A: Strongly disagree $\quad$ B: Somewhat disagree $\quad$ C: Neutral $\quad$ D: Somewhat agree $\quad$ E: Strongly agree}

12. When leaming science, people can understand the material better if they relate it to their own ideas.

13. If physics and chemistry teachers gave really clear lectures, with plenty of real-life examples and sample problems, then most good students could learn those subjects without doing lots of sample questions and practice problems on their own.

14. Understanding science is really important for people who design rockets, but not important for politicians.

15. When solving problems, the key thing is knowing the methods for addressing each particular type of question. Understanding the "big ideas" might be helpful for specially-written problems, but not for most regular problems.

16. Given enough time, almost everybody could leam to think more scientifically, if they really wanted to.

17. To understand chemistry and physics, the formulas (equations) are really the main thing; the other material is mostly to help you decide which equations to use in which situations.

\section{Part 2}

DIRECTIONS: Multiple choice. On the answer sheet, fill in the answer that best fits your view.

18. If someone is trying to learn physics, is the following a good kind of question to think about?

Two student want to break a rope. Is it better for them to (1) grab opposite ends of the rope and pull (like in tus-of-war), or (2) tie one end of the rope to a wall and both pull on the other end together?

(a) Yes, definitely. It's one of the best kinds of questions to study.

(b) Yes, to some extent. But other kinds of questions are equally good.

(c) Yes, a little. This kind of question is helpful, but other kinds of questions are more helpful.

(d) Not roally. This kind of question isn't that great for learning the main ideas.

(e) No, definitely not. This kind of question isn't helpful at all. 
19. Scientists are having trouble predicting and explaining the behavior of thunder storms. This could be because thunder storms behave according to a very complicated or hard-to-apply set of rules. Or, that could be because some thunder storms don't behave consistently according to any set of rules, no matter how complicated and complete that set of rules is.

In general, why do scientists sometimes have trouble explaining things? Please read all options before choosing one.

(a) Although things behave in accordance with rules, those rules are often complicated, hard to apply, or not fully known.

(b) Some things just don't behave according to a consistent set of rules.

(c) Usually it's because the rules are complicated, hard to apply, or unknown; but sometimes it's because the thing doesn't follow rules.

(d) About half the time, it's because the rules are complicated, hard to apply, or unknown; and half the time, it's because the thing doesn't follow rules.

(e) Usually it's because the thing doesn't follow rules; but sometimes it's because the rules are complicated, hard to apply, or unknown.

20. In physics and chemistry, how do the most important formulas relate to the most important concepts? Please read all choices before picking one.

(a) The major formulas summarize the main concepts; they're not really separate from the concepts. In addition, those formulas are helpful for solving problems.

(b) The major formulas are kind of "separate" from the main concepts, since concepts are ideas, not equations. Formulas are better characterized as problem-solving tools, without much conceptual meaning.

(c) Mostly (a), but a little (b).

(d) About half (a) and half (b).

(e) Mostly (b), but a little (a).

21. To be successful at most things in life...

(a) Hard work is much more important than inborn natural ability.

(b) Hard work is a little more important than natural ability.

(c) Natural ability and hard work are equally important.

(d) Natural ability is a little more important than hard work

(e) Natural ability is much more important than hard work

22. To be successful at science...

(a) Hard work is much more important than inborn natural ability.

(b) Hard work is a little more important than natural ability.

(c) Natural ability and hard work are equally important.

(d) Natural ability is a little more important than hard work.

(e) Natural ability is much more important than hard work. 
23. Of the following test formats, which is best for measuring how well students understand the material in physics and chemistry? Please read each choice before picking one.

(a) A large collection of short-answer or multiple choice questions, each of which covers one specific fact or concept.

(b) A small number of longer questions and problems, each of which covers several facts and concepts.

(c) Compromise between (a) and (b), but leaning more towards (a).

(d) Compromise between (a) and (b), favoring both equally.

(e) Compromise between (a) and (b), but leaning more towards (b).

\section{Part 3}

DIRECTIONS: In each of the following items, you will read a short discussion between two students who disagree about some issue. Then you'll indicate whether you agree with one student or the other

24.

Brandon: A good science textbook should show how the material in one chapter relates to the material in other chapters. It shouldn't treat each topic as a separate "unit," because they're not really separate.

Jamal: But most of the time, each chapter is about a different topic, and those different topics don't always have much to do with each other. The textbook should keep everything separate, instead of blending it all together.

With whom do you agree? Read all the choices before circling one.

(a) I agree almost entirely with Brandon.

(b) Although I agree more with Brandon, I think Jamal makes some good points.

(c) I agree (or disagree) equally with Jamal and Brandon.

(d) Although I agree more with Jamal, I think Brandon makes some good points.

(e) I agree almost entirely with Jamal.

25.

Anna: I just read about Kay Kinoshita, the physicist. She sounds naturally brilliant.

Envily: Maybe she is. But when it comes to being good at science, hard work is more important than "natural ability." I bet Dr. Kinoshita does well because she has worked really hard.

Anna: Well maybe she did. But let's face it, some people are just smarter at science than other people. Without natural ability, hard work won't get you anywhere in science!

(a) I agree almost entirely with Anna.

(b) Although I agree more with Anna, I think Emily makes some good points.

(c) I agree (or disagree) equally with Anna and Emily.

(d) Although I agree more with Emily, I think Anna makes some good points.

(e) I agree almost entirely with Emily. 
26.

Justin: When I'm learning science concepts for a test, I like to put things in my own words, so that they make sense to me.

Dave: But putting things in your own words doesn't help you learn. The textbook was written by people who know science really well. You should learn things the way the textbook presents them.

(a) I agree almost entirely with Justin

(b) Although I agree more with Justin, I think Dave makes some good points.

(c) I agree (or disagree) equally with Justin and Dave.

(d) Although I agree more with Dave, I think Justin makes some good points.

(e) I agree almost entirely with Dave.

27.

Julia: I like the way science explains things I see in the real world.

Carla: I know that's what we're "supposed" to think, and it's true for many things. But let's face it, the science that explains things we do in lab at school can't really explain earthquakes, for instance. Scientific laws work well in some situations but not in most situations.

Julia: I still think science applies to almost all real-world experiences. If we can't figure out how, it's because the stuff is very complicated, or because we don't know enough science yet.

(a) I agree almost entirely with Julia.

(b) I agree more with Julia, but I think Carla makes some good points.

(c) I agree (or disagree) equally with Carla and Julia.

(d) I agree more with Carla, but I think Julia makes some good points.

(e) I agree almost entirely with Carla.

28.

Leticia: Some scientists think the dinosaurs died out because of volcanic eruptions, and others think they died out because an asteroid hit the Earth. Why can't the scientists agree?

Nisha: Maybe the evidence supports both theories. There's often more than one way to interpret the facts. So we have to figure out what the facts mean.

Leticia: I'm not so sure. In stuff like personal relationships or poetry, things can be ambiguous. But in science, the facts speak for themselves.

(a) I agree almost entirely with Leticia.

(b) I agree more with Leticia, but I think Nisha makes some good points.

(c) I agree (or disagree) equally with Nisha and Leticia.

(d) I agree more with Nisha, but I think Leticia makes some good points.

(e) I agree almost entirely with Nisha. 
29.

Jose: In my opinion, science is a little like fashion; something that's "in" one year can be "out" the next. Scientists regularly change their theories back and forth.

Miguel: I have a different opinion. Once experiments have been done and a theory has been made to explain those experiments, the matter is pretty much settled. There's little room for argument.

(a) I agree almost entirely with Jose.

(b) Although I agree more with Jose, I think Miguel makes some good points.

(c) I agree (or disagree) equally with Miguel and Jose.

(d) Although I agree more with Miguel, I think Jose makes some good points.

(e) I agree almost entirely with Miguel.

30.

Jessica and Mia are working on a homework assignment together..

Jessica: O.K, we just got problem \#1. I think we should go on to problem \#2.

Mia: No, wait. I think we should try to figure out why the thing takes so long to reach the ground.

Jessica: Mia, we know it's the right answer from the back of the book, so what are you worried about? If we didn't understand it, we wouldn't have gotten the right answer.

Mia: No, I think it's possible to get the right answer without really understanding what it means.

(a) I agree almost entirely with Jessica.

(b) I agree more with Jessica, but I think Mia makes some good points.

(c) I agree (or disagree) equally with Mia and Jessica.

(d) I agree more with Mia, but I think Jessica makes some good points.

(e) I agree almost entirely with Mia. 


\section{Which EBAPS items belong to which subscales?}

Axis 1: Structure of scientific knowledge

$2,8,10,15,17,19,20,23,24,28$

Axis 2: Nature of knowing and learning

$1,7,11,12,13,18,26,30$

Axis 3: Real-life applicability

$3,14,19,27$

Axis 4: Evolving knowledge

$6,28,29$

Axis 5: Source of ability to learn

$5,9,16,22,25$

Overall

All questions on the survey, equally weighted.

NOTE - The following items belong to no axis except for Overall: 4, 21

The following pages list all the EBAPS items sorted by axes and include the scoring scheme for each item. 


\section{Axis 1: Structure of scientific knowledge}

2. When it comes to understanding physics or chemistry, remembering facts isn't very important.

$$
\mathrm{A}=0, \mathrm{~B}=1.5, \mathrm{C}=2.5, \mathrm{D}=3.5, \mathrm{E}=4
$$

8. Scientists should spend almost all their time gathering information. Worrying about theories can't really help us understand anything.

$$
A=4, B=3, C=1.5, D=0.5, E=0
$$

10. Often, a scientific principle or theory just doesn't make sense. In those cases, you have to accept it and move on, because not everything in science is supposed to make sense.

$$
A=4, B=3, C=2, D=1, E=0
$$

15. When solving problems, the key thing is knowing the methods for addressing each particular type of question. Understanding the "big ideas" might be helpful for specially-written problems, but not for most regular problems.

$$
A=4, B=3, C=2, D=1, E=0
$$

17. To understand chemistry and physics, the formulas (equations) are really the main thing; the other material is mostly to help you decide which equations to use in which situations.

$$
A=4, B=3, C=1.5, D=0.5, E=0
$$

19. Scientists are having trouble predicting and explaining the behavior of thunder storms. This could be because thunder storms behave according to a very complicated or hard-to-apply set of rules. Or, that could be because some thunder storms don't behave consistently according to any set of rules, no matter how complicated and complete that set of rules is.

In general, why do scientists sometimes have trouble explaining things? Please read all options before choosing one.

(a) Although things behave in accordance with rules, those rules are often complicated, hard to apply, or not fully known.

(b) Some things just don't behave according to a consistent set of rules. 
(c) Usually it's because the rules are complicated, hard to apply, or unknown; but sometimes it's because the thing doesn't follow rules.

(d) About half the time, it's because the rules are complicated, hard to apply, or unknown; and half the time, it's because the thing doesn't follow rules.

(e) Usually it's because the thing doesn't follow rules; but sometimes it's because the rules are complicated, hard to apply, or unknown.

$$
A=4, B=0, C=3, D=2, E=1
$$

20. In physics and chemistry, how do the most important formulas relate to the most important concepts? Please read all choices before picking one.

(a) The major formulas summarize the main concepts; they're not really separate from the concepts. In addition, those formulas are helpful for solving problems.

(b) The major formulas are kind of "separate" from the main concepts, since concepts are ideas, not equations. Formulas are better characterized as problem-solving tools, without much conceptual meaning.

(c) Mostly (a), but a little (b).

(d) About half (a) and half (b).

(e) Mostly (b), but a little (a).

$$
A=4, B=0, C=3, D=2, E=1
$$

23. Of the following test formats, which is best for measuring how well students understand the material in physics and chemistry? Please read each choice before picking one.

(a) A large collection of short-answer or multiple choice questions, each of which covers one specific fact or concept.

(b) A small number of longer questions and problems, each of which covers several facts and concepts.

(c) Compromise between (a) and (b), but leaning more towards (a).

(d) Compromise between (a) and (b), favoring both equally.

(e) Compromise between (a) and (b), but leaning more towards (b).

$$
A=0, B=4, C=1, D=2, E=3
$$

24.

Brandon: A good science textbook should show how the material in one chapter relates to the material in other chapters. It shouldn't treat each topic as a separate "unit," because they're not really separate.

Jamal: But most of the time, each chapter is about a different topic, and those different topics don't always have much to do with each other. The textbook should keep everything separate, instead of blending it all together.

With whom do you agree? Read all the choices before circling one.

(a) I agree almost entirely with Brandon.

(b) Although I agree more with Brandon, I think Jamal makes some good points. 
(c) I agree (or disagree) equally with Jamal and Brandon.

(d) Although I agree more with Jamal, I think Brandon makes some good points.

(e) I agree almost entirely with Jamal.

$$
A=4, B=4, C=2, D=1, E=0
$$

28.

Leticia: Some scientists think the dinosaurs died out because of volcanic eruptions, and others think they died out because an asteroid hit the Earth. Why can't the scientists agree?

Nisha: Maybe the evidence supports both theories. There's often more than one way to interpret the facts. So we have to figure out what the facts mean.

Leticia: I'm not so sure. In stuff like personal relationships or poetry, things can be ambiguous. But in science, the facts speak for themselves.

(a) I agree almost entirely with Leticia.

(b) I agree more with Leticia, but I think Nisha makes some good points.

(c) I agree (or disagree) equally with Nisha and Leticia.

(d) I agree more with Nisha, but I think Leticia makes some good points.

(e) I agree almost entirely with Nisha.

$$
A=0, B=1, C=2, D=3, E=4
$$




\section{Axis 2: Nature of knowing and learning}

1. Tamara just read something in her science textbook that seems to disagree with her own experiences. But to learn science well, Tamara shouldn't think about her own experiences; she should just focus on what the book says.

$$
A=4, B=3, C=1, D=0.5, E=0
$$

7. A teacher once said, "I don't really understand something until I teach it." But actually, teaching doesn't help a teacher understand the material better; it just reminds her of how much she already knows.

$$
A=4, B=3, C=2, D=1, E=0
$$

11. When handing in a physics or chemistry test, you can generally have a sense of how well you did even before talking about it with other students.

$$
A=0, B=1, C=2, D=3, E=4
$$

12. When learning science, people can understand the material better if they relate it to their own ideas.

$$
A=0, B=0.5, C=1, D=3, E=4
$$

13. If physics and chemistry teachers gave really clear lectures, with plenty of real-life examples and sample problems, then most good students could learn those subjects without doing lots of sample questions and practice problems on their own.

$$
A=4, B=3, C=1, D=0.5, E=0
$$

18. If someone is trying to learm physics, is the following a good kind of question to think about?

"Two students want to break a rope. Is it better for them to (1) grab opposite ends of the rope and pull (like in tug-of-war), or (2) tie one end of the rope to a wall and both pull on the other end together?"

(a) Yes, definitely. It's one of the best kinds of questions to study.

(b) Yes, to some extent. But other kinds of questions are equally good.

(c) Yes, a little. This kind of question is helpful, but other kinds of questions are more helpful.

(d) Not really. This kind of question isn't that great for learning the main ideas.

(e) No, definitely not. This kind of question isn't helpful at all. 


$$
A=4, B=3.5, C=1.5, D=0.5, E=0
$$

26.

Justin: When I'm learning science concepts for a test, I like to put things in my own words, so that they make sense to me.

Dave: But putting things in your own words doesn't help you learn. The textbook was written by people who know science really well. You should leam things the way the textbook presents them.

(a) I agree almost entirely with Justin

(b) Although I agree more with Justin, I think Dave makes some good points.

(c) I agree (or disagree) equally with Justin and Dave.

(d) Although I agree more with Dave, I think Justin makes some good points.

(e) I agree almost entirely with Dave.

$$
A=4, B=4, C=2, D=1, E=0
$$

30.

Jessica and Mia are working on a homework assignment together...

Jessica: OK, we just got problem \#1. I think we should go on to problem \#2.

Mia: No, wait. I think we should try to figure out why the thing takes so long to reach the ground.

Jessica: Mia, we know it's the right answer from the back of the book, so what are you worried about? If we didn't understand it, we wouldn't have gotten the right answer.

Mia: No, I think it's possible to get the right answer without really understanding what it means.

(a) I agree almost entirely with Jessica.

(b) I agree more with Jessica, but I think Mia makes some good points.

(c) I agree (or disagree) equally with Mia and Jessica.

(d) I agree more with Mia, but I think Jessica makes some good points.

(e) I agree almost entirely with Mia.

$$
A=0, B=1, C=2, D=3, E=4
$$




\section{Axis 3: Real-life applicability}

3. Obviously, computer simulations can predict the behavior of physical objects like comets. But simulations can also help scientists estimate things involving the behavior of people, such as how many people will buy new television sets next year.

$$
\mathrm{A}=0, \mathrm{~B}=1, \mathrm{C}=2, \mathrm{D}=3.5, \mathrm{E}=4
$$

14. Understanding science is really important for people who design rockets, but not important for politicians.

$$
A=4, B=3, C=2, D=1, E=0
$$

19. Scientists are having trouble predicting and explaining the behavior of thunder storms. This could be because thunder storms behave according to a very complicated or hard-to-apply set of rules. Or, that could be because some thunder storms don't behave consistently according to any set of rules, no matter how complicated and complete that set of rules is.

In general, why do scientists sometimes have trouble explaining things? Please read all options before choosing one.

(a) Although things behave in accordance with rules, those rules are often complicated, hard to apply, or not fully known.

(b) Some things just don't behave according to a consistent set of rules.

(c) Usually it's because the rules are complicated, hard to apply, or unknown; but sometimes it's because the thing doesn't follow rules.

(d) About half the time, it's because the rules are complicated, hard to apply, or unknown; and half the time, it's because the thing doesn't follow rules.

(e) Usually it's because the thing doesn't follow rules; but sometimes it's because the rules are complicated, hard to apply, or unknown.

$$
A=4, B=0, C=3, D=2, E=1
$$

27.

Julia: I like the way science explains things I see in the real world.

Carla: I know that's what we're "supposed" to think, and it's true for many things. But let's face it, the science that explains things we do in lab at school can't really explain earthquakes, for instance. Scientific laws work well in some situations but not in most situations.

Julia: I still think science applies to almost all real-world experiences. If we can't figure out how, it's because the stuff is very complicated, or because we don't know enough science yet.

(a) I agree almost entirely with Julia.

(b) I agree more with Julia, but I think Carla makes some good points. 
(c) I agree (or disagree) equally with Carla and Julia.

(d) I agree more with Carla, but I think Julia makes some good points.

(e) I agree almost entirely with Carla.

$$
A=4, B=4, C=2, D=1, E=0
$$




\section{Axis 4: Evolving knowledge}

6. When it comes to controversial topics such as which foods cause cancer, there's no way for scientists to evaluate which scientific studies are the best. Everything's up in the air!

$$
A=4, B=4, C=2, D=1, E=0
$$

28.

Leticia: Some scientists think the dinosaurs died out because of volcanic eruptions, and others think they died out because an asteroid hit the Earth. Why can't the scientists agree?

Nisha: Maybe the evidence supports both theories. There's often more than one way to interpret the facts. So we have to figure out what the facts mean.

Leticia: I'm not so sure. In stuff like personal relationships or poetry, things can be ambiguous. But in science, the facts speak for themselves.

(a) I agree almost entirely with Leticia.

(b) I agree more with Leticia, but I think Nisha makes some good points.

(c) I agree (or disagree) equally with Nisha and Leticia.

(d) I agree more with Nisha, but I think Leticia makes some good points.

(e) I agree almost entirely with Nisha.

$$
\mathrm{A}=0, \mathrm{~B}=1, \mathrm{C}=2, \mathrm{D}=3, \mathrm{E}=4
$$

29.

Jose: In my opinion, science is a little like fashion; something that's "in" one year can be "out" the next. Scientists regularly change their theories back and forth.

Miguel: I have a different opinion. Once experiments have been done and a theory has been made to explain those experiments, the matter is pretty much settled. There's little room for argument.

(a) I agree almost entirely with Jose.

(b) Although I agree more with Jose, I think Miguel makes some good points.

(c) I agree (or disagree) equally with Miguel and Jose.

(d) Although I agree more with Miguel, I think Jose makes some good points.

(e) I agree almost entirely with Miguel.

$$
A=0, B=2, C=4, D=2, E=0
$$




\section{Axis 5: Source of ability to learn}

5. If someone is having trouble in physics or chemistry class, studying in a better way can make a big difference.

$$
A=0, B=1, C=2, D=3, E=4
$$

9. Someone who doesn't have high natural ability can still learn the material well even in a hard chemistry or physics class.

$$
A=0, B=1, C=2, D=3, E=4
$$

16. Given enough time, almost everybody could learn to think more scientifically, if they really wanted to.

$$
A=0, B=1, C=2, D=3, E=4
$$

22. To be successful at science..

(a) Hard work is much more important than inborn natural ability.

(b) Hard work is a little more important than natural ability.

(c) Natural ability and hard work are equally important.

(d) Natural ability is a little more important than hard work.

(e) Natural ability is much more important than hard work.

$$
A=4, B=3, C=2, D=1, E=0
$$

25 .

Anna: I just read about Kay Kinoshita, the physicist. She sounds naturally brilliant. Emily: Maybe she is. But when it comes to being good at science, hard work is more important than "natural ability." I bet Dr. Kinoshita does well because she has worked really hard.

Anna: Well, maybe she did. But let's face it, some people are just smarter at science than other people. Without natural ability, hard work won't get you anywhere in science!

(a) I agree almost entirely with Anna.

(b) Although I agree more with Anna, I think Emily makes some good points.

(c) I agree (or disagree) equally with Anna and Emily.

(d) Although I agree more with Emily, I think Anna makes some good points.

(e) I agree almost entirely with Emily.

$$
A=0, B=1, C=2, D=4, E=4
$$




\section{My Ideas About Science}

Please provide honest answers to the following questions. There are no right or wrong answers, and these questions are simply to reveal what you think about science, so I can improve my teaching. I'll ask these questions again at the end of the course to see if your thoughts have changed. In each case circle your answer and explain why you think that way.

About Professional Scientists...

1) When scientists are conducting scientific research, do they use their imagination?

Yes. No. Please Explain:

2) Are scientific investigations influenced by scientists' personal beliefs?

Yes. No. Please Explain:

3) Do professional scientists collect data mainly to show others that they are right?

Yes. No. Please Explain:

4) Should all scientists use the same or similar methods to carry out investigations?

Yes. No. Please Explain:

5) Do you agree that repeating other scientists' experiments is a waste of time?

Yes. No. Please Explain:

6) If a scientist graphs the data, there is no need for an equation to show the same thing.

Yes. No. Please Explain: 
About Students in Science Class...

1) If science teachers gave really clear lectures with plenty of real-life examples and sample problems, would there still be a need for laboratory activities?

Yes. No. Please Explain

2) Some people say that group work in science class is helpful only if at least one person in the group already understands the ideas. Do you agree?

Yes. No. Please Explain:

3) If two students make measurements of the same event, would you expect them to come up with the same data?

Yes. No. Please Explain:

4) Some students say that in order to solve science problems it is more important to understand the basic concepts than to make mathematical calculations. Do you agree?

Yes. No. Please Explain:

5) Some students say that in order to solve science problems it is more important to make mathematical calculations than to understand the basic concepts. Do you agree?

Yes. No. Please Explain:

6) Do you agree that the kinds of problems you leam to solve in science class have little or no relation to what you experience in the real world?

Yes. No. Please Explain:

7) Data points on a graph and a mathematical equation are two entirely different things.

Yes. No. Please Explain- 
Appendix D: Patterns in Nature unit test

Page | 150 
Name:

Answer questions 1-3 based on the following focused research question: "How does the speed of a ball rolling down a ramp depend on the height from which the it was released on the ramp?"

1. What is the independent variable?

2. What is the dependent variable?

3. What are the controlled variables? (i.e. what must you keep constant to make the experiment precise?)

4. A student observes that a hanging mass accelerates a cart horizontally across a table, as diagramed below. The student experiments with the cart by placing heavier and heavier masses in the cart, while keeping the hanging mass the same, and finds the following data. Please fill in the average and the uncertainty.

\begin{tabular}{|l|l|l|l|l|l|}
\hline \multirow{2}{*}{$\begin{array}{l}\text { Mass }(\mathrm{kg}) \\
+/-0.5\end{array}$} & \multicolumn{3}{|l|}{ Acceleration $\left(\mathrm{m} / \mathrm{s}^{2}\right)$} & $\begin{array}{l}\text { Average } \\
\text { Acceleration } \\
\left(\mathrm{m} / \mathrm{s}^{2}\right)\end{array}$ & $\begin{array}{l}\text { Uncertainty in } \\
\text { Average } \\
\text { Acceleration } \\
\left(\mathrm{m} / \mathrm{s}^{2}\right)\end{array}$ \\
\cline { 2 - 6 } & Trial 1 & Trial 2 & Trial 3 & & \\
\hline 2.0 & 10.6 & 10.0 & 9.4 & & \\
\hline 4.0 & 5.0 & 4.6 & 5.4 & & \\
\hline 8.0 & 2.6 & 3.0 & 2.2 & & \\
\hline 12.0 & 1.2 & 1.6 & 2.0 & & \\
\hline 20.0 & 1.2 & 0.8 & 1.0 & & \\
\hline
\end{tabular}

5. Plot the data points on the grid to the right. Be sure to check the range of each axis so that you can scale the axis to fit your data! Also label your graph, axes and add error bars!

6. Draw a best-fit line and identify the pattern in the data you graphed :

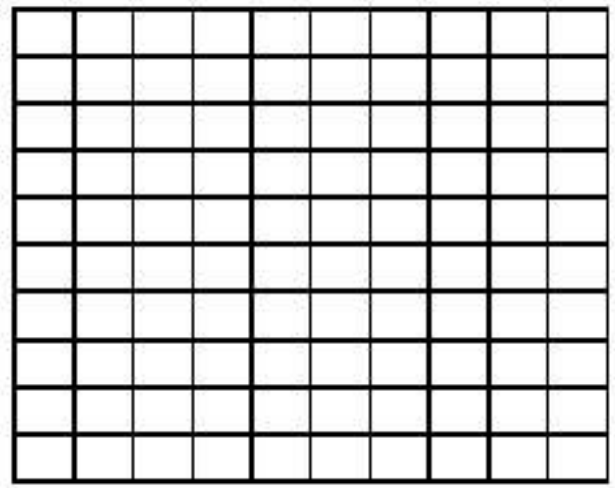

7. Write a one-sentence conclusion for the relationship between mass and acceleration: -Use the prompt...

Because between I conclude there is a relationship

That is to say in mathematical language

-Or say it in your own words here.... 
Name:

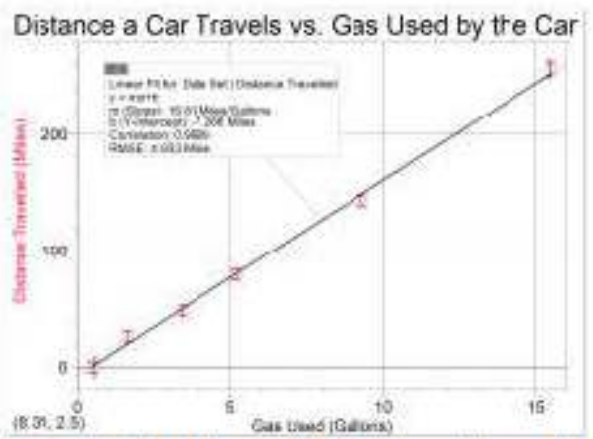

8. For the graph above, what does the value of the slope tell you about the car?

9. How would the graph change for a more fuel efficient car?

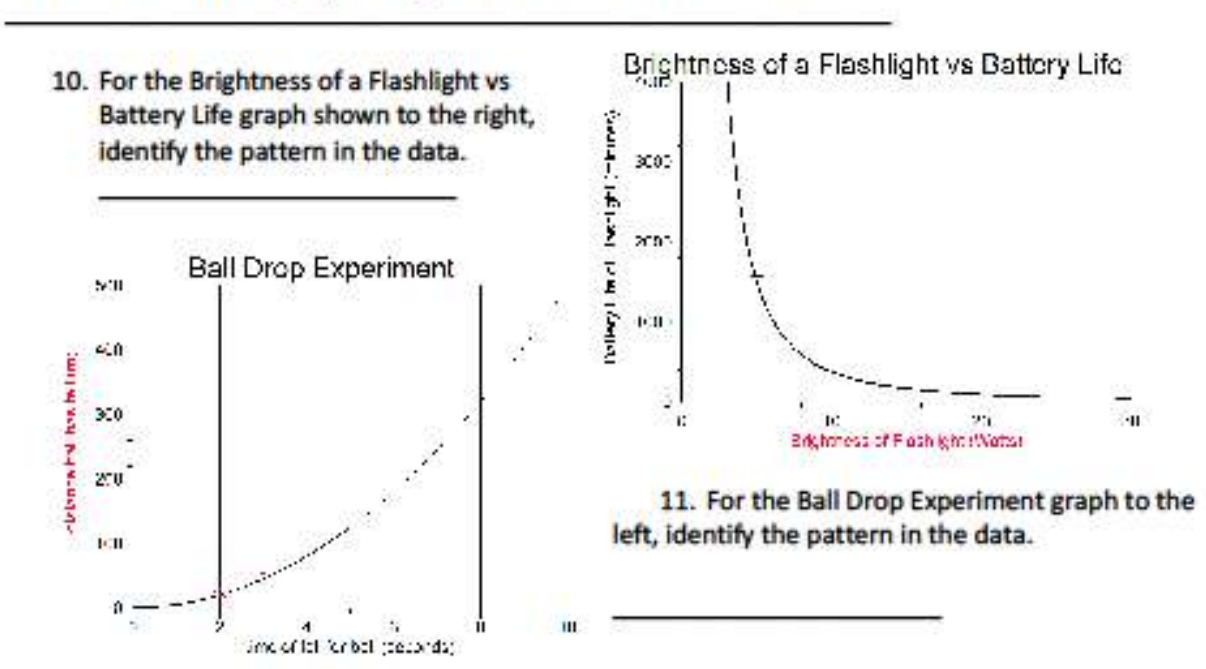

12. How many seconds are in a year? (Show your steps)

13. Convert the speed of light, $3 \times 10^{8}$ meters/second, into Miles per hour. (Show your steps)

14. If you went the speed of light for a year how far have you travelled? (answer can be in meters or miles) 
Name:

Describe 4 common patterns in nature graphically, mathematically, and in words: (Use the example graphs on the next page to help you)

Pattern: Linear

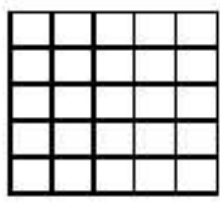

Mathematically...

$y=$

Words...

as $\mathrm{x}$ gets larger,

then $y$

Pattern: Inverse

\begin{tabular}{|l|l|l|l|l|}
\hline & & & & \\
\hline & & & & \\
\hline & & & & \\
\hline & & & & \\
\hline & & & & \\
\hline
\end{tabular}

Mathematically...

$y=$

Words...

as $\times$ gets larger,

then $\mathrm{y}$
Pattern: Quadratic

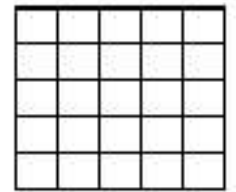

Mathematically... $y=$

Words...

as $\times$ gets larger,

then $y$

Pattern: Inverse Square

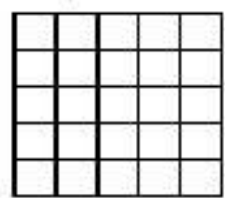

Mathematically...

$y=$

Words...

as $\mathrm{x}$ gets larger,

then $\mathrm{y}$ 
Appendix E: Interview questions and results 
-Content Questions (Picked one for each student)

1) -Here is a plot developed by a computer scientist trying to determine the relationship between the number of words and the number of pages in a book, each point on the graph represents a different book...

Draw an approximation of the best fit line of the data on the paper.

What sort of relationship does this line represent?

Describe it in plain words.

What are the uncertainties in these measurements?

What could the experimenter do to be more certain that this is the correct relationship between the 2 variables?

2) -An engineer is developing a crane equipped with a magnet for lifting wrecked cars. Here is her plot of the weight of the car vs. the distance between the magnet and the car to lift it off the ground...

Draw an approximation of the best fit line of the data on the paper.

What sort of relationship does this line represent?

Describe it in plain words.

What are the uncertainties in these measurements?

What could the experimenter do to be more certain that this is the correct relationship between the 2 variables?

\section{-Nature of science questions.}

What is Science?

If you were to repeat the experiment, would you expect to come up with the same results? Please explain why or why not.

How is the information given in a graph similar to or different than the equation of best fit?

Why is it better for someone to use these graphs to make a data informed decision than for them to simply make a wild guess?

You have developed the skill of interpreting graphs as a relationship between 2 variables.

Can you see yourself using this skill in future? If so, how? 
Interviewee \#1 (first graph)

Andy $\mathrm{T}$

-What is the best fit line?

- Linear...

-What does that mean about the relationship between the two variables?

- If one of them changes in the positive direction, The other one changes in the positive direction.

- How accurate do you think the measurements are?

-They appear pretty accurate as they are tightly grouped.

- Could vou aive me a number as to how uncertain wou think the measurements miaht be?

- in pages about 50 pages? (-In the number of words?)-A lot more (-why do vou think that?)-the scale on the $y$ is a lot more spread out. There are more words than pages...

- If you were doing this experiment, what would you do to try and make your results more accurate?

- Possibly adjust for words per page, or only count complete pages. Not include the short ones at the end of the chapter. Also adjust for font size or different fonts?

- Is there anything you could do to be more certain about the relationship?

- Use the pattern, Possibly take a really, really long book and see if it adheres to your relationship. -Are there any things that you would have to keep constant during this experiment?

- Font size, page size, justification, margins.

- I have a few general nature of science questions...

If you had to define science, what would you define it as?

- I would define science as predicting the future based on past events. Or investigating the past based on the present.

-If you were to repeat an experiment, would you expect to come up with the same results?

- If it was a well-planned experiment, yes. (-What do you mean by well-planned experiment?) - If all of the variables that need to be controlled are controlled. There is nothing that changed to make the experiment different. You keep all of the stuff that would affect the results that you wouldn't expect constant. (-Do vou think vou could control everuthina? - No, you could not possibly control everything. but you could get it within an acceptable margin of error.

- if you have information on a graph like this, a scatter plot, how is it different from your best fit line? - they are similar because they express the same pattern, but they are different because the scatterplot gives you more precise values and more realistic results. They are more true to life.

-If you had a margin for error, like error bars, it would be more true to life because the best fit is just that. The line does not give you the sense for minor jumps of bumps in your data, idiosyncrasies.

- Why is it better for someone to use graphs and equations to make a data informed decision?

- A graph, depending on how carefully it was collected, can allow you to make an exact guess or a better informed guess about what is going to happen.

- Do you see yourself using the skill of interpreting graphs in the future?

- Yes, all the time. (-Give me an example... - Lots of news is presented in graphs, stocks, weather patterns. Graphs are a highly useful mechanism for communicating data. More people will probably use them with the advent of personal portable media. (- How would vou see vourself using this in a career. if you had a career in mind? - I think that I will definitely use it as a software engineer, collecting data and being able to express it for research purposes. 
Interviewee \#2 (second graph)

Emerald

- Described graph. If you had to draw a line of best fit for that data, what would you draw?

- I remember lines of best fit, but not the name... Maybe inverse?

-What does that mean between the two variables? What is $y$ and what is $x$ ?

$-x$ is the weight of the car, $y$ is the magnet distance. (- As the weioht of the car increases, what happens

to the other variable? --Decreases. (-If you double the mass, using your inverse relationship, what

happens to your magnet distance? - It is divided by...2

-Based on the araph. what kinds of uncertainties do vou see?

- Exact? There are uncertainties in the max distance probably from movement and the weight of the car, but I can't say exactly. (-Can you think of any other things that would cause uncertainties in you measurements in this specific situation?- How much metal is in the car.

-lf vou were doino this experiment. what is one thing vou cosuld do to be more certain about vour results? - Use the same car every time. (-Whve)-Because you would know how much metal is in the car. Some cars are mostly plastic. I guess it would reduce the weight, but you would have to have some metal to pick it up. I think it is just good for control because then you are not changing car every time, you can just increase the weight.

-In vour opinion, what is science?

- I don't like those kinds of questions...I guess it is trying to answer questions about the world using experiments and observations.

- If vou repeat an experiment would vou expect to come up with the same results?

- Not the exact same. I would hope for the same results. I would not expect the exact same results, because you have that uncertainty and because of human error. That would be really hard, unless maybe you have computers doing it for you.

-Along with that, why is it better for someone to use graphs to make a decision than to guess?

-Because they are more exact. (Why) Because they use data from past experiments to graph how it will happen further along in the future. I am no good at this...

- How would you use this in the future. Modeling your data and interpreting graphs.

-1 have to use it in math, and you have use it in business. I don't plan on becoming a scientist. (-Do only science people use graphs? - No, business people use graphs too. Scientists use them more; I don't think you use them very much in music. I want to know how a musician would use a graph.

(-Maybe if you are fixing your instrument you could use them.)-I guess the wavelengths you could graph. (-Or if you wanted to build your own instrument.)- I am not sure you would need a graph. 
Interviewee \#3 (first graph)

Spencer

- Look at the first graph. Explained. If you had to give it a best fit line, what would it be?

- It would be a linear fit because all of them are pretty much close to each other going in the same direction. (What do you mean by that) They are all really close to each other as they all travel along the line.

- If you double the number of pages in the book, what happens to the number of words? - It doubles, it just goes up and up and up and up.

-What kind of uncertainties do you think there are in those measurements?

- Like how many words here are on the page? Is that what you are looking for? - Diagrams, if those take up part of the page.

- If you were doing this experiment, what could you do to be more certain about the relationship you

found?

- I would do twice the number of books to try to get more accurate best fit line. (anything else) That is pretty much it

- What is science?

- An explanation of facts! It is explaining things that previously we explained in les sensible ways. For example, when god is angry lightning strikes. That makes less sense than friction caused by air masses moving against each other. I view it as explaining things and fueling our curiosities. It is our tool.

- If you repeat an experiment do you expect to come up with the same results?

- Generally every time. If I don't then either my original experiment was flawed or I did something wrong. - How is data on the oraph different than the equation that vou aet with the best fit line.

-Well the best fit line just goes straight through it. It is not accurate to all of the points exactly, it is accurate to line that all of the points make.

- Why is it better to use a graph to make a decision than to make a quess.

- Graphs are a very nice visual aide. A guess has a very high margin for error. -How would vou see vourself usine oraphs and best fit lines in the future?

- My dad and I like to do random science experiments about anything from transportation to light speed travel. If we actually get to do something along those lines and graph it, that could be helpful for us learning how crazy or super cool it could be. (what is an example of something you do?) -We try to prove if warp, on star trek, would be possible. Although there are so many things that we don't know that it kind of makes our findings invalid. 
Interviewee \#4 (second graph)

Nathan M

-Looking at the second graph, explained. What do you think the best fit line of that data would be, what relationship would it have?

- I would say an inverse equation..

-If vou doubled the mass of the car. what would hapoen to the distance vou would need to have?

-It would decrease by $1 / 2$. So like if the distance was 10 meter, it would go to 5 meters.

-What kind of uncertainties are there in that graph or experiment?

- Wind, the type of material because some cars could be more magnetic than others.

- If vou were the experimenter and vou wanted to be more certain about that relationship. what could vou do?

- Use the same car every time, that's it

-If lasked, what is science, what would vou sav?

- Science is taking something unknown and figuring it out and figuring out why and how it works. That is what we use science for.

-if you repeat an experiment, would you expect to come up with the same results?

- I would hope so. If not, I would do the experiment a $3^{\text {rd }}$ time and see how they compared.

- how is the best fit line different from what vou see on a araph?

- The best fit line is taking the points closest to the line, some of them might be a little bit off, but you see which they relate closest to, like the linear or the quadratic or the inverse.

-Why is it better for someone to use oraphs to make a decision than iust ovess.

- Because then you can see the entire sample size and also other scientists can look at your results and check it out to see if the graph makes sense. To check your work.

- How would you use this skill in the future?

- Using what, the difference between 2 graphs? (of interpreting data on a graph) I could use it if I were buying a new car and looking at how fast it goes. Tell me the acceleration from speed. If I were going into a science field I could use it to plot something, if I had a question about what was going on. (-What careers do you think use graphs? ?- Obviously science and physics and math, but I think accounting and business have graphs relating to other kinds of stuff.-- Did I fail?? 
Interviewee \#5 (first Graph)

Aaron

- If you had to draw a best fit line for that dat what do you think it would look like?

- Pretty much a straight line. Starting at 0,0 and going up. A positive relationship.

-If vou doubled the number of pages what would happen to the number of words?

- It would probably double too.

- What do you think the uncertainties for that experiment would be?

- Plus or minus $5 \%$ for the words I think.

- What kind of stuff do vou think would lead to uncertainties?

- The font size and if the words would go into the margins

-What could you do to be more certain about your relationship?

- Maybe use books by the same author. They would probably use the same font.

-What is science?

- Basically using resources to understand our world in a better way. (What do you mean by resources?) Like doing experiments.

- If you were to repeat an experiment would you come up with the same results?

- Depending on what the experiment is. If they were different, I would figure out what was different between the experiments.

- How is the best fit line different from the points on the graph?

- Well the line of best fit seems like they get further away the points as you get further along the $\mathrm{x}$ axis.

(in general?) The data points won"t always line up on the line, but they will usually be pretty close?

-Why is it better to use araphs than to make a quess?

- Graphs help you visualize it better and you can actually follow the line. Like you can actually predict

that if you have more word there will be more pages.

- How do you see yourself using this skill in the future?

- Writing down graphs and visualizing? It would help to predict stocks and everyday things like is this person going to be able to stop before I cross the street? Lots of engineering jobs use it, like civil engineers have to graph the strain on different points of the bridge. 
Interviewee \#6 (second graph)

Quinlan

- That Graph is an engineer developing a crane that has a magnet for lifting wrecked cars. There is a plot showing the weight of the car vs. the maximum distance away to pick up the car. Does that make sense? - Yes

- If vou had to draw a best fit line for that data, what would the relationship be?

- It looks kind of like an inverse

- If you double the weight of the car what would happen to the maximum distance?

- It would get doubly smaller. It is hard to tell... If it is heavier it will get twice as small. -What kind of uncertainties do vou think there would be in this experiment? You can estimate. - It goes up to 25,000 ? Maybe the distance because it only goes to 10 meters. (so you are saying that the distance would be more uncertain because it is a smaller range?) Yes

-If vou wanted to be more sure about vour relationship. if vou were doing the experiment. what would vou do?

- I would do it again. Repeat it and see if you get the same data. Or take more data points to make it more exact. $(-$ In this experiment, what factors would make your measurements less accurate or cause error? - I don't know. If the car was a different... It seems pretty accurate if you are just lifting a car with a magnet.

- If I asked you the general question, 'what is science?' what would you say?

$-I$ don't know. The study of the world. I don't know, it is so general... A scientist studies a specific thing about the world, they make experiments.

-If vou do an experiment and vou repeat it. would vou expect to oet the same results?

- You would probably get the same results if you performed it exactly the same way. (- If you didn't get the same results, what would you do? - Make sure you are controlling all of the variables.

- On a graph, how is the best fit equation that you use to model your data, how is that different than the data moints?

- Well it is the average, right? Well it is the best fit... I don't know what I am trying to say. (-Ok, so if voy used your equation and calculated a value and put that on your graph, how is that different than your measured values. - - It is simulated from the equation. It is like a hypothesis, kind of an educated guess based off of the equation.

- Leading to the next avestion. why is it better to use araphs make a decision than to auess.

- It is probably more accurate. If there is previous data, that could lead you to believe that it is a certain way.

- How can you see yourself using your graphing skills in the future?

- As a career or daily life? (either one) Probably. Just looking at how 2 things relate to each other, or how more than 2 things relate. I am interested in business. (how would you use something like this in business?) Tracking trends... Graphs are in everyday life so it is useful to know how to use them. Just looking at how things fluctuate over time... 